\title{
Saponins as cytotoxic agents: a review
}

\author{
Irma Podolak • Agnieszka Galanty • Danuta Sobolewska
}

Received: 13 January 2010/ Accepted: 29 April 2010/Published online: 25 June 2010

(C) The Author(s) 2010. This article is published with open access at Springerlink.com

\begin{abstract}
Saponins are natural glycosides which possess a wide range of pharmacological properties including cytotoxic activity. In this review, the recent studies (2005-2009) concerning the cytotoxic activity of saponins have been summarized. The correlations between the structure and the cytotoxicity of both steroid and triterpenoid saponins have been described as well as the most common mechanisms of action.
\end{abstract}

Keywords Cytotoxic mechanisms . Glycosides · Sar $\cdot$ Steroid · Triterpenoid

$\begin{array}{ll}\begin{array}{l}\text { Abbreviations } \\ \text { AMPK }\end{array} & \text { AMP activated protein kinase } \\ \text { BiP } & \text { Binding protein } \\ \text { BrDU } & \text { Bromodeoxyuridine } \\ \text { CCAAT } & \begin{array}{l}\text { Cytidine-cytidine-adenosine- } \\ \text { adenosine-thymidine }\end{array} \\ \text { CD } & \text { Cluster of differentiation molecule } \\ \text { CDK } & \text { Cyclin-dependent kinase } \\ \text { CEBP } & \text { CCAAT-enhancer-binding protein } \\ \text { CHOP } & \text { CEPB homology protein }\end{array}$

I. Podolak $(\bowtie) \cdot$ A. Galanty $\cdot$ D. Sobolewska Department of Pharmacognosy, Jagiellonian University, Medical College, Medyczna 9, 30-688 Cracow, Poland e-mail:mfpodola@cyf-kr.edu.pl

$\begin{array}{ll}\text { Con A } & \text { Concanavalin A } \\ \text { ER } & \text { Endoplasmic reticulum } \\ \text { ERK } & \text { Extracellular signal-regulated } \\ & \text { kinase } \\ \text { GADD } & \begin{array}{l}\text { Growth arrest and DNA damage- } \\ \text { inducible gene }\end{array} \\ \text { GRP } & \text { Glucose regulated protein } \\ \text { hTERT } & \text { Telomerase reverse transcriptase } \\ \text { JAK } & \text { Janus kinase } \\ \text { MEK }=\text { MAPK } & \text { Mitogen-activated protein kinase } \\ \text { MMP } & \text { Matrix metalloproteinase } \\ \text { mTOR } & \text { Mammalian target of rapamycin } \\ \text { NF } \kappa \text { B } & \text { Nuclear factor kappa-light-chain- } \\ & \text { enhancer of activated B cells } \\ \text { NO } & \text { Nitric oxide } \\ \text { PARP } & \text { Poly ADP ribose polymerase } \\ \text { PCNA } & \text { Proliferating cell nuclear antigen } \\ \text { PI3K } & \text { Phosphoinositide-3-kinase } \\ \text { PP } & \text { Protein phosphatase } \\ \text { PPAR- } \gamma & \text { Peroxisome proliferator-activated } \\ & \text { receptor } \gamma \\ \text { Raf } & \text { Serine/threonine specific kinase } \\ \text { STAT } & \text { Signal transducer and activator of } \\ \text { transcription } \\ \text { TIMP } & \text { Tissue inhibitor of metallo- } \\ \text { proteinase } \\ \text { TSC } & \text { Tuberous sclerosis complex } \\ \text { VEGF } & \text { Vascular endothelial growth factor } \\ \text { XIAP } & \text { protein } \\ & \end{array}$




\section{Introduction}

Saponins are secondary metabolites of glycosidic nature widely distributed in higher plants but also found in some animal sources, like e.g. marine invertebrates. Despite their fairly large structural diversity these compounds share some unique biological properties like the ability to lyse erythrocytes or to foam (Bruneton1995; Rao and Gurfinkel 2000; Francis et al. 2002). The latter contributed to naming this group "saponins", which is derived from Latin sapo meaning soap. Haemolysis of red blood cells seems to result from saponin ability to form complexes with cell membrane cholesterol leading in consequence to pore formation and cell permeabilization, and also to cause alterations in the negatively charged carbohydrate portions on the cell surface (Abe et al. 1981; Melzig et al. 2001; Gauthier et al. 2009a). It should be mentioned however that the exact mechanism of haemolytic activity of saponins is not clearly understood and is the subject of discussions within the scientific community.

Surface activity responsible for foaming properties, as well as some other biological functions including haemolytic activity, are attributed to characteristic structural features of saponins and their amphiphilic nature which results from the presence of a hydrophilic sugar moiety and a hydrophobic genin (called sapogenin). Saponins can possess from one to three straight or branched sugar chains, most often composed of D-glucose, L-rhamnose, D-galactose, D-glucuronic acid, L-arabinose, D-xylose or D-fucose. The sugar chain can contain from one to several monosaccharide residues, and is usually attached at C-3 (Vincken et al. 2007).

The aglycone may have steroid or triterpenoid structure according to which saponins are usually classified. Steroidal compounds are less common and usually found among the Liliopsida (former Monocotyledones) in members of such families as Liliaceae, Dioscoreaceae, Agavaceae, while triterpenoid saponins are more widely distributed and typical of the Magnoliopsida families (former Dicotyledones), e.g. Primulaceae, Sapotaceae, Caryophyllaceae and others. In rare cases both types of saponins may accumulate in a plant, like for example in Avena sp. (monocotyledonous Poaceae) (Osbourn 2003) or Lysimachia paridiformis (dicotyledonous Myrsinaceae) (Xu et al. 2007b).
Steroidal sapogenins (27C) can have a 6-ring spirostane or a 5-ring furostane skeleton whereas in the case of triterpenoid sapogenins (30C), which are much more structurally diverse, the basic ring system is most often made of five or, more seldom, of four units. Pentacyclic triterpenoid saponins belong, in a majority of cases, to oleanane-type, other skeleton types include ursane, lupane, hopane, germanicane, dammarane (Vincken et al. 2007). The presence in the polycyclic sapogenin of different substituents, such as for example hydroxyls, hydroxymethyls, carboxyls and acyl groups, as well as differences in the composition, linkage and number of sugar chains account for significant structural diversity of saponins and also their diverse bioactivity.

Saponins exert a wide range of pharmacological activities including expectorant, antiinflammatory, vasoprotective, hypocholesterolemic, immunomodulatory, hypoglycaemic, molluscicidal, antifungal, antiparasitic and many others (Sparg et al. 2004; Sahu et al. 2008). Plants rich in saponins, like Panax ginseng or Glycyrrhiza glabra, have been used for medicinal purposes since ancient times (Fiore et al. 2005) and to date continue to play a significant role not only in medicine but also in food and cosmetic industry, where they are utilized as emulsifiers or sweeteners (Güçlü-Üstündağ and Mazza 2007). Another important application of saponins is their use as adjuvants in the production of vaccines (Sun et al. 2009b). Steroidal sapogenins since many years have served as economically important raw materials for the pharmaceutical industry in the production of steroidal hormones (Blunden et al. 1975; GüçlüÜstündağ and Mazza 2007).

Many reviews summarized different aspects related to saponins, some of the more recent tackled biosynthesis (Haralampidis et al. 2002; Kalinowska et al. 2005), distribution (Henry 2005; Vincken et al. 2007), structures (Vincken et al. 2007; Sahu et al. 2008), biological and pharmacological activities of saponins (Sparg et al. 2004; Yang et al. 2006; Wang et al. 2007; Sun et al. 2009b), application and processing (Güçlü-Üstündağ and Mazza 2007), methods employed in their analysis (Oleszek and Bialy 2006; Sahu et al. 2008) and chemical synthesis of saponins (Yu et al. 2007; Yu and Sun 2009; Gauthier et al. 2009b).

Cytotoxicity and the chemopreventive role of saponins was also discussed in a number of review 
papers (Rao and Sung 1995; Konoshima 1996; Shibata 2001; Kerwin 2004; Kim 2008; Bachran et al. 2008; Fuchs et al. 2009). While most of these focus on triterpenoids, and especially on ginseng and soy saponins, chemopreventive and cancer control activity of a steroidal sapogenin-diosgenin has been recently summarized (Raju and Mehta 2009). Cytotoxicity of dioscins was also discussed in a review on bioactive steroid saponins from the Dioscorea genus (Sautour and Mitaine-Offer 2007). Bachran et al. (Bachran et al. 2008) in their review of saponins playing a role in tumor therapy focused on certain groups of compounds, such as dioscins, saikosaponins, julibrosides, avicins, soy and ginseng saponins, and on combinations of saponins and conventional anti-tumorigenic drugs.

This review focuses on the studies from the last 5 years referring to saponins for which cytotoxic activity in vitro against human cancer cell lines was reported. Some data from animal models are also presented.

Due to enormous number of reports that appear worldwide in which some reference to cytotoxicity is made we had to set some limits. Thus, literature searches were conducted in the following electronic databases: MEDLINE/PubMed, SCOPUS/Elsevier, Springer/ICM, INSPEC/ICM, SCI-Ex/ICM. The search terms used were: saponins, cancer, cytotoxicity.

In this review special emphasis is given to studies on structure-activity relationship and a summary of mechanisms of action is also provided.

\section{Cytotoxic saponins (2005-2009)}

In the past 5 years a relatively large number of publications devoted to various aspects of phytochemical analysis of saponins contained also some references to their biological activity including cytotoxicity. These data are summarized in Tables 1 and 2.

In the majority of cases, while structure elucidation process was the main focus of the research, cytotoxic activity tests were performed as additional part of experimental studies. However, there was also a considerable number of reports in which the mechanisms of action or structure-activity relationships were tackled in more detail and these are reviewed in the following sections of this paper.
As far as cytotoxicity data are concerned the following observations can be made. Most studies were performed on a relatively narrow range of cell lines, usually from one to five, sometimes up to ten. The most notable exceptions in this respect are the reports, in which isolated compounds were assayed by National Cancer Institute (NCI) in anticancer drug discovery screen. For example, Zhang (Zhang and Li 2007) tested triterpenoid saponins isolated from Aesculus pavia against a panel of 59 cell lines from nine different human cancers such as leukemia, nonsmall cell lung, colon, CNS, melanoma, ovarian, renal, prostate and breast. Similarly, cytotoxicity of seven steroid saponins, isolated from Dioscorea collettii var. hypoglauca, was compared on such a wide panel of cancer cell lines (Sautour and Mitaine-Offer 2007). One of the saponins, furostanol protoneodioscin (NSC-698789) isolated from the rhizomes of this plant, showed high activity against leukemia lines (CCRF-CEM, K562 and MOLT-4), colon cancer lines (HCT-15, KM12), CNS cancer line (SNB-75), melanoma line (M14), renal cancer line (CAKI-1), prostate cancer (DU-145) and breast cancer line (MDA-MB435) with $\mathrm{GI}_{50} \leq 2.0 \mu \mathrm{mol} \mathrm{l}^{-1}$. Leukemia, CNS cancer, and prostate cancer appeared the most sensitive subpanels to protoneodioscin. A comparison with other compounds in the NCI's database indicated that protoneodioscin had a novel mechanism of anticancer action (Hu and Yao 2002). Also, the corresponding methyl artifacts such as e.g. methyl protodioscin (Fig. 1), have shown cytotoxic activity at concentrations below $2 \mu \mathrm{mol} 1^{-1}$ in most studies performed so far (Hu and Yao 2003a; Wang et al. 2006).

Generally, in most papers cited here, the choice of cell lines seems to be random, most studies with a wider range of lines use leukemia and solid tumors cells. Very few studies compared cells from the same tumor but differing in malignancy or other characteristics. For example, Tapandjou et al. and Noté et al. evaluated cytotoxicity of isolated triterpene saponins against two colon cancer cell lines, HCT116 and HT-29 (Tapondjou et al. 2006; Noté et al. 2009). There were slight differences in the potency of tested compounds, however none of them seemed to be selective. In a study by Einbond et al., saponins from Cimicifuga sp. were tested in two human breast cancer lines, MDA-MB-453 (ER negative, Her2 overexpressing) and MCF-7 (ER positive, Her2 low). The latter cells were found much more resistant 


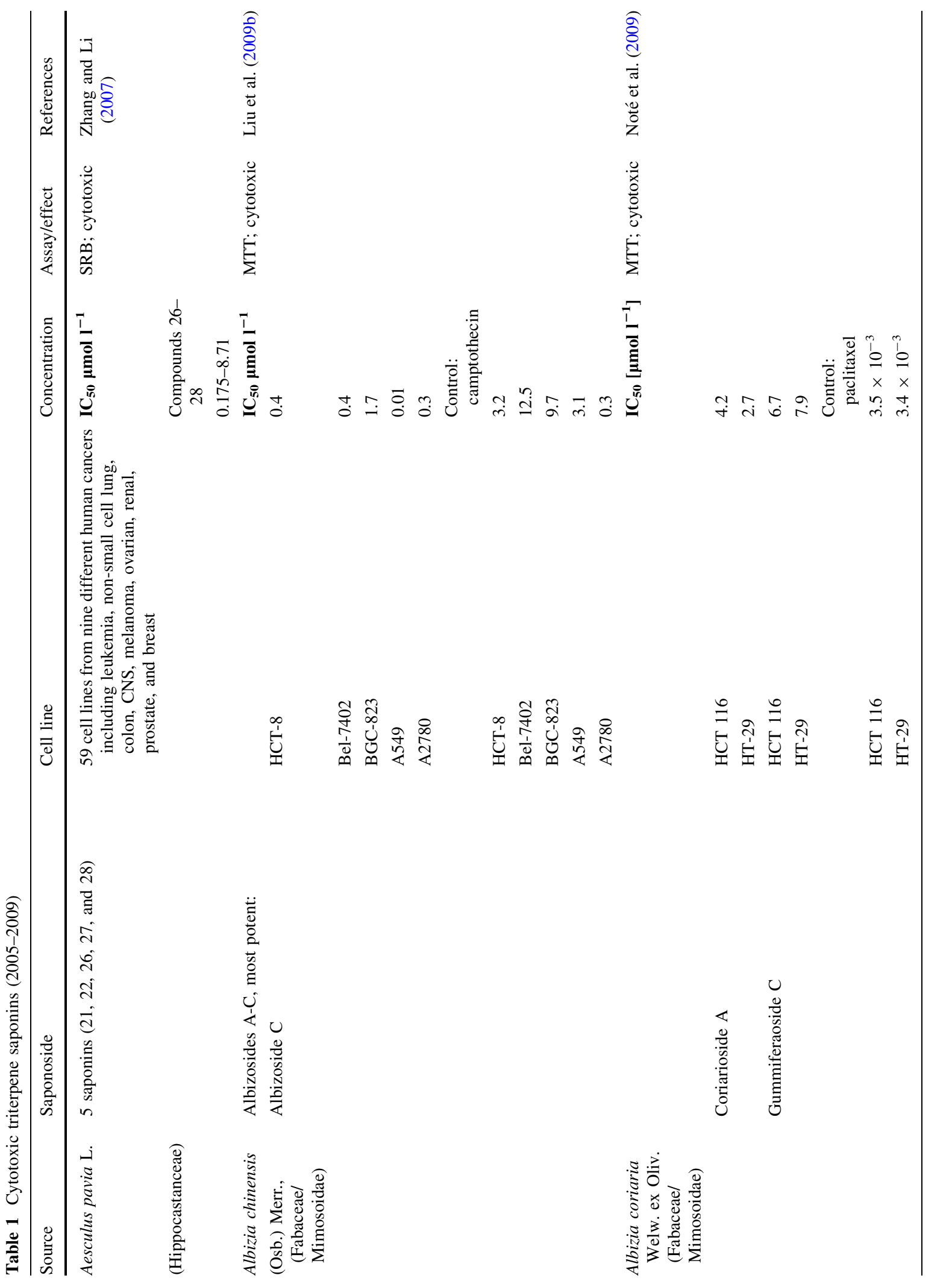




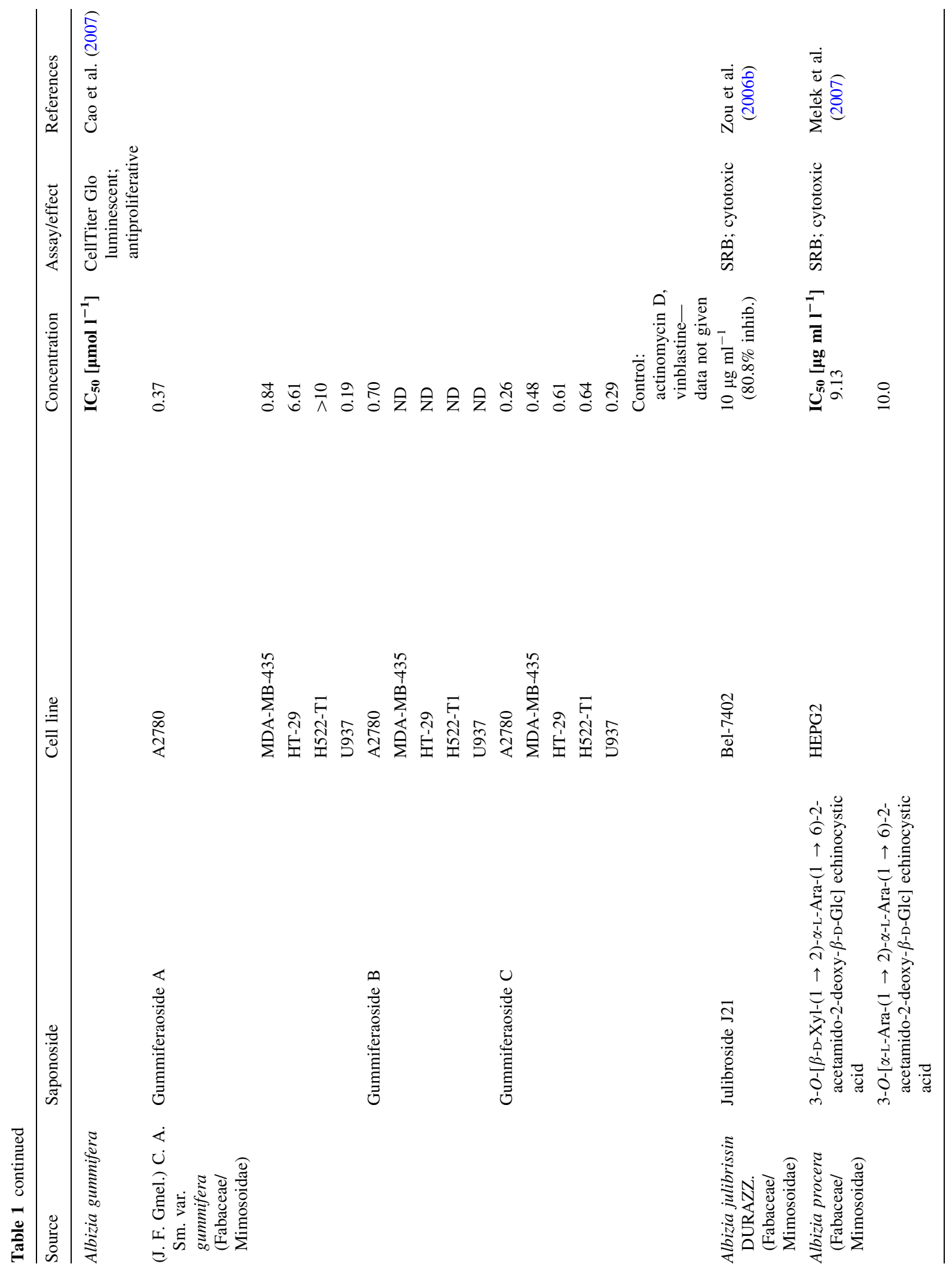




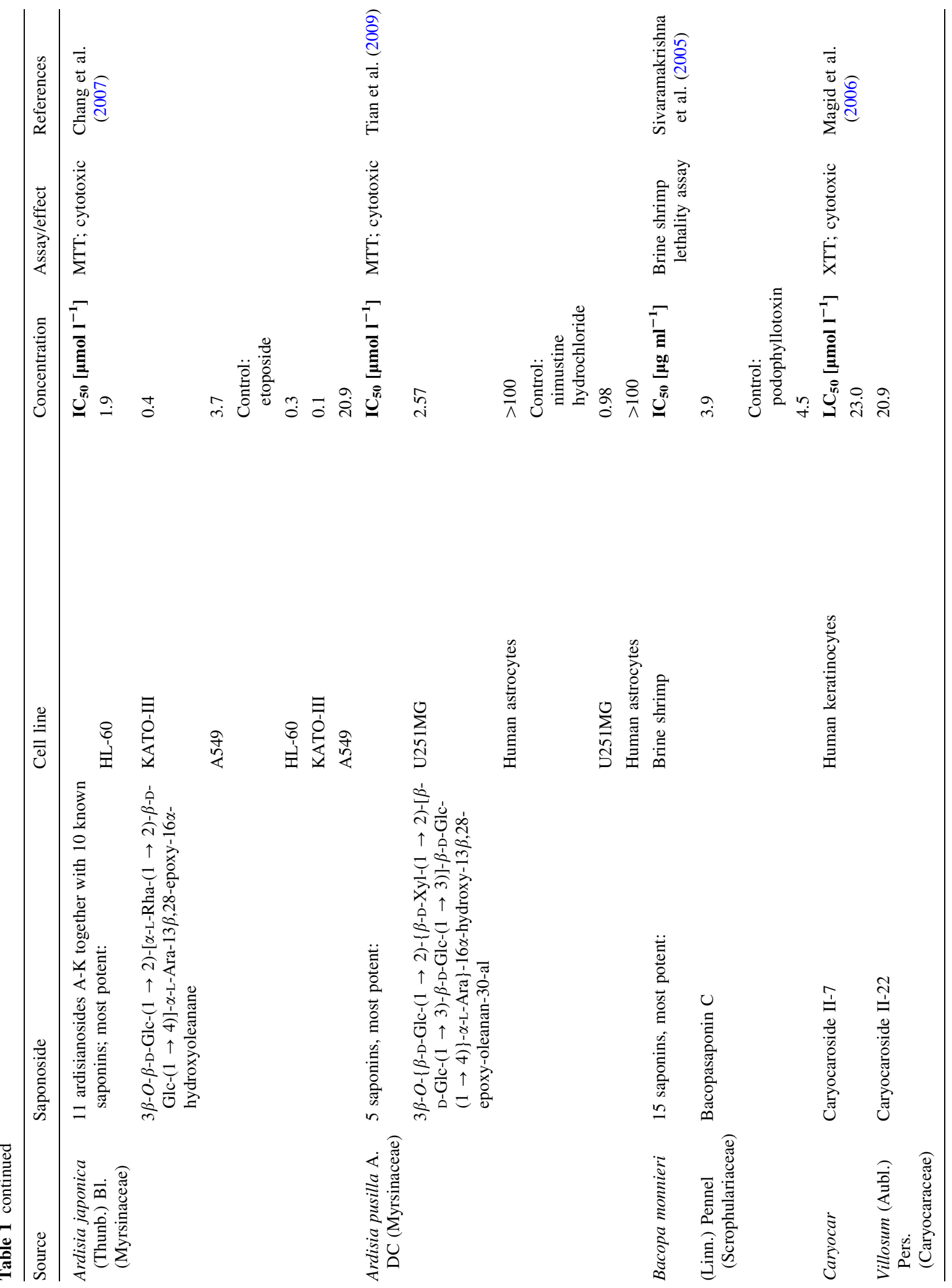




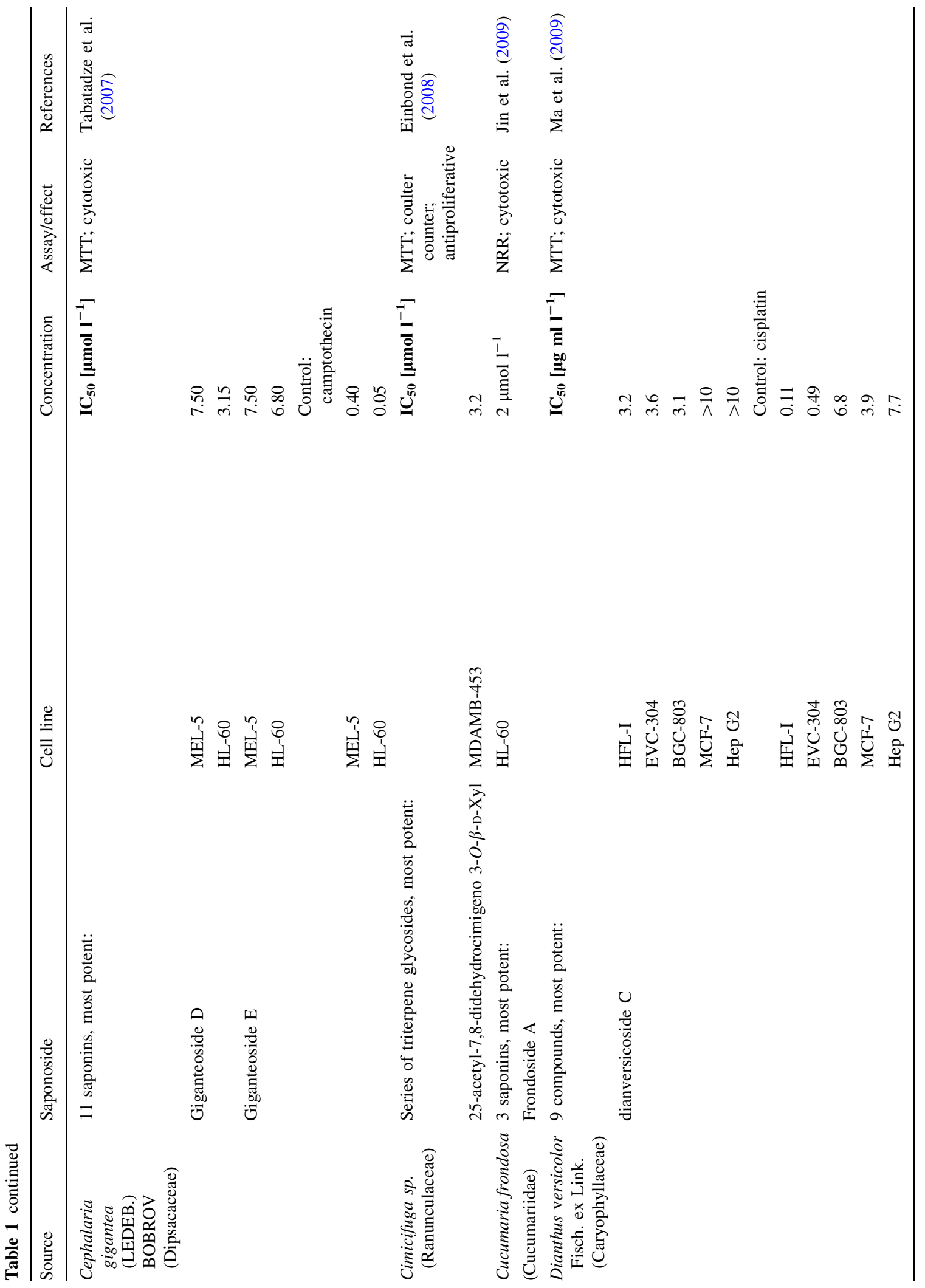




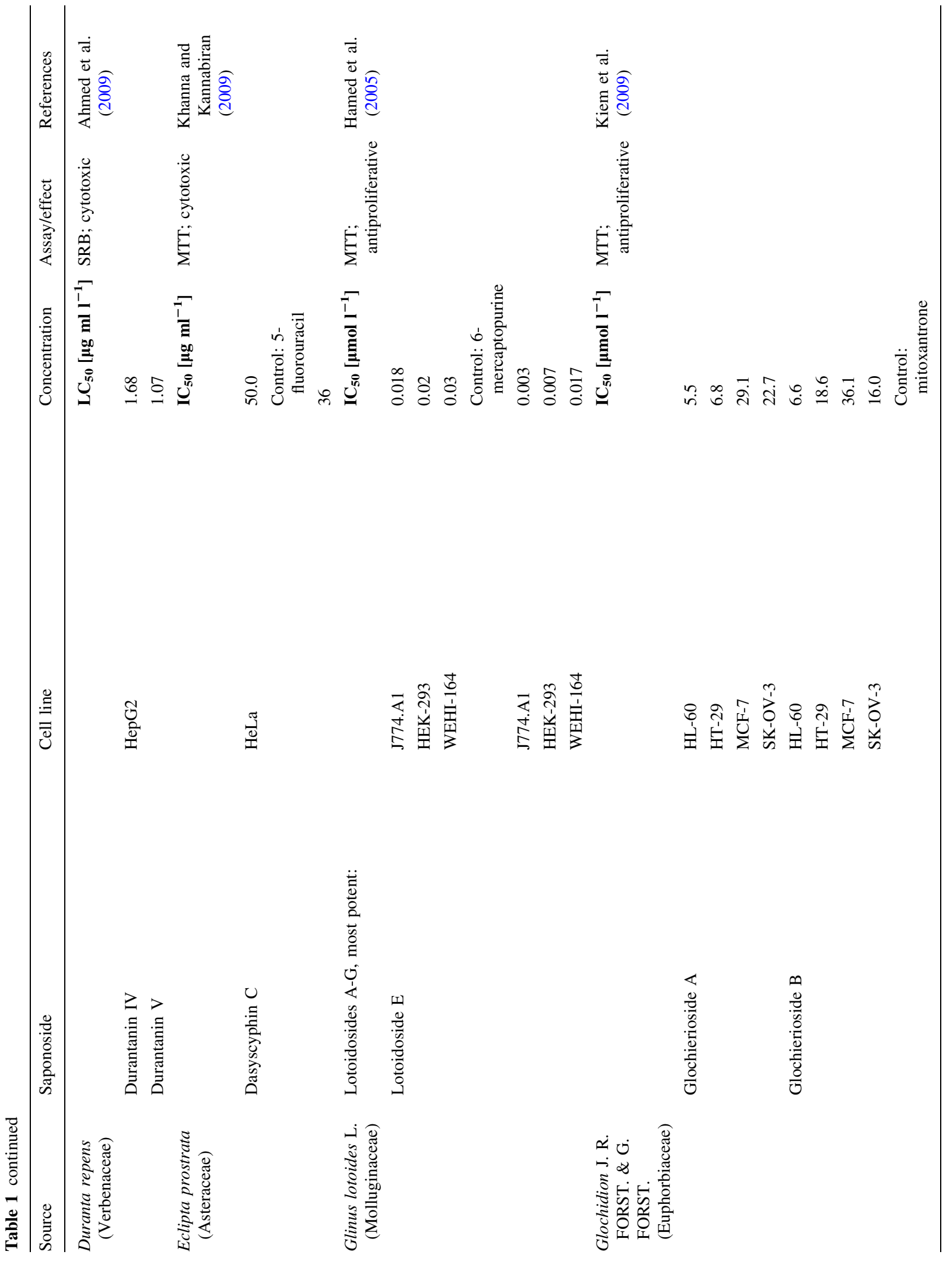




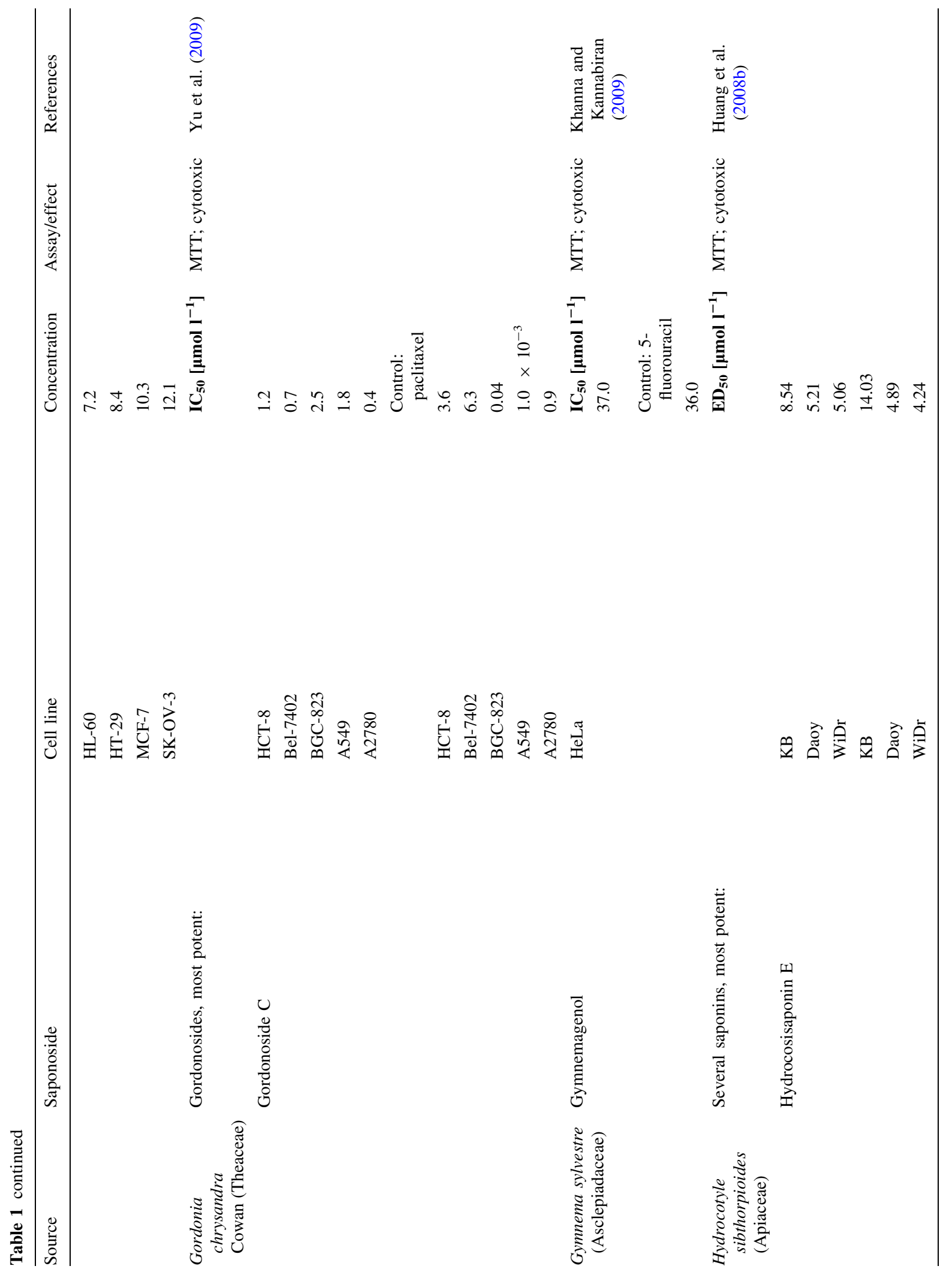




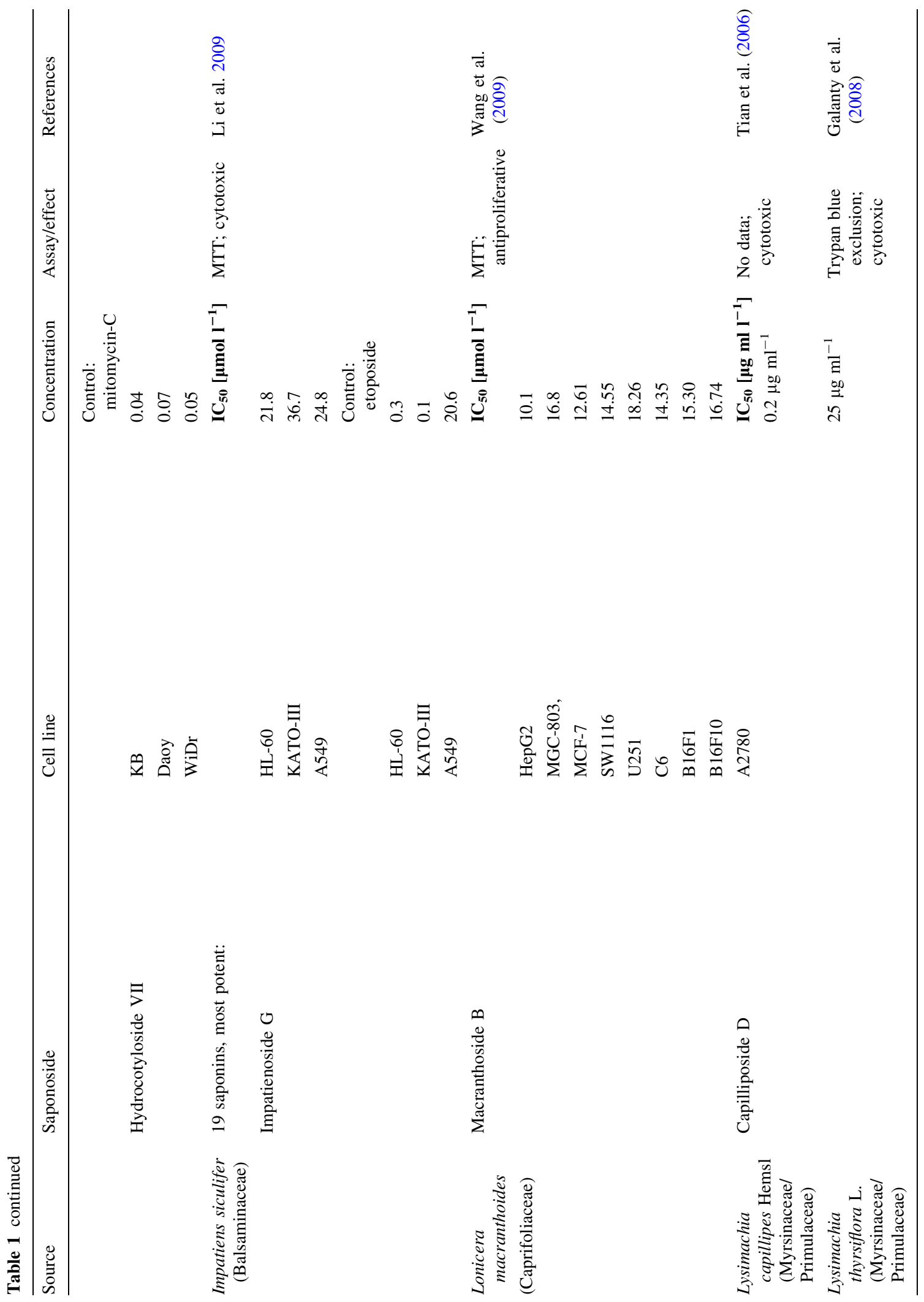




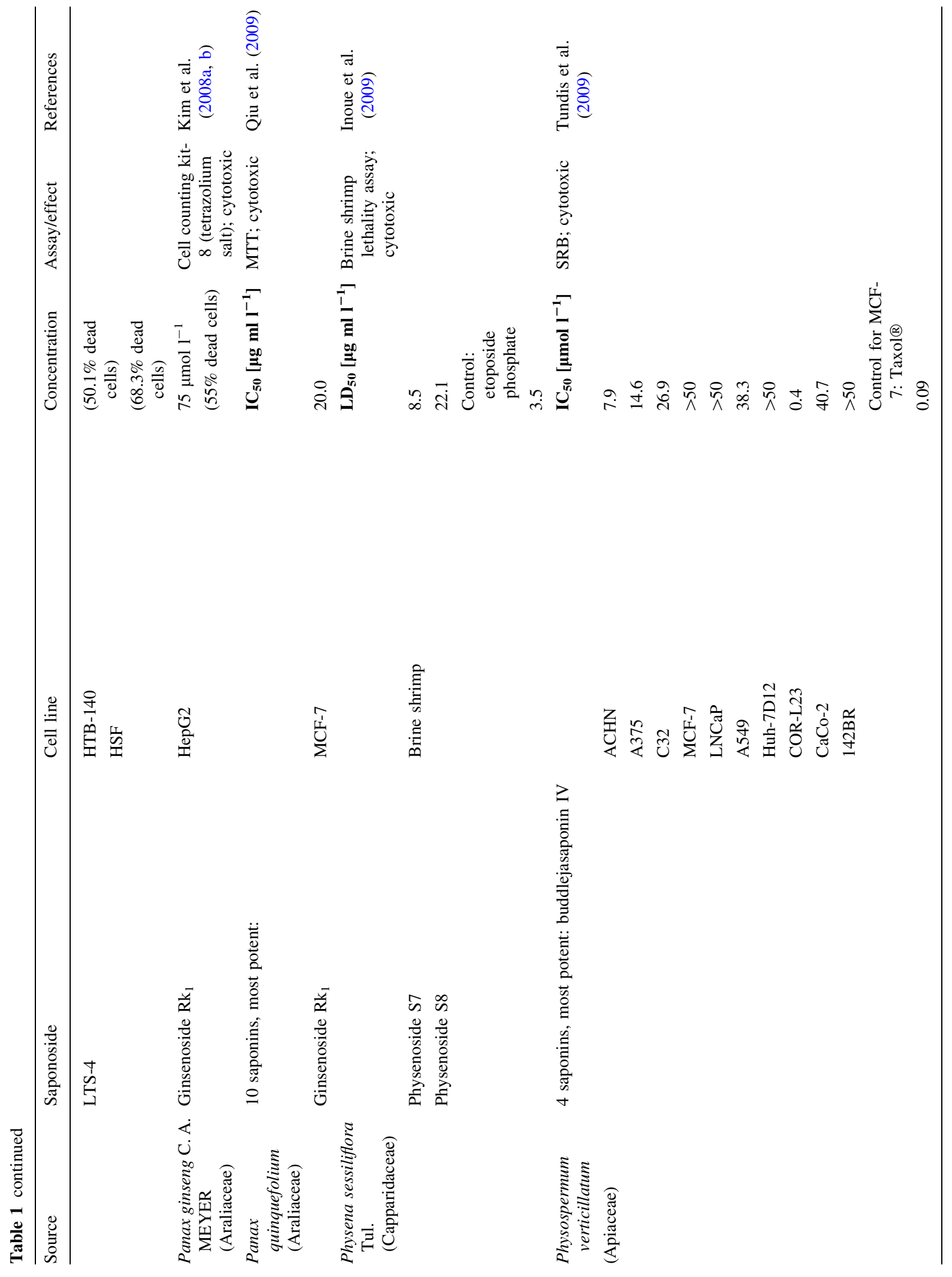




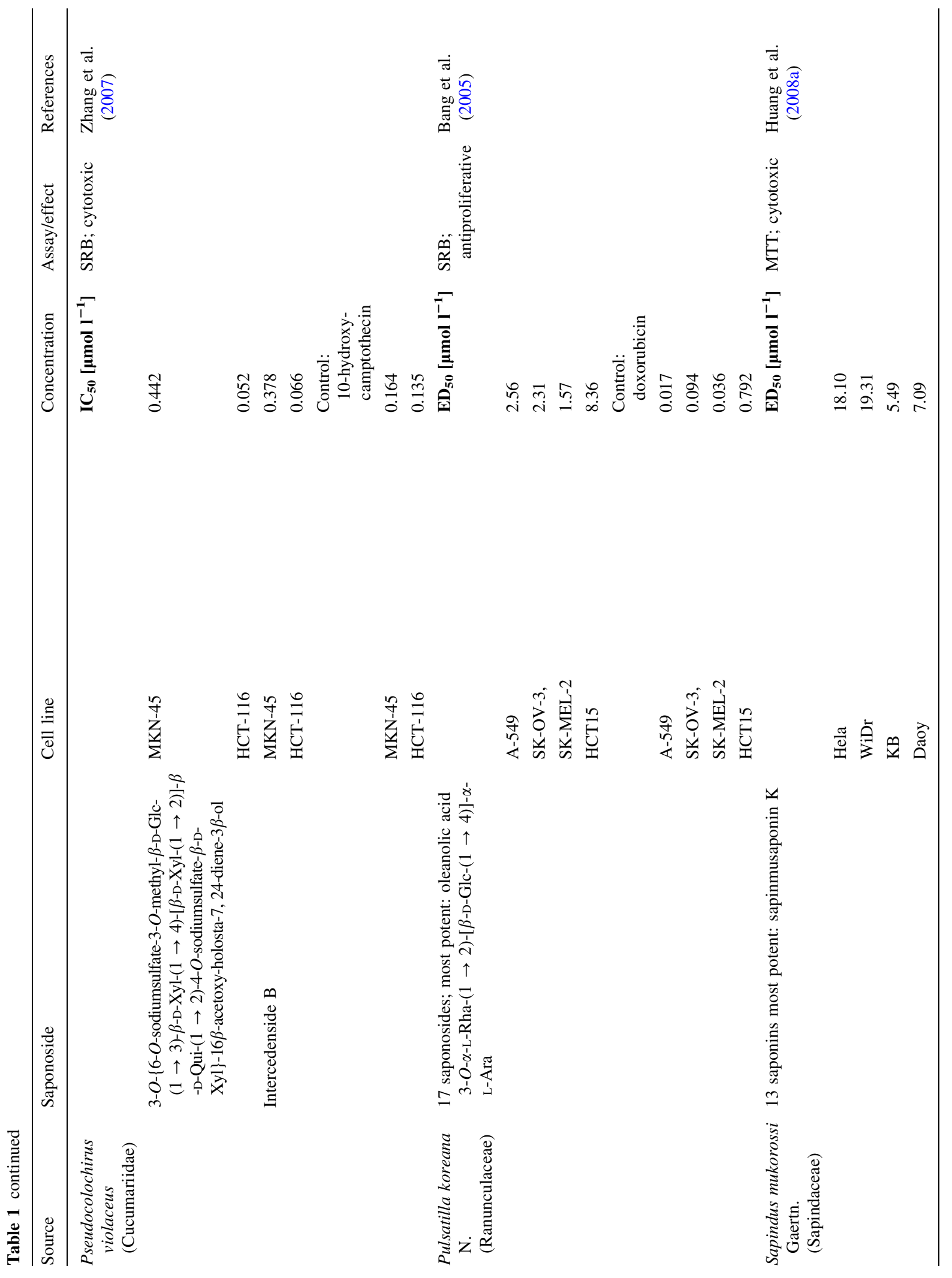




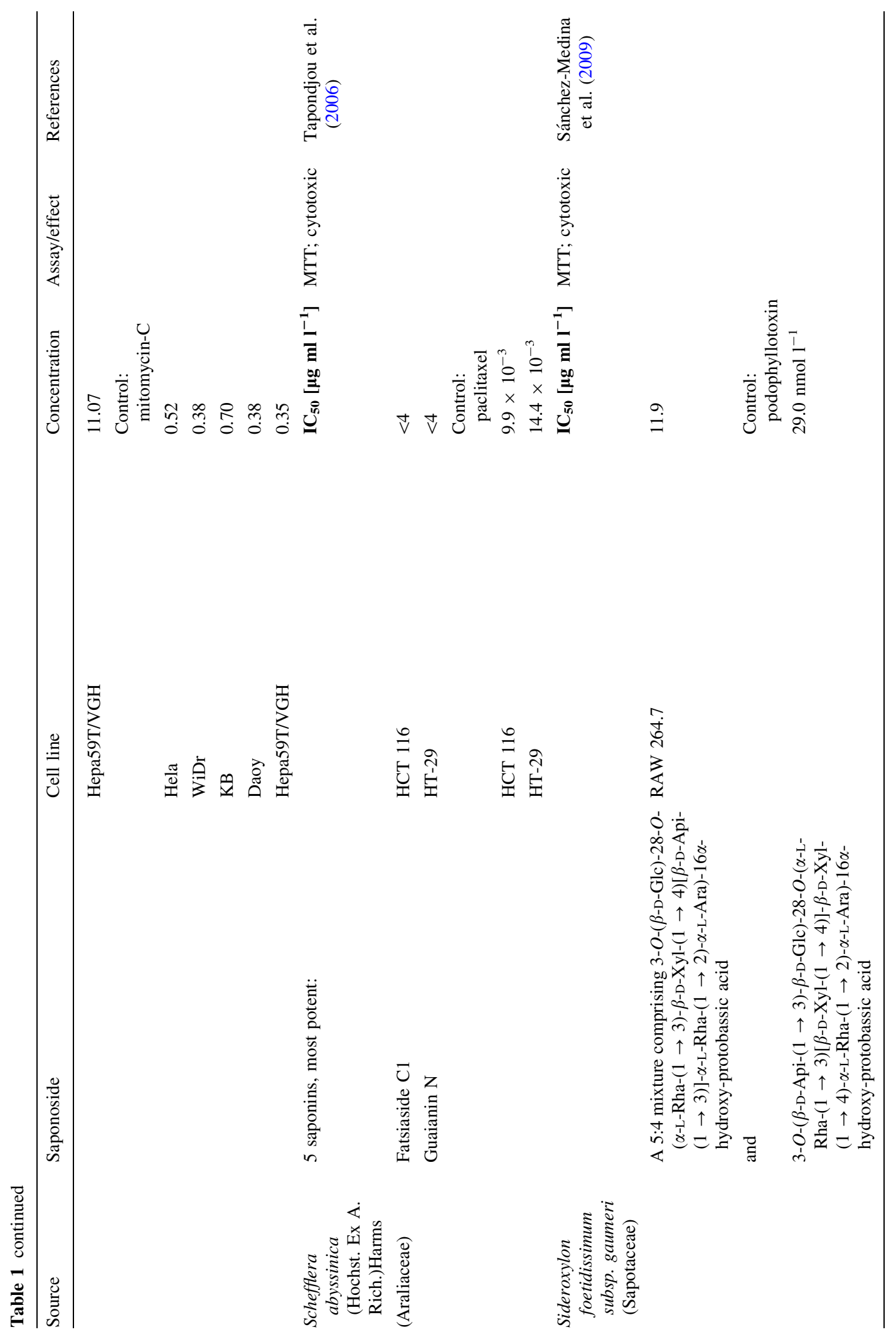




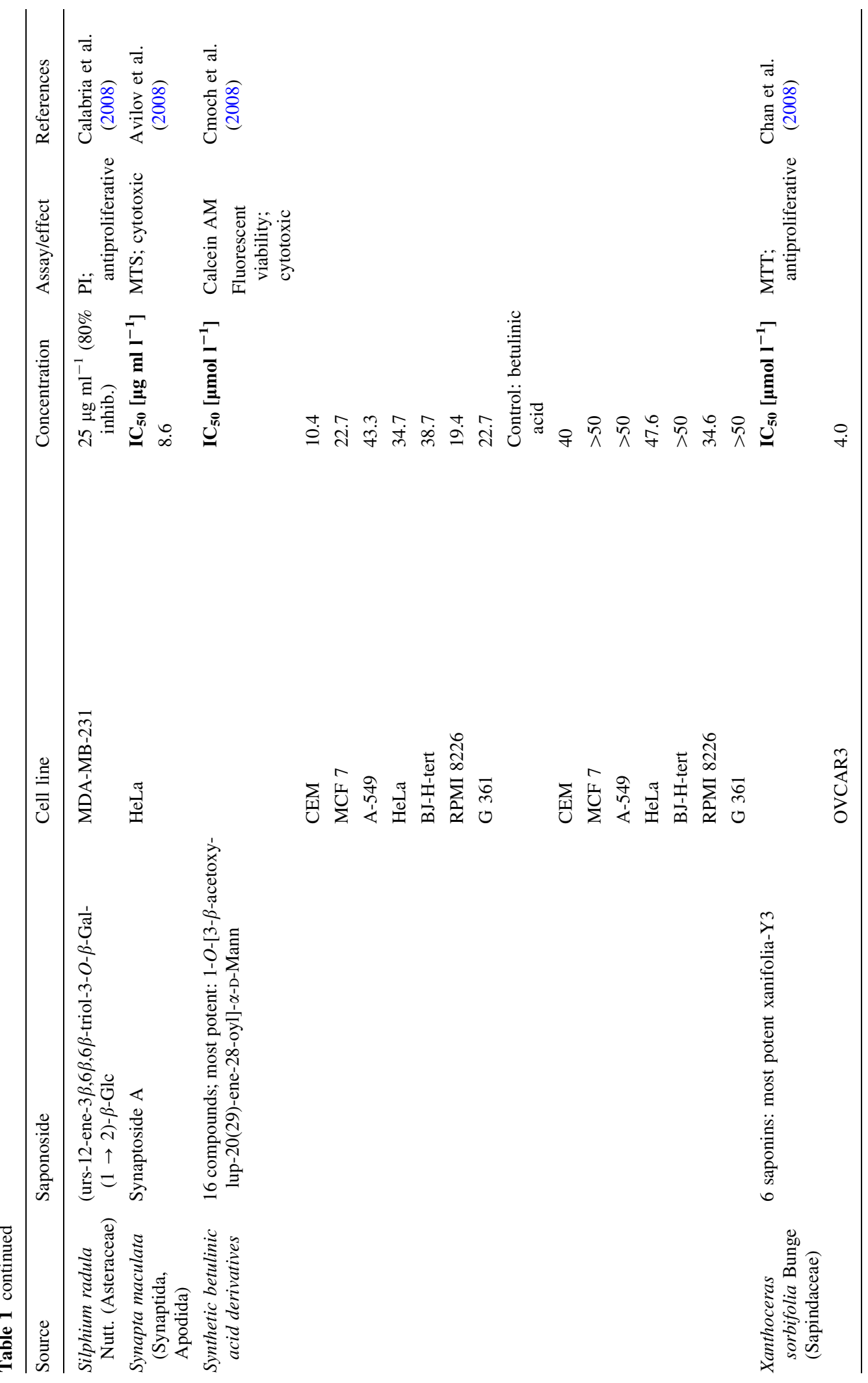




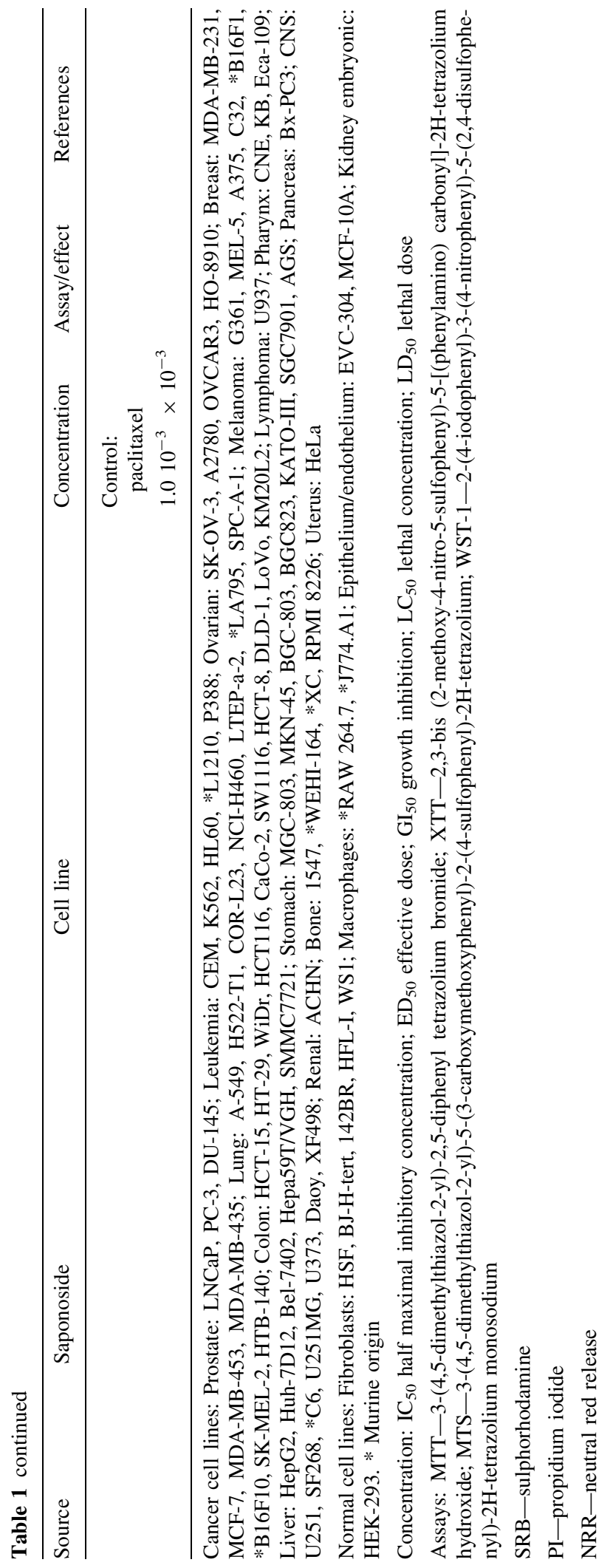


Table 2 Cytotoxic steroid saponins (2005-2009)

\begin{tabular}{|c|c|c|c|c|c|}
\hline Source & Saponoside & Cell line & Concentration & Assay & References \\
\hline \multirow[t]{8}{*}{$\begin{array}{l}\text { Agave utahensis } \\
\text { (Agavaceae) }\end{array}$} & & & $\mathrm{IC}_{50}\left[\mu \mathrm{g} \mathrm{ml} \mathrm{l}^{-1}\right]$ & $\begin{array}{l}\text { MTT; } \\
\text { atiproliferative }\end{array}$ & $\begin{array}{l}\text { Yokosuka } \\
\text { and } \\
\text { Mimaki } \\
2009\end{array}$ \\
\hline & $\begin{array}{l}(25 R) \text { - } 2 \beta \text {-hydroxy- } 5 \alpha \text {-spirostan- } 3 \beta \text {-yl } \\
O-\beta \text {-D-Xyl- }(1 \rightarrow 2)-O-\beta \text {-D-Glc- } \\
(1 \rightarrow 4)-\beta \text {-D-Gal }\end{array}$ & HL-60 & 12.3 & & \\
\hline & $\begin{array}{l}(25 R)-5 \alpha \text {-spirostan-3 } \beta \text {-yl } O-\beta \text {-D-Glc- } \\
\quad(1 \rightarrow 2)-O-[\beta \text {-D-Glc- }(1 \rightarrow 3)]-O-\beta \text { - } \\
\text { D-Glc- }(1 \rightarrow 4)-\beta \text {-D-Gal }\end{array}$ & & 9.4 & & \\
\hline & $\begin{array}{l}(25 R)-2 \alpha \text {-hydroxy- } 5 \alpha \text {-spirostan- } 3 \beta \text {-yl } \\
O-\beta \text {-D-Glc- }(1 \rightarrow 2)-O-[\beta \text {-D-Glc- } \\
(1 \rightarrow 3)]-O-\beta \text {-D-Glc- }(1 \rightarrow 4)-\beta \text {-D- } \\
\text { Gal }\end{array}$ & & 5.5 & & \\
\hline & $\begin{array}{l}(25 R)-2 \alpha \text {-hydroxy- } 5 \alpha \text {-spirostan- } 3 \beta \text {-yl } \\
O-\beta \text {-D-Glc- }(1 \rightarrow 2)-O \text { - } \beta \text {-D-Glc- } \\
(1 \rightarrow 4)-\beta \text {-D-Gal }\end{array}$ & & 11.3 & & \\
\hline & & & Control: etoposide & & \\
\hline & & & 0.20 & & \\
\hline & $\begin{array}{l}(25 R-5 \beta \text {-spirostan- } 3 \beta \text {-yl } O-\beta \text {-D-Glc- } \\
\quad(1 \rightarrow 4)-\beta \text {-D-Gal }\end{array}$ & & 4.90 & & $\begin{array}{l}\text { Yokosuka } \\
\text { et al. } \\
\text { (2009) }\end{array}$ \\
\hline \multirow[t]{23}{*}{$\begin{array}{l}\text { Allium leucanthum } \\
\quad \text { (Alliaceae) }\end{array}$} & & & $\mathrm{IC}_{50}\left[\mu \mathrm{mol} \mathrm{I}{ }^{-1}\right]$ & $\begin{array}{l}\text { Resazurin } \\
\text { reduction; } \\
\text { antiproliferative }\end{array}$ & $\begin{array}{l}\text { Mskhiladze } \\
\text { et al. } \\
\text { (2008) }\end{array}$ \\
\hline & Yayoisaponin & A549 & 3.7 & & \\
\hline & & DLD-1 & 5.6 & & \\
\hline & & WS1 & 3.0 & & \\
\hline & Eruboside B & A549 & 5.3 & & \\
\hline & & DLD-1 & 8.2 & & \\
\hline & & WS1 & 3.6 & & \\
\hline & Aginoside & A549 & 5.8 & & \\
\hline & & DLD-1 & 7.9 & & \\
\hline & & WS1 & 3.6 & & \\
\hline & $(25 R)-5 \alpha$-spirostane- $3 \beta, 6 \beta$-diol 3-O- & A549 & 9.0 & & \\
\hline & $\beta$-D-Glc- $(1 \rightarrow 2)-[\beta$-D-Xyl- & DLD-1 & 13.0 & & \\
\hline & 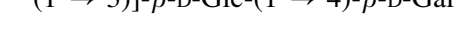 & WS1 & 3.1 & & \\
\hline & Leucospiroside A & A549 & 5.0 & & \\
\hline & & DLD-1 & 7.2 & & \\
\hline & & WS1 & 4.55 & & \\
\hline & (25R)-5 $\alpha$-spirostane- $2 \alpha, 3 \beta, 6 \beta$-triol & A549 & 22.0 & & \\
\hline & 3-O- $\beta$-D-Glc- $(1 \rightarrow 2)-\beta$-D-Glc- & DLD-1 & 22.0 & & \\
\hline & $(1 \rightarrow 4)-\beta$-D-Gal & WS1 & 14.5 & & \\
\hline & $(25 R)-5 \alpha$-spirostane- $3 \beta, 6 \beta$-diol 3-O- & A549 & 7.8 & & \\
\hline & $\beta$-D-Glc-(1 $\rightarrow 3)-\beta$-D-Glc- $(1 \rightarrow 2)$ - & DLD-1 & 8.9 & & \\
\hline & $\begin{array}{l}{[\beta \text {-D-Glc- }(1 \rightarrow 3)]-\beta \text {-D-Glc- }} \\
(1 \rightarrow 4)-\beta \text {-D-Gal }\end{array}$ & WS1 & 7.7 & & \\
\hline & & & Control: etoposide & & \\
\hline
\end{tabular}


Table 2 continued

\begin{tabular}{|c|c|c|c|c|c|}
\hline Source & Saponoside & Cell line & Concentration & Assay & References \\
\hline & & A549 & 1.1 & & \\
\hline & & DLD-1 & 4.8 & & \\
\hline & & WS1 & Not determined & & \\
\hline & & & Control: 5-fluorouracil & & \\
\hline & & A549 & 48.0 & & \\
\hline & & DLD-1 & 11.0 & & \\
\hline & & WS1 & 20.01 & & \\
\hline \multirow{4}{*}{$\begin{array}{l}\text { Allium } \\
\text { macrostemon } \\
\text { (Alliaceae) }\end{array}$} & & & $\mathrm{IC}_{50}\left[\boldsymbol{\mu m o l ~ \mathrm { I } ^ { - 1 } ]}\right.$ & MTT; cytotoxic & $\begin{array}{l}\text { Chen et al. } \\
\text { (2009) }\end{array}$ \\
\hline & $\begin{array}{l}\text { 26- } O \text { - } \beta \text {-D-Glc-5 } \alpha \text {-furost- } 25(27) \text {-ene- } \\
3 \beta, 12 \beta, 22,26 \text {-tetraol } 3-O-\beta \text {-D-Glc- } \\
(1 \rightarrow 2)-[\beta \text {-D-Glc- }(1 \rightarrow 3)]-\beta \text {-D- } \\
\text { Glc- }(1 \rightarrow 4)-\beta \text {-D-Gal }\end{array}$ & SF-268 & 35.2 & & \\
\hline & 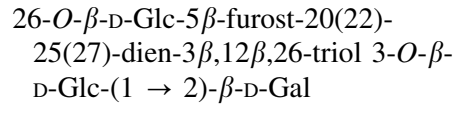 & NCI-H460 & 25.7 & & \\
\hline & & SF-268 & 35.4 & & \\
\hline \multirow[t]{4}{*}{$\begin{array}{l}\text { Allium ursinum } \\
\text { (Alliaceae) }\end{array}$} & A mixture of: & & $2 \mu \mathrm{g} \mathrm{ml}^{-1}$ & Trypan Blue & $\begin{array}{l}\text { Sobolewska } \\
\text { et al. } \\
(2006)\end{array}$ \\
\hline & $\begin{array}{l}(25 R) \text {-spirost-5-en- } 3 \beta \text {-ol 3- } O \text { - } \alpha \text {-L-Rha- } \\
\quad(1 \rightarrow 4)-\alpha \text {-L-Rha- }(1 \rightarrow 4) \text {-[ } \alpha \text {-L-Rha- } \\
\quad(1 \rightarrow 2)]-\beta \text {-D-Glc }\end{array}$ & B16 & (100\% dead cells) & Exclusion; & \\
\hline & and & $\mathrm{XC}$ & (100\% dead cells) & cytotoxic & \\
\hline & $\begin{array}{l}(25 R) \text {-spirost-5,25(27)-dien-3 } \beta \text {-ol } \\
\text { 3- } O \text { - } \alpha \text {-L-Rha- }(1 \rightarrow 4) \text { - } \alpha \text {-L-Rha- } \\
(1 \rightarrow 4) \text { - }[\alpha \text {-L-Rha- }(1 \rightarrow 2)]-\beta \text {-D-Glc }\end{array}$ & & & & \\
\hline \multirow{3}{*}{$\begin{array}{l}\text { Anemarrhena } \\
\text { asphodelodes } \\
\text { (Liliaceae) }\end{array}$} & & & $\mathrm{IC}_{50}\left[\mu \mathrm{g} \mathrm{ml}^{-1}\right]$ & MTT; cytotoxic & $\begin{array}{l}\text { Bao et al. } \\
\quad(2007)\end{array}$ \\
\hline & Sarsapogenin & HepG2 & $42.4(48 \mathrm{~h})$ & & \\
\hline & & & $25.0(72 \mathrm{~h})$ & & \\
\hline \multirow[t]{13}{*}{$\begin{array}{c}\text { Asparagus filicinus } \\
\text { (Asparagaceae) }\end{array}$} & & & $\mathrm{IC}_{50}\left[\mu \mathrm{g} \mathrm{ml}^{-1}\right]$ & SRB; cytotoxic & $\begin{array}{l}\text { Zhou et al. } \\
\text { (2007) }\end{array}$ \\
\hline & Filiasparoside A & A549 & 13.3 & & \\
\hline & & MCF-7 & 11.2 & & \\
\hline & Filiasparoside B & A549 & 16.4 & & \\
\hline & & MCF-7 & 16.8 & & \\
\hline & Filiasparoside C & A549 & 2.3 & & \\
\hline & & MCF-7 & 3.0 & & \\
\hline & Filiasparoside D & A549 & 2.4 & & \\
\hline & & MCF-7 & 10.3 & & \\
\hline & Aspafilioside A & A549 & 9.4 & & \\
\hline & & MCF-7 & $>20$ & & \\
\hline & Aspafilioside B & A549 & 7.6 & & \\
\hline & & MCF-7 & 10.4 & & \\
\hline
\end{tabular}


Table 2 continued

\begin{tabular}{|c|c|c|c|c|c|}
\hline Source & Saponoside & Cell line & Concentration & Assay & References \\
\hline & & A549 & Control: etoposide & & \\
\hline & & & 0.8 & & \\
\hline & & MCF-7 & 2.8 & & \\
\hline \multirow{4}{*}{$\begin{array}{l}\text { Asparagus } \\
\text { officinalis } \\
\text { (Asparagaceae) }\end{array}$} & Asparanin A & HepG2 & $\mathrm{IC}_{50}\left[\mu \mathrm{mol} \mathrm{l^{-1 }}\right]$ & MTT; cytotoxic & $\begin{array}{r}\text { Liu et al. } \\
(2009 a)\end{array}$ \\
\hline & & & $6.20(24 \mathrm{~h})$ & & \\
\hline & & & $4.11(48 \mathrm{~h})$ & & \\
\hline & & & $2.90(72 \mathrm{~h})$ & & \\
\hline \multirow{29}{*}{$\begin{array}{l}\text { Asparagus } \\
\text { officinalis } \\
\text { (Asparagaceae) }\end{array}$} & & & $\mathrm{IC}_{50}\left[\mu \mathrm{mol} \mathrm{l^{-1 }}\right]$ & MTT; cytotoxic & $\begin{array}{l}\text { Huang et al. } \\
\quad(2008 \mathrm{c})\end{array}$ \\
\hline & $\begin{array}{l}(25 S)-5 \beta \text {-spirostan- } 3 \beta \text {-ol 3-O- } \beta \text {-D- } \\
\text { Glc- }(1 \rightarrow 2)-\beta \text {-D-6- } O \text {-acetyl-Glc }\end{array}$ & A2780 & 10.57 & & \\
\hline & & MGC-803 & 8.39 & & \\
\hline & & $\mathrm{CNE}$ & 5.50 & & \\
\hline & Asparagoside A & A 2780 & 10.22 & & \\
\hline & & HO-8910 & 5.04 & & \\
\hline & $(25 R)-5 \beta$-spirostan- $3 \beta$-ol $3-O-\beta$-D-Glc & HO-8910 & 24.83 & & \\
\hline & & L1210 & 12.33 & & \\
\hline & Sarsasapogenin & A2780 & 6.09 & & \\
\hline & $(25 S)$-neospirost-4-en-3-one & A2780 & 18.85 & & \\
\hline & & Eca-109 & 2.91 & & \\
\hline & $\begin{array}{l}(25 S)-5 \beta \text {-spirostan-3 } \beta \text {-ol 3-O- } \beta \text {-D- } \\
\text { Glc- }(1 \rightarrow 2)-[\beta \text {-D-Xyl- }(1 \rightarrow 4)]- \\
\beta \text {-D-Glc }\end{array}$ & LTEP-a-2 & 2.85 & & \\
\hline & & $\mathrm{KB}$ & 2.66 & & \\
\hline & & L1210 & 1.46 & & \\
\hline & $\begin{array}{l}(25 S)-5 \beta \text {-spirostan-3 } \beta \text {-ol 3-O- } \beta \text {-D- } \\
\quad \text { Glc- }(1 \rightarrow 2)-\beta \text {-D-Glc }\end{array}$ & Eca-109 & 4.03 & & \\
\hline & & MGC-803 & 3.72 & & \\
\hline & & LTEP-a-2 & 3.16 & & \\
\hline & & KB & 1.38 & & \\
\hline & & L1210 & 4.32 & & \\
\hline & $\begin{array}{l}(25 S)-5 \beta \text {-spirostan- } 3 \beta \text {-ol } 3-O-\alpha \text {-L- } \\
\text { Rha- }(1 \rightarrow 2)-[\alpha \text {-L-Rha- }(1 \rightarrow 4)- \\
\beta \text {-D-Glc }]\end{array}$ & Eca-109 & 10.15 & & \\
\hline & & $\mathrm{CNE}$ & 12.88 & & \\
\hline & & & Control: doxorubicin & & \\
\hline & & A 2780 & 0.15 & & \\
\hline & & HO-8910 & 1.45 & & \\
\hline & & Eca-109 & 0.36 & & \\
\hline & & MGC-803 & 0.72 & & \\
\hline & & $\mathrm{CNE}$ & 0.58 & & \\
\hline & & LTEP-a-2 & 1.33 & & \\
\hline & & KB & 0.43 & & \\
\hline
\end{tabular}


Table 2 continued

\begin{tabular}{|c|c|c|c|c|c|}
\hline Source & Saponoside & Cell line & Concentration & Assay & References \\
\hline & & L1210 & 0.26 & & \\
\hline \multirow{22}{*}{$\begin{array}{l}\text { Asparagus } \\
\text { oligoclonos } \\
\text { (Asparagaceae) }\end{array}$} & & & $\mathrm{IC}_{50}\left[\mu \mathrm{g} \mathrm{ml}^{-1}\right]$ & SRB; cytotoxic & $\begin{array}{l}\text { Kim et al. } \\
(2005)\end{array}$ \\
\hline & Asparanin A & A549 & 2.05 & & \\
\hline & & SK-OV-3 & 2.43 & & \\
\hline & & SK-MEL-2 & 2.41 & & \\
\hline & & XF498 & 2.56 & & \\
\hline & & HCT15 & 2.47 & & \\
\hline & Aspaoligonin A & A549 & 2.25 & & \\
\hline & & SK-OV-3 & 2.66 & & \\
\hline & & SK-MEL-2 & 2.53 & & \\
\hline & & XF498 & 2.84 & & \\
\hline & & HCT15 & 2.59 & & \\
\hline & Aspaoligonin B & A549 & 2.55 & & \\
\hline & & SK-OV-3 & 2.73 & & \\
\hline & & SK-MEL-2 & 2.59 & & \\
\hline & & XF498 & 2.51 & & \\
\hline & & HCT15 & 2.57 & & \\
\hline & & & Control: adriamycin & & \\
\hline & & A549 & 0.004 & & \\
\hline & & SK-OV-3 & 0.18 & & \\
\hline & & SK-MEL-2 & 0.03 & & \\
\hline & & XF498 & 0.012 & & \\
\hline & & HCT15 & 0.08 & & \\
\hline \multirow{18}{*}{$\begin{array}{l}\text { Balanites } \\
\quad \text { aegyptiaca } \\
\text { (Balanitaceae) }\end{array}$} & & & $\mathrm{IC}_{50}\left[\mu \mathrm{mol} \mathrm{I}^{-1}\right]$ & MTT; cytotoxic & Gnoula et al. \\
\hline & $\begin{array}{l}\text { A mixture of balanitin- } 6 \text { and } \\
\text { balanitin- } 7\end{array}$ & A549 & 0.3 & & \\
\hline & & U373 & 0.5 & & \\
\hline & & PC-3 & 0.9 & & \\
\hline & & $\mathrm{Bx}-\mathrm{PC} 3$ & 1.2 & & \\
\hline & & LoVo & 1.5 & & \\
\hline & & MCF-7 & 2.6 & & \\
\hline & & & Control: oxaliplatin & & \\
\hline & & A549 & 3.9 & & \\
\hline & & U373 & 3.3 & & \\
\hline & & PC-3 & 9.2 & & \\
\hline & & $\mathrm{Bx}-\mathrm{PC} 3$ & $>10.0$ & & \\
\hline & & LoVo & 4.7 & & \\
\hline & & MCF-7 & 8.9 & & \\
\hline & & & Control: etoposide & & \\
\hline & & A549 & 3.1 & & \\
\hline & & U373 & 1.4 & & \\
\hline & & PC-3 & $>10.0$ & & \\
\hline
\end{tabular}


Table 2 continued

\begin{tabular}{|c|c|c|c|c|c|}
\hline Source & Saponoside & Cell line & Concentration & Assay & References \\
\hline & & $\mathrm{Bx}-\mathrm{PC} 3$ & $>10.0$ & & \\
\hline & & LoVo & 4.9 & & \\
\hline & & MCF-7 & $>10.0$ & & \\
\hline & & & $\begin{array}{l}\text { Control: 7-ethyl-10- } \\
\text { hydroxycamptothecin }\end{array}$ & & \\
\hline & & A549 & 0.04 & & \\
\hline & & U373 & 0.001 & & \\
\hline & & PC-3 & 0.2 & & \\
\hline & & $\mathrm{Bx}-\mathrm{PC} 3$ & 0.07 & & \\
\hline & & LoVo & 0.4 & & \\
\hline & & MCF-7 & 0.03 & & \\
\hline & & & Control: Taxol ${ }^{\circledR}$ & & \\
\hline & & A549 & 0.009 & & \\
\hline & & U373 & 0.001 & & \\
\hline & & PC-3 & 0.002 & & \\
\hline & & $\mathrm{Bx}-\mathrm{PC} 3$ & 0.003 & & \\
\hline & & LoVo & 0.005 & & \\
\hline & & MCF-7 & 0.001 & & \\
\hline \multirow[t]{6}{*}{$\begin{array}{l}\text { Chlorophytum } \\
\text { borivilianum } \\
\text { (Liliaceae) }\end{array}$} & Borivilianoside $\mathrm{H}$ & & $\mathrm{IC}_{50}\left[\mu \mathrm{mol} \mathrm{l} \mathrm{l}^{-1}\right]$ & MTT; cytotoxic & $\begin{array}{l}\text { Acharya } \\
\text { et al. } \\
(2009)\end{array}$ \\
\hline & & НТ-29 & 2.6 & & \\
\hline & & HCT 116 & 0.38 & & \\
\hline & & & Control: paclitaxel & & \\
\hline & & HT-29 & $3.6 \times 10^{-3}$ & & \\
\hline & & HCT 116 & $1.1 \times 10^{-3}$ & & \\
\hline \multirow{4}{*}{$\begin{array}{l}\text { Dioscorea } \\
\text { bulbifera } \\
\text { (Dioscoreaceae) }\end{array}$} & $\begin{array}{l}\text { Pennogenin-3- } O \text { - } \alpha \text {-L-Rha- }(1 \rightarrow 3)-[\alpha- \\
\text { L-Rha- }(1 \rightarrow 2)]-\beta \text {-D-Glc }\end{array}$ & Bel-7402 & $\begin{array}{l}10 \mu \mathrm{mol} 1^{-1}(99.1 \% \\
\text { inhib.) }\end{array}$ & $\begin{array}{l}\text { MTT; } \\
\text { antiproliferative }\end{array}$ & $\begin{array}{l}\text { Liu et al. } \\
(2009 a)\end{array}$ \\
\hline & & SMMC7721 & $\mathbf{I C}_{\mathbf{5 0}} 4.54 \mu \mathrm{mol} \mathrm{l}^{-1}$ & & \\
\hline & $\begin{array}{l}\text { Pennogenin-3- } O \text { - } \alpha \text {-L-Rha- }(1 \rightarrow 4)-[\alpha- \\
\text { L-Rha- }(1 \rightarrow 2)]-\beta \text {-D-Glc }\end{array}$ & Bel-7402 & $\begin{array}{l}10 \mu \mathrm{mol} 1^{-1}(92.6 \% \\
\text { inhib.) }\end{array}$ & & \\
\hline & & SMMC7721 & $\mathbf{I C}_{\mathbf{5 0}} 4.85 \mu \mathrm{mol} \mathrm{l}^{-1}$ & & \\
\hline \multirow[t]{4}{*}{$\begin{array}{r}\text { Dioscorea villosa } \\
\text { (Dioscoreaceae) }\end{array}$} & & & $\mathrm{IC}_{50}\left[\mu \mathrm{mol} \mathrm{l} \mathrm{l}^{-1}\right]$ & $\begin{array}{l}\text { MTT; } \\
\text { antiproliferative }\end{array}$ & $\begin{array}{l}\text { Hu et al. } \\
\text { (2007) }\end{array}$ \\
\hline & $\begin{array}{l}(25 R) \text {-spirost-5-en-3 } \beta \text {-ol 3- } O \text { - } \alpha \text {-L-Rha- } \\
\quad(1 \rightarrow 2)-O \text { - }[\beta \text {-D-Glc- }(1 \rightarrow 4)]-\beta \text {-D- } \\
\text { Glc }\end{array}$ & HepG2 & 9.02 & & \\
\hline & & HEK293 & 13.21 & & \\
\hline & & MCF7 & 16.74 & & \\
\hline \multirow[t]{6}{*}{$\begin{array}{l}\text { Paris polyphylla } \\
\quad \text { (Liliaceae) }\end{array}$} & & & $\mathrm{IC}_{50}\left[\mu \mathrm{mol} \mathrm{l^{-1 }}\right]$ & MTT; cytotoxic & $\begin{array}{l}\text { Siu et al. } \\
\text { (2008) }\end{array}$ \\
\hline & Polyphyllin D & NCI-H460 & 3.0 & & \\
\hline & & SF-268 & 3.0 & & \\
\hline & & Hep G2 & 3.5 & & \\
\hline & & HeLa & 3.7 & & \\
\hline & & MCF-7 & 3.7 & & \\
\hline
\end{tabular}


Table 2 continued

\begin{tabular}{|c|c|c|c|c|c|}
\hline Source & Saponoside & Cell line & Concentration & Assay & References \\
\hline & & HEK-293 & 11.0 & & \\
\hline & & & Control: cisplatin & & \\
\hline & & NCI-H460 & 25 & & \\
\hline & & SF-268 & 15.6 & & \\
\hline & & Hep G2 & 20.2 & & \\
\hline & & $\mathrm{HeLa}$ & 11.6 & & \\
\hline & & MCF-7 & 19 & & \\
\hline & & HEK-293 & $>100$ & & \\
\hline \multirow{26}{*}{$\begin{array}{l}\text { Paris polyphylla } \\
\text { var. chinensis } \\
\text { (Liliaceae) }\end{array}$} & & & $2.5 \mu \mathrm{g} \mathrm{ml}^{-1}$ & MTT; cytotoxic & $\begin{array}{l}\text { Yun et al. } \\
(2007)\end{array}$ \\
\hline & $\begin{array}{l}\text { Diosgenin-3- } O \text { - } \alpha \text {-L-Rha- }(1 \rightarrow 2)-O- \\
\quad \beta \text {-D-Glc }\end{array}$ & HepG2 & $60.59 \%$ dead cells & & \\
\hline & & SGC7901 & $70.14 \%$ dead cells & & \\
\hline & & BxPC3 & $76.52 \%$ dead cells & & \\
\hline & $\begin{array}{l}\text { Pennogenin-3- } O-\alpha \text {-L-Rha- }(1 \rightarrow 2)- \\
O-\beta \text {-D-Glc }\end{array}$ & HepG2 & $44.22 \%$ dead cells & & \\
\hline & & SGC7901 & $50.13 \%$ dead cells & & \\
\hline & & ВxРC3 & $73.32 \%$ dead cells & & \\
\hline & $\begin{array}{l}\text { Diosgenin-3- } O-\alpha \text {-L-Rha- }(1 \rightarrow 2)- \\
{[\alpha-\mathrm{L}-\text { Ara- }(1 \rightarrow 4)]-\beta \text {-D-Glc }}\end{array}$ & HepG2 & $83.76 \%$ dead cells & & \\
\hline & & SGC7901 & $88.19 \%$ dead cells & & \\
\hline & & BxPC3 & $87.06 \%$ dead cells & & \\
\hline & $\begin{array}{l}\text { Pennogenin-3- } O \text { - } \alpha \text {-L-Rha- }(1 \rightarrow 2) \text { - } \\
{[\alpha \text {-L-Ara- }(1 \rightarrow 4)]-\beta \text {-D-Glc }}\end{array}$ & HepG2 & $65.22 \%$ dead cells & & \\
\hline & & SGC7901 & $70.39 \%$ dead cells & & \\
\hline & & BxPC3 & $79.64 \%$ dead cells & & \\
\hline & $\begin{array}{l}\text { Diosgenin-3- } O \text { - } \alpha \text {-L-Rha- }(1 \rightarrow 2)- \\
{[\beta \text {-D-Glc- }(1 \rightarrow 3)]-\beta \text {-D-Glc }}\end{array}$ & HepG2 & $68.35 \%$ dead cells & & \\
\hline & & SGC7901 & $77.34 \%$ dead cells & & \\
\hline & & BxPC3 & $76.63 \%$ dead cells & & \\
\hline & $\begin{array}{l}\text { Diosgenin-3- } O \text { - } \alpha \text {-L-Rha- }(1 \rightarrow 4)-\alpha \text {-L- } \\
\text { Rha- }(1 \rightarrow 4)-[\alpha \text {-L-Rha- }(1 \rightarrow 2)]-\beta- \\
\text { D-Glc }\end{array}$ & HepG2 & $61.70 \%$ dead cells & & \\
\hline & & SGC7901 & $75.81 \%$ dead cells & & \\
\hline & & BxPC3 & $82.92 \%$ dead cells & & \\
\hline & $\begin{array}{l}\text { Pennogenin-3- } O \text { - } \alpha \text {-L-Rha- }(1 \rightarrow 4)-\alpha- \\
\text { L-Rha- }(1 \rightarrow 4)-[\alpha-\text {-Rha- }(1 \rightarrow 2)]- \\
\beta \text {-D-Glc }\end{array}$ & HepG2 & $35.75 \%$ dead cells & & \\
\hline & & SGC7901 & $47.58 \%$ dead cells & & \\
\hline & & BxPC3 & $81.77 \%$ dead cells & & \\
\hline & & & $\begin{array}{l}\text { Control: epirubicin- } \\
\mathrm{HCl}\end{array}$ & & \\
\hline & & HepG2 & $78.89 \%$ dead cells & & \\
\hline & & SGC7901 & $70.73 \%$ dead cells & & \\
\hline & & BxPC3 & $65.78 \%$ dead cells & & \\
\hline
\end{tabular}


Table 2 continued

\begin{tabular}{|c|c|c|c|c|c|}
\hline Source & Saponoside & Cell line & Concentration & Assay & References \\
\hline \multirow{6}{*}{$\begin{array}{l}\text { Paris polyphylla } \\
\text { var. yunnanensis } \\
\text { (Liliaceae) }\end{array}$} & & & $\mathrm{IC}_{50}\left[\mu \mathrm{mol} \mathrm{l^{-1 }}\right]$ & MTT; cytotoxic & $\begin{array}{l}\text { Yan et al. } \\
(2009)\end{array}$ \\
\hline & $\begin{array}{l}\text { Diosgenin-3- } O \text { - } \alpha \text {-L-Ara- }(1 \rightarrow 4)- \\
{[\alpha \text {-L-Rha- }(1 \rightarrow 2)]-\beta \text {-D-Glc }}\end{array}$ & LA795 & 1.85 & & \\
\hline & $\begin{array}{l}\text { Pennogenin-3- } O \text { - } \alpha \text {-L-Ara- }(1 \rightarrow 4)- \\
{[\alpha \text {-L-Rha- }(1 \rightarrow 2)]-\beta \text {-D-Glc }}\end{array}$ & & 5.14 & & \\
\hline & $\begin{array}{l}\text { Diosgenin-3- } O \text { - } \alpha \text {-L-Rha- }(1 \rightarrow 4)- \\
{[\alpha-\mathrm{L}-\mathrm{Rha}-(1 \rightarrow 2)]-\beta \text {-D-Glc }}\end{array}$ & & 3.06 & & \\
\hline & $\begin{array}{l}\text { Pennogenin-3- } O-\alpha \text {-L-Rha- }(1 \rightarrow 4)- \\
{[\alpha \text {-L-Rha- }(1 \rightarrow 2)]-\beta \text {-D-Glc }}\end{array}$ & & 2.26 & & \\
\hline & $\begin{array}{l}\text { Diosgenin-3- } O \text { - } \alpha \text {-L-Rha- }(1 \rightarrow 4)- \\
{[\alpha \text {-L-Rha- }(1 \rightarrow 4)]-[\alpha \text {-L-Rha- }} \\
(1 \rightarrow 2)]-\beta \text {-D-Glc }\end{array}$ & & 1.35 & & \\
\hline \multirow{13}{*}{$\begin{array}{l}\text { Paris polyphylla } \\
\text { var. yunnanensis } \\
\text { (Liliaceae) }\end{array}$} & & & $\mathrm{IC}_{50}\left[\mu \mathrm{g} \mathrm{ml}^{-1}\right]$ & MTT; cytotoxic & $\begin{array}{l}\text { Zhao et al. } \\
\text { (2009) }\end{array}$ \\
\hline & $\begin{array}{l}\text { Pennogenin-3- } O \text { - } \alpha \text {-L-Ara- }(1 \rightarrow 4)- \\
\quad[\alpha \text {-L-Rha- }(1 \rightarrow 2)]-\beta \text {-D-Glc }\end{array}$ & HL-60 & 0.51 & & \\
\hline & $\mathrm{Tg}$ & & 0.30 & & \\
\hline & $\mathrm{Tb}$ & & 1.72 & & \\
\hline & $\begin{array}{l}\text { Pennogenin-3- } O \text { - } \beta \text {-D-Glc- }(1 \rightarrow 3) \text { - } \\
\quad \alpha \text {-L-Rha- }(1 \rightarrow 2)]-\beta \text {-D-Glc }\end{array}$ & & 3.75 & & \\
\hline & $\mathrm{Pa}$ & & 0.18 & & \\
\hline & $\mathrm{Pb}$ & & 0.14 & & \\
\hline & Gracillin & & 0.53 & & \\
\hline & Prosapogenin A of dioscin & & 0.38 & & \\
\hline & Reclinatoside & & 0.52 & & \\
\hline & Loureiroside & & 0.72 & & \\
\hline & & & $\begin{array}{l}\text { Control: cis- } \\
\text { diamminedichloro- } \\
\text { platinum }\end{array}$ & & \\
\hline & & & 0.038 & & \\
\hline \multirow[t]{8}{*}{$\begin{array}{l}\text { Polygonatum } \\
\text { punctatum } \\
\text { (Liliaceae) }\end{array}$} & & & $\mathrm{IC}_{50}\left[\mu \mathrm{g} \mathrm{ml}^{-1}\right]$ & MTT; cytotoxic & $\begin{array}{l}\text { Yang and } \\
\text { Yang } \\
(2006)\end{array}$ \\
\hline & Polypunctoside A & $\mathrm{HeLa}$ & 39.8 & & \\
\hline & Polypunctoside B & & 3.2 & & \\
\hline & Polypunctoside $\mathrm{C}$ & & 2.5 & & \\
\hline & Polypunctoside D & & 2.6 & & \\
\hline & Dioscin & & 20.4 & & \\
\hline & & & Control: cisplatin & & \\
\hline & & & 0.75 & & \\
\hline \multirow{3}{*}{$\begin{array}{l}\text { Sansevieria } \\
\quad \text { ehrenbergii } \\
\text { (Agavaceae) }\end{array}$} & & & $\mathbf{G I}_{50}\left[\mu \mathrm{g} \mathrm{ml}^{-1}\right]$ & $\begin{array}{l}\text { SRB; } \\
\text { antiproliferative }\end{array}$ & $\begin{array}{l}\text { Pettit et al. } \\
\quad(2005)\end{array}$ \\
\hline & Sansevistatin 1 & P388 & 1.6 & & \\
\hline & & BXPC-3 & 1.1 & & \\
\hline
\end{tabular}


Table 2 continued

\begin{tabular}{|c|c|c|c|c|c|}
\hline Source & Saponoside & Cell line & Concentration & Assay & References \\
\hline & & MCF-7 & 1.1 & & \\
\hline & & SF-268 & 1.3 & & \\
\hline & & NCI-H460 & 0.43 & & \\
\hline & & KM20L2 & 0.47 & & \\
\hline & & DU-145 & 1.0 & & \\
\hline & Sansevistatin 2 & P388 & 1.7 & & \\
\hline & & BXPC-3 & 0.93 & & \\
\hline & & MCF-7 & 0.62 & & \\
\hline & & SF-268 & 0.68 & & \\
\hline & & NCI-H460 & 0.26 & & \\
\hline & & KM20L2 & 0.22 & & \\
\hline & & DU-145 & 0.42 & & \\
\hline & Dioscin & P388 & 1.5 & & \\
\hline & & BXPC-3 & 1.1 & & \\
\hline & & MCF-7 & 1.6 & & \\
\hline & & SF-268 & 1.2 & & \\
\hline & & NCI-H460 & 1.6 & & \\
\hline & & KM20L2 & 1.6 & & \\
\hline & & DU-145 & 1.6 & & \\
\hline & $\begin{array}{l}3 \beta \text { - } O \text { - }[\alpha \text {-L-Rha- }(1 \rightarrow 2)]-\beta \text {-D-Glc- } \\
\quad(25 R) \text {-spirost-5-ene }\end{array}$ & P388 & 1.5 & & \\
\hline & & BXPC-3 & 1.8 & & \\
\hline & & MCF-7 & 2 & & \\
\hline & & SF-268 & 1.8 & & \\
\hline & & NCI-H460 & 1.8 & & \\
\hline & & KM20L2 & 1.7 & & \\
\hline & & DU-145 & 1.6 & & \\
\hline & $\begin{array}{l}3 \beta \text { - } O \text { - }[\alpha-\mathrm{L}-\mathrm{Rha}-(1 \rightarrow 2)]-[\beta \text {-D-Xyl- } \\
\quad(1 \rightarrow 4)]-\beta \text {-D-Glc- }(25 R) \text {-spirost- } \\
\text { 5-ene }\end{array}$ & P388 & 2.6 & & \\
\hline & & BXPC-3 & 1.7 & & \\
\hline & & MCF-7 & 1.4 & & \\
\hline & & SF-268 & 1.3 & & \\
\hline & & NCI-H460 & 1.2 & & \\
\hline & & KM20L2 & 0.5 & & \\
\hline & & DU-145 & 1.1 & & \\
\hline \multirow[t]{8}{*}{$\begin{array}{l}\text { Solanum nigrum } \\
\text { (Solanaceae) }\end{array}$} & & & $\mathrm{IC}_{50}\left[\mu \mathrm{mol} \mathrm{l^{-1 } ]}\right.$ & MTT; cytotoxic & $\begin{array}{l}\text { Zhou et al. } \\
\text { (2006) }\end{array}$ \\
\hline & Degalactotigonin & HepG2 & 0.25 & & \\
\hline & & NCI-H460 & 4.49 & & \\
\hline & & MCF-7 & 1.57 & & \\
\hline & & SF-268 & 3.19 & & \\
\hline & & & $\begin{array}{l}\text { Control: } 10 \text {-hydroxy- } \\
\text { camptothecine }\end{array}$ & & \\
\hline & & HepG2 & 6.49 & & \\
\hline & & NCI-H460 & 38.55 & & \\
\hline
\end{tabular}


Table 2 continued

\begin{tabular}{|c|c|c|c|c|c|}
\hline Source & Saponoside & Cell line & Concentration & Assay & References \\
\hline & & MCF-7 & 19.12 & & \\
\hline & & SF-268 & 29.88 & & \\
\hline \multirow[t]{14}{*}{$\begin{array}{l}\text { Solanum torvum } \\
\text { (Solanaceae) }\end{array}$} & & & $\mathrm{IC}_{50}\left[\mu \mathrm{g} \mathrm{ml}^{-1}\right]$ & MTT; cytotoxic & $\begin{array}{l}\text { Lu et al. } \\
\text { (2009) }\end{array}$ \\
\hline & $\begin{array}{l}\text { Yamogenin-3-O- } \beta \text {-D-Glc- }(1 \rightarrow 6) \text { - } \\
\beta \text {-D-Glc }\end{array}$ & MGC-803 & 25.2 & & \\
\hline & & HepG2 & 32.7 & & \\
\hline & & AS49 & 34.2 & & \\
\hline & & MCF-7 & 29.4 & & \\
\hline & $\begin{array}{l}\text { Neochlorogenin-3- } O \text { - } \beta \text {-D-Glc- } \\
\quad(1 \rightarrow 6)-\beta \text {-D-Glc }\end{array}$ & MGC-803 & 57.5 & & \\
\hline & & HepG2 & 65.5 & & \\
\hline & & AS49 & 58.3 & & \\
\hline & & MCF-7 & 48.4 & & \\
\hline & & & $\begin{array}{l}\text { Control: cis-diammine- } \\
\text { dichloroplatinum }\end{array}$ & & \\
\hline & & MGC-803 & 14.4 & & \\
\hline & & HepG2 & 13.2 & & \\
\hline & & AS49 & 14.1 & & \\
\hline & & MCF-7 & 15.3 & & \\
\hline \multirow[t]{9}{*}{$\begin{array}{l}\text { Tribulus } \\
\text { parvispinus } \\
\text { (Zygophyllaceae) }\end{array}$} & & & $\mathrm{IC}_{\mathbf{5 0}}\left[\boldsymbol{\mu \mathrm { mol } \mathrm { l }} \mathbf{l}^{-1}\right]$ & $\begin{array}{l}\text { Acid phosphatase } \\
\text { assay; }\end{array}$ & $\begin{array}{l}\text { Perrone } \\
\text { et al. } \\
(2005)\end{array}$ \\
\hline & $\begin{array}{l}(25 R)-26-O-\beta \text {-D-Glc- } 5 \alpha \text {-furostan- } \\
3 \beta, 22 \alpha, 26 \text {-triol 3- } O-\{\beta \text {-D-Gal- } \\
(1 \rightarrow 2)-O-[\beta \text {-D-Xyl- }(1 \rightarrow 3)]-O- \\
\beta \text {-D-Glc- }(1 \rightarrow 4)-\beta \text {-D-Gal }\}\end{array}$ & U937 & 0.5 & & \\
\hline & Gitonin & U937 & 0.1 & WST1; cytotoxic & \\
\hline & & MCF-7 & 3.0 & & \\
\hline & & HepG2 & 3.0 & & \\
\hline & & & Control: resveratrol & & \\
\hline & & U937 & 17.0 & & \\
\hline & & MCF-7 & 100 & & \\
\hline & & HepG2 & 50 & & \\
\hline \multirow[t]{5}{*}{$\begin{array}{l}\text { Tupistra chinensis } \\
\text { (Liliaceae) }\end{array}$} & & & $10 \mu \mathrm{g} \mathrm{ml}^{-1}$ & $\begin{array}{l}\text { MTT; } \\
\text { antiproliferative }\end{array}$ & $\begin{array}{l}\text { Zou et al. } \\
\text { (2006a) }\end{array}$ \\
\hline & Fraction containing: & HeLa & (81\% inhib.) & & \\
\hline & $\begin{array}{l}(25 S) \text {-26- } O \text { - }(\beta \text {-D-Glc)-furost-5-en- } \\
3 \beta, 22 \alpha, 26 \text {-triol 3-O- } \beta \text {-D-Glc- } \\
(1 \rightarrow 2)-\beta \text {-D-Glc- }(1 \rightarrow 4)-\beta \text {-D-Glc }\end{array}$ & HL-60 & (92\% inhib.) & & \\
\hline & and & & & & \\
\hline & $\begin{array}{l}(25 R)-26-O-(\beta \text {-D-Glc }) \text {-furost-5-en- } \\
3 \beta, 22 \alpha, 26 \text {-triol 3- } O-\beta \text {-D-Glc- } \\
(1 \rightarrow 2)-\beta \text {-D-Glc- }(1 \rightarrow 4)-\beta \text {-D-Glc }\end{array}$ & & & & \\
\hline \multirow{2}{*}{$\begin{array}{l}\text { Ypsilandra } \\
\text { thibetica } \\
\text { (Liliaceae) }\end{array}$} & & & $\mathrm{IC}_{50}\left[\mu \mathrm{g} \mathrm{ml}^{-1}\right]$ & MTT; cytotoxic & $\begin{array}{l}\text { Xie et al. } \\
\text { (2009) }\end{array}$ \\
\hline & Ypsilandroside $\mathrm{G}$ & K562 & 4.4 & & \\
\hline
\end{tabular}


Table 2 continued

\begin{tabular}{|c|c|c|c|c|c|}
\hline Source & Saponoside & Cell line & Concentration & Assay & References \\
\hline & $\begin{array}{l}\text { Pennogenin-3-O- } \alpha \text {-L-Rha- }(1 \rightarrow 2)-[\alpha- \\
\text { L-Rha- }(1 \rightarrow 4)-\alpha \text {-L-Rha- }(1 \rightarrow 4)]- \\
\beta \text {-D-Glc }\end{array}$ & SPC-A-1 & 6.3 & & \\
\hline & & BGC-823 & 6.9 & & \\
\hline & & Eca-109 & 8.0 & & \\
\hline & & AGS & 8.9 & & \\
\hline & & K562 & 4.7 & & \\
\hline & & SPC-A-1 & 6.3 & & \\
\hline & & BGC-823 & 6.9 & & \\
\hline & & Eca-109 & 8.0 & & \\
\hline & & AGS & 8.9 & & \\
\hline & & & $\begin{array}{l}\text { Control: cisplatin- } \\
\text { data not given }\end{array}$ & & \\
\hline
\end{tabular}

Cancer cell lines: Prostate: LNCaP, PC-3, DU-145; Leukemia: CEM, K562, HL60, *L1210, P388; Ovarian: SK-OV-3, A2780, OVCAR3, HO-8910; Breast: MDA-MB-231, MCF-7, MDA-MB-453, MDA-MB-435; Lung: A-549, H522-T1, COR-L23, NCIH460, LTEP-a-2, *LA795, SPC-A-1; Melanoma: G361, MEL-5, A375, C32, *B16F1, *B16F10, SK-MEL-2, HTB-140; Colon: HCT-15, HT-29, WiDr, HCT116, CaCo-2, SW1116, HCT-8, DLD-1, LoVo, KM20L2; Lymphoma: U937; Pharynx: CNE, KB, Eca109; Liver: HepG2, Huh-7D12, Bel-7402, Hepa59T/VGH, SMMC7721; Stomach: MGC-803, MKN-45, BGC-803, BGC823, KATOIII, SGC7901, AGS; Pancreas: Bx-PC3; CNS: U251, SF268, *C6, U251MG, U373, Daoy, XF498; Renal: ACHN; Bone: 1547, *WEHI-164, *XC, RPMI 8226; Uterus: HeLa

Normal cell lines: Fibroblasts: HSF, BJ-H-tert, 142BR, HFL-I, WS1; Macrophages: *RAW 264.7, *J774.A1; Epithelium/ endothelium: EVC-304, MCF-10A; Kidney embryonic: HEK-293; * Murine origin

Concentration: $\mathrm{IC}_{50}$ half maximal inhibitory concentration; $\mathrm{ED}_{50}$ effective dose; $\mathrm{GI}_{50}$ growth inhibition; $\mathrm{LC}_{50}$ lethal concentration; $\mathrm{LD}_{50}$ lethal dose

Assays: MTT-3-(4,5-dimethylthiazol-2-yl)-2,5-diphenyl tetrazolium bromide; XTT-2,3-bis (2-methoxy-4-nitro-5-sulfophenyl)-5[(phenylamino) carbonyl]-2H-tetrazolium hydroxide; MTS-3-(4,5-dimethylthiazol-2-yl)-5-(3-carboxymethoxyphenyl)-2-(4sulfophenyl)-2H-tetrazolium; WST-1-2-(4-iodophenyl)-3-(4-nitrophenyl)-5-(2,4-disulfophenyl)-2H-tetrazolium monosodium, $\mathrm{SRB}$ — sulphorhodamine. PI—propidium iodide. NRR—neutral red release

to saponin treatment (Einbond et al. 2008). Another interesting example is a study on the effect of avicin D from Acacia victoriae on apoptosis (Zhang et al. 2008). It was observed on three lymphoma cell lines (MJ, Hut78, HH) and on cells from patients with Sézary syndrome. Moreover, cells from healthy donors and two normal T-cell lines (CD4+ and activated $\mathrm{CD} 4+$ ) were used as comparative material. Apoptosis was seen in all lymphoma cell lines and in Sézary syndrome patient cells whereas only slight apoptotic changes were detected in normal cells.

The study by Zhang et al. was well designed also in another aspect, because the major drawback of cytotoxicity tests summarized in this review, is that only few compare the effect on cancer cells with the effect on normal cells. Thus, it is very hard to draw any conclusions on the future potential of these compounds as anticancer drugs because no data on their selectivity are provided. One of worth noting recent examples is the study by Tian et al. who tested triterpenoid saponins isolated from Ardisia crispa against human glioblastoma U251MG cell line (Tian et al. 2009). While all the four compounds exhibited significant cytotoxicity against cancer cells $\left(\mathrm{IC}_{50}\right.$ 2.57-12.20 $\mu \mathrm{mol} \mathrm{1^{-1 }}$ ) they did not affect the growth of primary cultured human astrocytes at concentrations as high as $>100$ $\mu \mathrm{mol} 1^{-1}$.

The most preferred methods used for cytotoxicity screening were MTT (formazan based assay) and SRB (sulphorhodamine B assay), however in some studies other techniques were also applied, like eg. neutral red release assay. In rare cases, brine shrimp lethality test is still applied even though it is rather unspecific. According to Houghton et al. the SRB assay is more sensitive and rapid than MTT, which was more popular among authors of studies cited in Tables 1 
Fig. 1 Chemical structures of polyphyllin D (1), methyl protodioscin (2), albizoside C (3) and saponin PE (4)

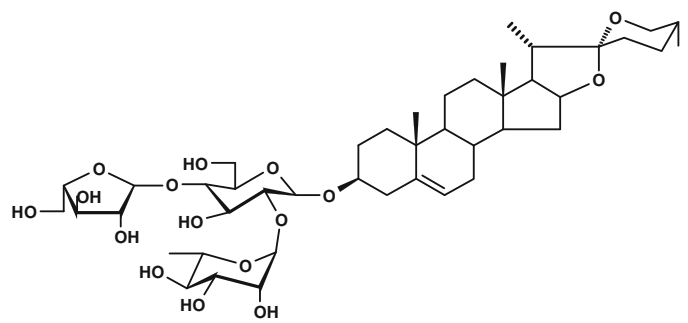

1.

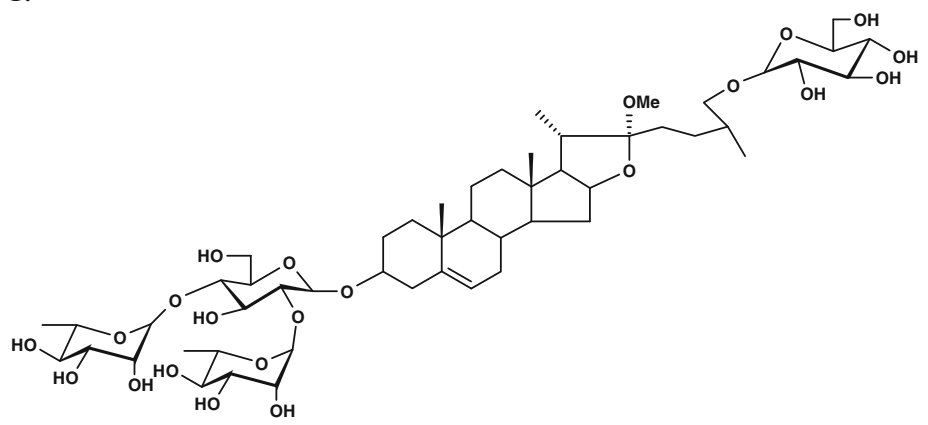

2.

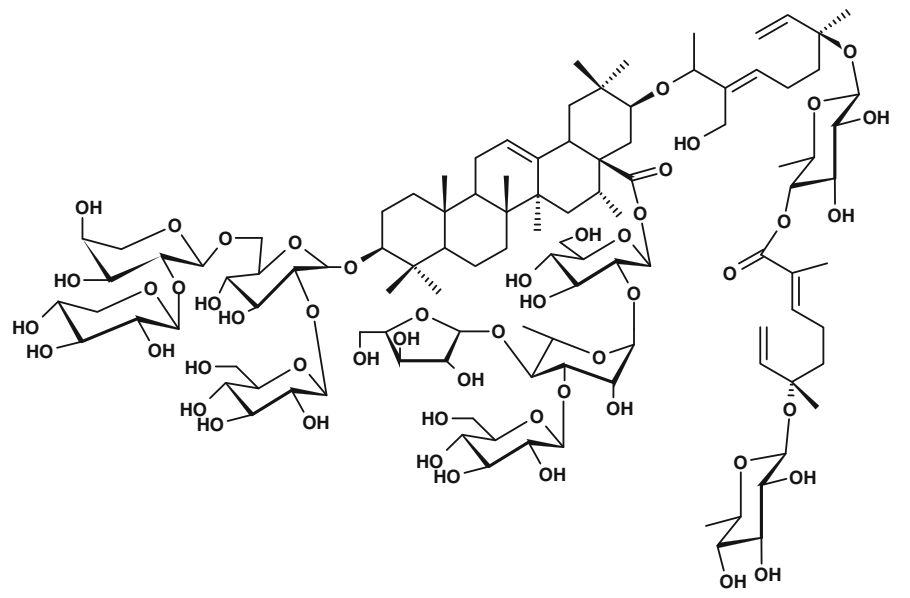

3.

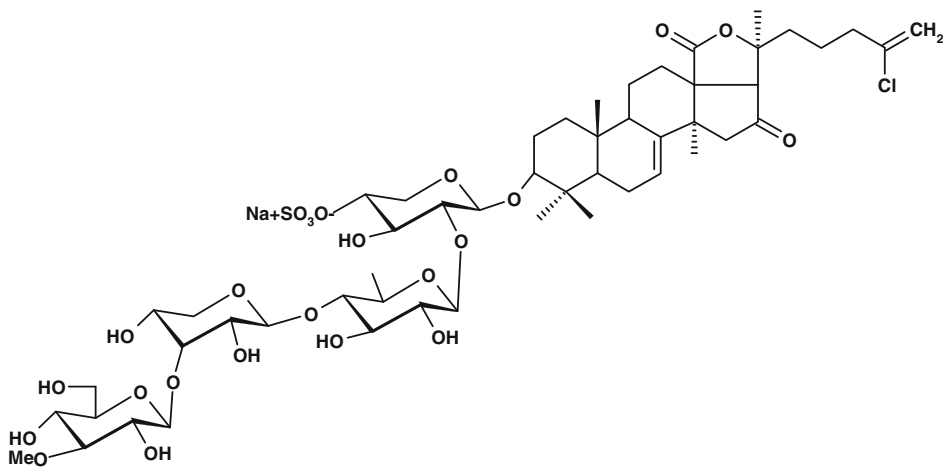

4. 
and 2 (Houghton et al. 2007). There may be some minute differences in $\mathrm{IC}_{50}$ values obtained with these methods (Dongre et al. 2007).

In the majority of cases $\mathrm{IC}_{50}$ values were compared with a control. Usually, the reference substance was a known, clinically used anticancer agent, like etoposide, paclitaxel, doxorubicin, adriamycin, cisplatin, in some cases however, compounds still under investigation like betulinic acid (Cmoch et al. 2008) or resveratrol (Perrone et al. 2005) were applied. Sometimes, information on the use of a positive control was not accompanied by $\mathrm{IC}_{50}$ data (Xie et al. 2009; Cao et al. 2007).

As can be seen from comparison of $\mathrm{IC}_{50}$ values (Tables 1, 2) most saponins, both triterpenoid and steroid, were less active than the reference compounds. In some cases, however, their cytotoxicity was comparable or even higher. Among triterpenoid saponins, acylated oleanane-type glochierioside A, was cytotoxic against HL-60, MCF-7, SK-OV-3 and HT-29 cell lines with $\mathrm{IC}_{50}$ values similar to mitoxantrone (Kiem et al. 2009). One of the structurally related acylated oleanane-type albizosides, albizoside C (Fig. 1) isolated from Albizia chinensis, was more potent than camptothecin on five cell lines, the difference was especially notable against lung carcinoma A549, with $\mathrm{IC}_{50} 0.01 \mu \mathrm{mol} \mathrm{l}^{-1}$ vs. $3.1 \mu \mathrm{mol} 1^{-1}$ (Liu et al. 2009b). Other examples worth noting are holostane saponins from a sea cucumber Pseudocolochirus violaceus, which exhibited distinctly higher cytotoxicity than 10-hydroxycamptothecin used as a positive control against colon cancer HCT-116 (IC (50 $_{0.052-0.066}$ and $0.135 \mu \mathrm{mol} \mathrm{l}^{-1}$, respectively) (Zhang et al. 2007). Among steroid saponins, the activity of filiasparoside C (Asparagus filicinus) against MCF-7 was comparable to etoposide $\left(\mathrm{IC}_{50} 3.0\right.$ and $2.8 \mu \mathrm{g} \mathrm{ml}^{-1}$, respectively) (Zhou et al. 2007). Also, similar levels of cell growth inhibition were observed for diosgenin-3-O- $\alpha$ L-Rhap- $(1 \rightarrow 2)$-[ $\alpha$-L-Araf- $(1 \rightarrow 4)]-\beta$-D-Glc $p \quad$ and control epirubicin-HCl against HepG2, SGC7901 and BxPC3 (Yun et al. 2007). Degalactotigonin from Solanum nigrum exhibited much higher cytotoxicity than 10-hydroxycamptothecin on a panel of four cell lines (HepG2, MCF-7, SF-268, NCI-H460) with $\mathrm{IC}_{50}$ values ranging from $0.25-4.49$ and 6.49$38.55 \mu \mathrm{mol} \mathrm{l}^{-1}$, respectively (Zhou et al. 2006).

Comparison of cytotoxicity level is, however, only an approximation as there are notable differences in
$\mathrm{IC}_{50}$ values between control compounds, for example $\mathrm{IC}_{50}$ of etoposide against $\mathrm{A} 549$ was $1.1 \mu \mathrm{mol} 1^{-1}$ whereas $\mathrm{IC}_{50}$ of 5-fluorouracil against the same cell line was as high as $48 \mu \mathrm{mol} 1^{-1}$ (Mskhiladze et al. 2008). Gnoula et al. in their study of cytotoxic activity of a mixture of balanitin- 6 and balanitin-7 against a panel of six cell lines (A549, U373, PC-3, Bx-PC3, LoVo, MCF-7) compared $\mathrm{IC}_{50}$ values with as much as four reference substances: oxaliplatin, etoposide, 7-ethyl-10-hydroxycamptothecin and paclitaxel (Gnoula et al. 2008). The tested saponin mixture was significantly more active $\left(\mathrm{IC}_{50}\right.$ from 0.3 to $2.6 \mu \mathrm{mol} \mathrm{1^{-1 }}$ ) than oxaliplatin ( $\mathrm{IC}_{50}$ from 3.3 to $>10 \mu \mathrm{mol} 1^{-1}$ ) but significantly less active than paclitaxel $\left(\mathrm{IC}_{50}\right.$ from 0.001 to $0.009 \mu \mathrm{mol} \mathrm{l}^{-1}$ ). Thus, a choice of reference may lead to various conclusions with respect to the potency of cytotoxic compounds.

Most often, $\mathrm{IC}_{50}$ values for paclitaxel are of $\mathrm{nmol} \mathrm{l}^{-1}$ order whereas for saponins in the same cell line $-\mu \mathrm{mol} 1^{-1}$. It is interesting to note that one of triterpene saponins isolated from Gordonia chrysandra (Theaceae)-gordonoside $\mathrm{C}$, was significantly more potent than paclitaxel against Bel-7402 $\left(\mathrm{IC}_{50}\right.$ 0.7 and $6.3 \mu \mathrm{mol} 1^{-1}$, respectively) (Yu et al. 2009).

Another issue worth mentioning with respect to cytotoxicity values presented in Tables 1 and 2 is that there is often no obvious correlation between the in vitro and in vivo effects, therefore compounds of lesser activity might prove more valuable when tested in animal models. A good example is provided by the study of Bang et al. An oleanolic acid saponin which was most active in vitro had an inferior in vivo antitumor activity, contrary to a hederagenin glycoside (Bang et al. 2005).

Bioavailability would be an important aspect to discuss in this respect and more studies are certainly needed as only limited data are available in the literature with regard to the pharmacokinetics and bioavailability of saponins both triterpene and steroidal. Most of the available data indicate that these compounds are very poorly absorbed following oral administration to animals and humans. As these issues are outside the scope of the present review, only examples of reports which refer to saponins with cytotoxic or anti-tumor activities are presented.

In the study by Li et al., it was shown that the absolute bioavailability of dioscin after oral administration to rats was very low $(0.2 \%)$. Dioscin underwent a prolonged absorption from the 
intestines, its level in the intestine remained quite high even after $120 \mathrm{~h}$ after administration ( $\mathrm{Li}$ et al. 2005). Similar results were obtained in the study by Ren et al. The ${ }^{3} \mathrm{H}$ labeled total saponins of Dioscorea nipponica (including dioscin, pseudoprotodioscin, protodioscin and methyl protodioscin) were orally administered $\left(80 \mathrm{mg} \mathrm{kg}^{-1}\right)$ to rats. The compounds were found to have a long half-life in rats. The highest emission of radioactivity level at the 120th $\mathrm{h}$ was measured in the liver, adrenal gland, and walls of the gastrointestinal tract. The blood concentration of ${ }^{3} \mathrm{H}$ labeled compounds was very low (Ren et al. 2008).

$\mathrm{He}$ et al. concluded that oral bioavailability of methyl protodioscin in rat $\left(80 \mathrm{mg} \mathrm{kg}^{-1}\right)$ was good. Ten metabolites of the parent compound, including dioscin, were identified in the urine. Some of them showed potent antiproliferative activities towards HepG2, NCI-H460, MCF-7 and HeLa human cell lines, but their cytotoxic effects were much weaker in comparison to methyl protodioscin activity (He et al. 2006).

Amongst triterpene saponins, tubeimoside I, isolated from the tubers of Bolbostemma paniculatum which has gained much attention due to its antitumor and antitumor-promoting effects, has been examined in order to assess pharmacokinetics and bioavailability after intravenous and oral administration to rats. Its oral bioavailability ( $50 \mathrm{mg} \mathrm{kg}^{-1}$ ) was only $0.23 \%$ which indicated poor absorption or acid-induced degradation (Liang et al. 2007).

However, there were also reports which proposed new strategies to increase absorption of such amphiphilic compounds as saponins. In studies on ginseng saponins it was suggested that worse permeability from gastrointestinal tract may be due to surface activity of saponins which might self-assemble as micelles in solution. Such micellar aggregates would have an increased molecular size and hydrophyllic property and thus result in poor permeability. To prove that this suggestion holds true Xiong et al. designed a lipid-based formulation that was expected to prevent ginsenosides from aggregation and then compared the relative bioavailability of ginsenosides $\mathrm{Rg}_{1}$ and $R b_{1}$ from an aqueous solution and this new formulation. After intraduodenal administration of the new formulation ginsenoside bioavailability in rats was remarkably enhanced relative to the aqueous solution $\left(\mathrm{AUC}_{0-\infty}\right.$ of $\mathrm{Rg}_{1}$ and $\mathrm{Rb}_{1}$ were 207.52 \pm 53.95 and
$1,961.72 \pm 686.60 \mu \mathrm{g} \mathrm{ml}^{-1} \mathrm{~h}$ compared to $7.87 \pm$ 2.85 and $148.58 \pm 36.73 \mu \mathrm{g} \mathrm{ml}^{-1} \mathrm{~h}$ ). (Xiong et al. 2008).

Another interesting example that shows how by modifying a drug's formulation its bioavailability may be enhanced is a study of Gu et al. on beagle dogs. The authors compared oral bioavailability of anti-tumor 20(R)-ginsenoside $\mathrm{Rh}_{2}$ and its micronized formulation. The results obtained indicated that the bioavailability of oral micronized $20(R)-\mathrm{Rh}_{2}$ was almost two-fold higher than that of native ginsenoside $\left(\mathrm{AUC}_{0-\infty}\right.$ $2375.9 \pm 882.5$ and $1,215.7 \pm 598.6 \mathrm{ng} \mathrm{ml}^{-1} \mathrm{~h}$, respectively; $C_{\max } 730.0 \pm 325.5$ and $371 \pm 199.6$ ng ml${ }^{-1}$, respectively; $T_{\max } 1.8 \pm 0.7$ and $2.6 \pm$ $1.3 \mathrm{~h}$, respectively). The authors concluded that $\mathrm{Rh}_{2}$ in the micro-particle formulation seems to be better dissolved in the intestinal juice and transported across the intestinal epithelial cells (Gu et al. 2006).

\section{Correlation between the structure and cytotoxicity of saponins}

Observations from numerous studies confirm that the biological activity of saponins is influenced both by the aglycone and the sugar moiety. Most existing information of the structure-activity relationships comes from research on the haemolytic action of saponins. As was shown for triterpenoid and steroid compounds there are certain structural features which seem to influence the strength of the lysis of erythrocytes, however, it is hardly possible to establish any uninamous correlation. In the case of triterpene saponins for example, acylation seems to be beneficial in terms of their haemolytic potential (Melzig et al. 2001; Chwalek et al. 2004), for steroid saponins most studies conclude that furostanols are in general inactive. Similarly, the nature of carbohydrate constituents influences haemolytic action of both types of saponins but this effect is not repeatable with the same sugar moiety and a different aglycone.

The lysis of erythrocytes is one of the most characteristic biological features of saponins and is considered as a major drawback in their clinical development. As was mentioned earlier, it is believed to result mainly from the ability of these compounds to interact with membrane cholesterol leading to membrane destabilization but not only (Francis et al. 
2002; Melzig et al. 2001). The same mechanism is also involved in the cytotoxicity of saponins however, as was shown in many studies, a large number of compounds act via different modes of action, including apoptotic and non-apoptotic cell death inducement, which are also reviewed in this paper.

Comparison of the steroidal saponins haemolytic activity with their cytotoxicity revealed that these two activities were not correlated because of different mechanisms of action (Wang et al. 2007). It was observed however, that some highly haemolytic compounds were highly cytotoxic as well, and similarly some weakly toxic steroidal saponins had weak haemolytic activity. At the same time, several glycosides showing similar cytotoxicity had disparate haemolytic activity and opposite, some compounds possessing comparable haemolysis potency had disparate cytotoxicity. Therefore, there is no clear correlation between the haemolytic activity and cytotoxicity of steroidal saponins and similarly the SAR data referring to haemolysis cannot be directly extrapolated to relationships crucial for cytotoxic activity.

While most studies in which cytotoxic activity of saponins is reported focus on structure elucidation there are sparse data, if any, on SAR relevant to cytotoxicity results, which are often published as additional information accompanying structure elucidation procedures. Some information is usually provided by authors who isolate, from a given plant source, a greater variety of structures. However, there is still a fairly limited number of comparative studies which directly concentrate on establishment of structure-activity relationships relevant to cytotoxicity.

Several studies which explored the correlation between haemolytic activity and cytotoxicity of saponins have been published, the most recent are the reports by Gauthier et al. on triterpenoid glycosides and by Wang et al. on steroid saponins (Gauthier et al. 2009a; Wang et al. 2007). Most crucial structure-cytotoxic activity relationships are summarized in Table 3.

Correlation between the structure and cytotoxicity of triterpenoid saponins

The most recent SAR study by Gauthier et al. compared the effect on haemolysis, cytotoxicity and membrane cell permeabilization of 35 semi-synthetic and natural triterpenoid saponins (Gauthier et al. 2009a). In their previous work (Gauthier et al. 2006), the authors investigated only lupane-type compounds, this extended study encompassed compounds with lupane and oleanane skeleton The authors subdivided the tested compounds into five groups: free triterpenoids such as betulin, betulinic acid, hederagenin and oleanolic acid; lupane monodesmosides (with $\alpha$-L-Rha,$\alpha$-L-Ara $f, \alpha$-D-Man $p, \beta$-D-Glc $p, \beta$-D-Gal $p$, $\beta$-D-Xylp); lupane bidesmosides (with $\alpha$-L-Rhap and $\beta$-D-Glc $p$ or $\alpha$-L-Rhap); lupane saponins containing $\alpha$-L-arabinopyranose (mono and bidesmosides with either $\alpha$-L-Rhap or/and $\beta$-D-Glc $p$ ); oleanane saponins ( $\alpha$-hederin, $\beta$-hederin, $\delta$-hederin, hederacolchiside $\mathrm{A}$ and hederacolchiside $A_{1}$ ). Human cell lines assessed in this study included lung carcinoma A549, colorectal adenocarcinoma DLD-1 as well as normal skin fibroblasts WS1.

Based on the obtained results the authors concluded, that in the case of oleanane type saponins those having oleanolic acid as an aglycone were more potent than hederagenin saponins irrespective of the sugar moiety. Again, this study confirms that as far as sugar part is concerned it seems that the presence at the C-3 position of the aglycone of an $\alpha$-L-Rhap$(1 \rightarrow 2)-\alpha$-L-Arap moiety is a structural requirement essential for potent cytotoxic activity of oleanane saponins.

What is worth noting is the fact, that the same sugar sequence has no effect on the cytotoxicity of lupane-type saponins, such compounds were inactive even at the highest concentrations tested in this study $\left(\mathrm{IC}_{50}>100 \mu \mathrm{mol} \mathrm{l^{-1 }}\right)$ whereas the presence of the sole $\alpha$-L-Ara $p$ moiety had a significantly positive effect. The cytotoxicity of betulin and betulinic acid derivatives significantly varied according to the nature of monosaccharides linked to C-3 and C-28. In monodesmosidic compounds the most active were $\alpha$-L-rhamnopyranosides and in bidesmosidic saponins those containing two rhamnose moieties. In fact, betulin bis-3,28- $\alpha$-L-rhamnopyranoside was the most potent inhibitor of cell lines of all compounds tested, with $\mathrm{IC}_{50}$ ranging from 1.3 to $1.9 \mu \mathrm{mol}^{-1}$. However, this last saponoside was not selective towards cancer cells. In this respect, the most promising was betulinic acid $\alpha$-L-rhamnopyranoside, which exerted strong cytotoxicity on cancer lines with $\mathrm{IC}_{50}$ from 2.6 to $3.9 \mu \mathrm{mol}^{-1}$ while $\mathrm{IC}_{50}$ for human fibroblasts was as high as $31 \mu \mathrm{mol} \mathrm{l}^{-1}$. 
Table 3 Structure-cytotoxic activity relationships of saponins

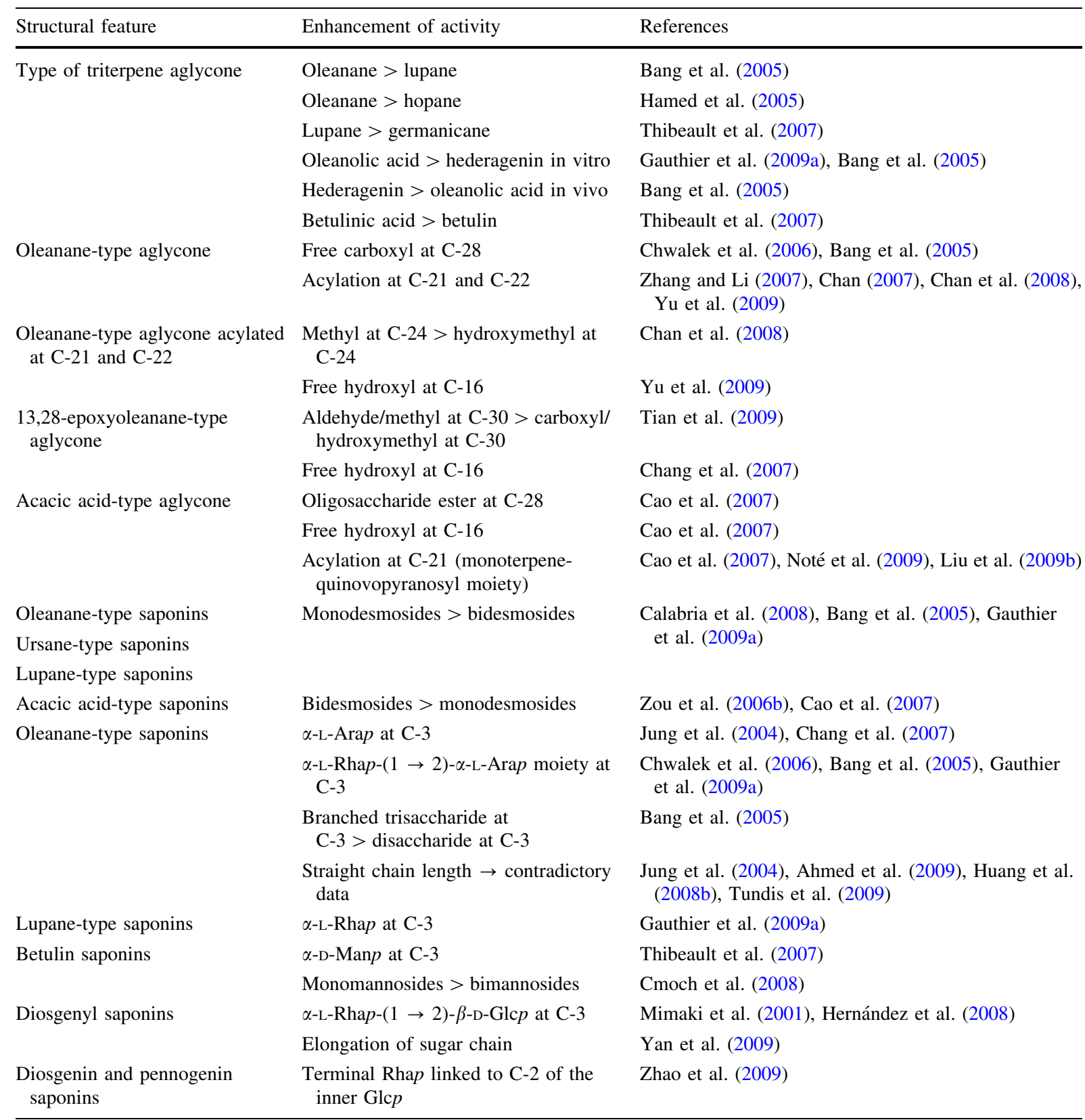

With regard to the other monosaccharides evaluated in this study, it seems that the presence of a $\beta$-DGlc $p$ either at C-3 or C-28 has a detrimental effect on the cytotoxicity of lupane-type saponins. The possible explanation of this phenomenon may be the high polarity of the glucose moiety which might hinder the diffusion of glucose bearing saponins into the cytoplasm. On the other hand, it was postulated that rhamnose facilitates this process by its interaction with lectins and thus, saponins bearing this sugar-unit more easily enter the cell exerting anticancer action.

The presence of a rhamnose residue in the sugar chain attached at $\mathrm{C}-3$ as a feature responsible for cytotoxicity was also pointed out by other reports (Chang et al. 1998; Cham and Daunter 1990), and more recently by Tabatadze et al. who studied the 
effect of giganteosides D and E on leukemia HL-60 and MEL-5 cell lines (Tabatadze et al. 2007).

Another observation from the study of Gauthier et al. (2009a) is that haemolytic activity, membrane cell permeabilization and cytotoxicity of oleananetype saponins seem to be directly correlated whereas the cytotoxic action of lupane saponins does not result from inducement of membrane permeabilization and is due to another mechanisms.

In another SAR study by the same group with synthetic triterpenoid glycosides of germanicane- and lupane-type (Thibeault et al. 2007) the authors concluded that: (1) germanicane-type saponins are weaker anticancer agents than lupane-type compounds, (2) betulinic acid saponins generally exert higher in vitro cytotoxicity than those derived from betulin, with the exception of betulin $3 \beta-O-\alpha-\mathrm{D}-$ mannopyranoside, (3) other sugars linked to the $\mathrm{C} 3$ of betulin (D-glucose, L-rhamnose, D-arabinose, D-galactose, D-xylose) supress anticancer activity.

Based on reports that mono- and trimannosyl residues may be regarded a convenient means of delivering drugs into human dendritic cells or macrophages, Cmoch et al. synthesized a number of such mannosylated derivatives of lupeol, betulin and betulinic acid and compared their cytotoxic activity (Cmoch et al. 2008). Cytotoxicity was assayed on normal human fibroblasts (BJ-H-tert) and a panel of cancer cells: T-lymphoblastic leukemia (CEM), breast carcinoma (MCF-7), lung carcinoma (A-549), multiple myeloma (RPMI 8226), cervical carcinoma (HeLa), malignant melanoma (G361). The data obtained from this study showed that the tested lupane-type compounds selectively inhibit the growth of cancer cells without affecting normal cells. With regard to the sugar moiety, monomannosyl derivatives of lupeol, betulinic acid and betulin were strongly cytotoxic whereas trisaccharide analogues were inactive.

Similar groups of saponins, that is of lupane-type (eight compounds) and oleanane-type (nine compounds) were evaluated by Bang et al. against human solid tumors cell lines A-549, SK-OV-3, SK-MEL-2 and HCT-15 and also subjected to in vivo test (Bang et al. 2005). The compounds were isolated from one plant species, namely Pulsatilla koreana roots. Previously, one of the saponins from this plant species, so called Pulsatilla saponin D (hederagenin 3-O- $\alpha-\mathrm{L}-$ rhamnopyranosyl-( $1 \rightarrow 2)$-[ $\beta$-D-glucopyranosyl-
$(1 \rightarrow 4)]-\alpha$-L-arabino-pyranoside) gained much interest as it showed only moderate activity against cancer cells in vitro whereas had a potent antitumor action on a solid tumor in vivo (IR, $82 \%$ ), which was higher than adriamycin (IR, 64\%) (Kim et al. 2004).

The results from a SAR study by Bang et al. (2005) indicate that generally, the cytotoxicities of the lupane-type saponins were much weaker than those of oleananes, when an $\alpha$-L-Rhap-(1 $\rightarrow 2)$ - $\alpha$-LArap sequence was present in a branched sugar moiety at C-3 of the aglycone. These results were in agreement with those obtained by Gauthier (Gauthier et al. 2009a) however sugar moieties in most compounds evaluated by Bang et al. were composed of more monosaccharide units. Another observation concerning aglycone part, that the existence of a free carboxyl at C-28 is important for antitumor activity, conformed with some reports (Chwalek et al. 2006) but was contradictory to other (Gauthier et al. 2009a) who showed that some bidesmosidic betulinic acid saponins glycosylated at C-28 were highly cytotoxic. Moreover, comparison of activities exerted by saponins derived from oleanolic acid and hederagenin made the authors postulate that the hydroxyl group at C-23 has a negative effect on cytotoxicity.

The comparison of the relationship between the structure of the sugar moiety and cytotoxic activity of oleanane saponins was in agreement with other reports (Gauthier et al. 2009a) —again the presence of an $\alpha$-L-Rhap-( $\rightarrow 2)$ - $\alpha$-L-Arap sequence at C-3 produced higher cytotoxicity. Moreover, trisaccharides with a third sugar linked at C-4' of arabinose or $\mathrm{C}-3^{\prime}$ of rhamnose exhibited stronger cytotoxicities than disaccharides.

A very interesting observation comes from in vivo experiments, as no direct correlation was seen with in vitro cytotoxicity. The main difference was in oleanane aglycones-oleanolic acid derivatives showing much stronger cytotoxicities in vitro than those of hederagenin, had an inferior in vivo antitumor activity. This may be due to the differences in bioavailability of these structures, so the presence of a hydroxyl at C-23 seems to be more effective for in vivo antitumor activity. With regard to sugar moiety, both the number of glucopyranosides and their binding position to the active O- $\alpha$-L-Rhap- $(1 \rightarrow 2)$ $\alpha$-L-Arap sequence is of importance for in vivo effects. The authors postulate that this may be related to the rate of glucose hydrolysis in the cell, the more 
glucose molecules in the chain the lower hydrolysis rate. Moreover, the third glucopyranoside attached at $\mathrm{C}-4^{\prime \prime}$ is more resistant to glucose-hydrolase than at $\mathrm{C}-2^{\prime \prime}$ and thus, such a saponin can more effectively reach the target site. So, it seems that a trisaccharide chain $O-\alpha$-L-Rhap- $(1 \rightarrow 2)$-[ $\beta$-D-Glcp- $(1 \rightarrow 4)]-\alpha-\mathrm{L}-$ Arap is responsible for the improvement of the bioavailability in tumor tissue in vivo. In a later study by Bang (Bang et al. 2007), a method for simple synthesis of this trisaccharide moiety was described.

Chwalek et al. examined structure-activity relationships of oleanane glycosides with cytotoxicity, apoptosis induction and haemolysis (Chwalek et al. 2006). The tested saponins were 25 synthetic hederagenin derivatives including six methyl esters. The authors focused mainly on determination of the influence of the monosaccharide composition and interglycosidic linkages within the sugar moieties because they aimed at verification of the importance of sugar chain. However, a comparison was also made between compounds with a free or esterified carboxyl at C-28. The compounds were divided into two groups of hederagenin saponins, those containing an $\alpha$-L-arabinose or $\beta$-D-glucose as the first sugar as well as their methyl esters. Moreover, saponins having a non-naturally occurring $\beta$ configuration between the aglycone and L-arabinose were also investigated. In the arabinose series, positional disaccharide isomers bearing $\alpha$-L-rhamnose, $\beta$-Dxylose or $\beta$-D-glucose attached to positions 2,3 or 4 were included in the study, whereas in the glucose series, saponins with the following dissaccharide residues were considered: cellobiosyl, lactosyl, maltosyl, gentiobiosyl, isomaltosyl and melibiosyl. Cytotoxicity was tested on KB cells with SN 38 as a positive control.

As far as the sugar moiety is concerned, the following observations were made. Saponins having a non-natural anomeric configuration of $\beta$-L- or $\alpha$-Dwere inactive or only slightly active. Glucose at the first position of the disaccharide chain is unfavorable for cytotoxic activity when compared to arabinose. Neither the nature of the second sugar nor the interglycosidic linkages are in themselves determinant as each sugar can affect cytotoxicity when at a specific position. Thus, for an $\alpha$-L-rhamnose the following order of activity was established $(1 \rightarrow 2)>(1 \rightarrow 3)>(1 \rightarrow 4)$ and for $\beta$-D-xylose $(1 \rightarrow 2)>(1 \rightarrow 4)>(1 \rightarrow 3)$. The most potent saponin was $\alpha$-hederin. This fact provided further evidence that the $\alpha$-L-Rhap-(1 $\rightarrow 2)$ - $\alpha$-L-Ara $p$ osidic sequence is essential for the cytotoxic activity of hederagenin glycosides.

As far as aglycone is concerned, esterification in position 28 generally decreased cytotoxicity. It is interesting to note that haemolytic activity was increased in the majority of cases what supports previous observations that it is impossible to correlate haemolytic and cytotoxic activities of saponins.

In another SAR study (Jung et al. 2004) oleanane disaccharides isolated from Akebia quinata were evaluated against the same human cell lines as those used in the study by Bang et al., that is lung cancer A549, ovarian cancer SK-OV-3, melanoma SKMEL-2, colon cancer HCT-15 and in addition brain tumor XF498. Cytotoxicity against normal human cells was not evaluated. The study included a more limited number of compounds - six saponins with oleanolic acid or hederagenin as aglycones and with $\alpha$-L-Ara $p$ as the first sugar attached to the sapogenin. The authors suggested that cytotoxicity of saponins is predominantly due to the sugar moiety as the effects of the two compounds with the same sugar sequence were very similar. Moreover, comparison of saponins with a different linkage position between monosaccharides, namely $1 \rightarrow 2$ and $1 \rightarrow 3$, showed, that these linkages are not crucial for cytotoxicity. However, the nature and linkage of the second sugar is of importance, rhamnose manifested more potent activity than glucose, and axially attached $4^{\prime}-O-\beta$-Dglucosyl was the least effective. Also, elongation of the sugar chain had a detrimental effect on cytotoxicity.

This last observation seems to need further confirmation as there are also reports with contradictory data. For example, in another study on hederagenin saponins (isolated from Duranta repens) those with four sugar units exhibited greater cytotoxicity than those possessing three sugars (Ahmed et al. 2009), however these differences were seen on only one cell line-HepG2. Same effects were noted when comparing cytotoxic activity of seven oleanane-type saponins (hydrocosisaponins A-F and hydrocotyloside VII) from a Chinese folk medicinal plant Hydrocotyle sibthorpioides (Huang et al. 2008b). Compounds with four sugar units, three D-glucoses and one L-arabinose, were much more active than those depleted of a terminal glucose. 
On the other hand, cytotoxicity assay performed on a wider panel of human cell lines (malignant melanoma A375, amelanotic melanoma C32, Caucasian lung carcinoma A549, hepatocellular carcinoma Huh-7D12, Caucasian lung large cell carcinoma COR-L23, Caucasian colon adenocarcinoma CaCo2, prostate carcinoma $\mathrm{LNCaP}$, renal adenocarcinoma ACHN, breast cancer MCF-7, skin fibroblast 142BR) of two saponins sharing the same aglycon, buddlejasaponin IV and songarosaponin D but differing in the sugar chain length (two glucoses + fucose; three glucoses + fucose, respectively) does not indicated any general influence of this structural feature on the cytotoxicity. Compound with three monosaccharides was much more active than saponin bearing a foursugar chain against ACHN cells $\left(\mathrm{IC}_{50} 7.9 \mu \mathrm{mol} \mathrm{1^{-1 }}\right.$ vs. $37.2 \mu \mathrm{mol} \mathrm{l}^{-1}$ ) whereas it was much weaker against $\mathrm{CaCo}-2$ cells $\left(\mathrm{IC}_{50} 40.7 \mu \mathrm{mol} \mathrm{l}^{-1}\right.$ vs. $16.7 \mu \mathrm{mol} \mathrm{l}^{-1}$ ) (Tundis et al. 2009).

Calabria et al., in their study on the effects on cancer cells proliferation of nine oleanene- and ursene-type saponins from Silphium radula, also observed that the length and linkage of the sugar chain influences cytotoxicity. Moreover, the authors suggested that a monodesmosidic disaccharide chain containing a galactopyranosyl residue produces higher activity than bidesmosidic or monodesmosidic single sugar moiety (Calabria et al. 2008).

In a cytotoxicity assay of dammarane saponins on human breast cancer MCF-7 cell line it was shown that the number of glycosyls affects the activity of ginsenosides, those with one glycosyl are more potent than those bearing three or four glycosyls (Qiu et al. 2009). In this study ginsenoside $\mathrm{Rh}_{2}$ was used as a positive control ( $\mathrm{IC}_{50} 20 \mu \mathrm{mol} \mathrm{l^{-1 }}$ ). In another study on dammarane-type saponins, it was concluded that the number of hydroxyl groups in the side-chain plays a crucial role in their cytotoxicity, two hydroxyls being more beneficial than one or three (Huang et al. 2008a).

Zhang and Li screened five pre-selected saponins isolated from Aesculus pavia against a panel of 59 cell lines from nine human cancers: leukemia, nonsmall cell lung, colon, CNS, melanoma, ovarian, renal, prostate and breast. These saponins were polyhydroxyoleanenes with or without acyl groups at C-21 and/or C-22 and a sugar moiety composed of $\alpha$-L-Ara $f, \beta$-D-GlcA $p, \beta$-D-Gal $p$. From the results obtained with a large array of cancer cell lines it seems that the presence of two acyl groups is important for cytotoxicity as non-acylated saponins showed no or only weak activity (Zhang and $\mathrm{Li}$ 2007).

This observation conformed with other reports, for example on saponins isolated from Xanthoceras sorbifolia (Chan 2007). Structure-activity relationship study was performed on an oleanane-type compound Xantifolia-Y, the characteristic features of which are diangeloyl groups at C-21 and C-22 and a trisaccharide chain at C-3 composed of (-[ $\beta$-D-galactopyranosyl$(1 \rightarrow 2)$ ]- $\alpha$-L-arabinofuranosyl-( $1 \rightarrow 3)$ - $\beta$-D-glucuronopyranosyl). For the purpose of the SAR study, angeloyl groups or sugar moiety were separately removed and thus obtained derivatives together with $\beta$-escin and xantifolia-X (saponin with one angelolyl at $\mathrm{C}$-22) were comparatively assayed against ovarian cancer cells OVCAR3. Moreover, effect on haemolysis was also evaluated. Based on the obtained results it was concluded that while removal of the sugar moiety significantly decreases both cytotoxicity and haemolytic activity the removal of angelolyls at C-21 and C-22 completely eliminates these activities. It seems also that acylation with angelolyl group increases cytotoxicity when compared to acetyl group.

In this study by Chan a very limited number of compounds were compared versus only one cell line, however in a later report (Chan et al. 2008) six more saponins were evaluated. Again it was confirmed that acylation at both C-21 and C-22 increases cytotoxicity, and moreover it was postulated that analogues with a C-24 methyl group (instead of $\mathrm{CH}_{2} \mathrm{OH}$ ) and a galactose unit (instead of glucose) in the trisacharide moiety at C-3 exhibit higher potency.

Seven structurally related oleanane-type saponins with diangeloyl groups at C-21 and C-22, additional oxygenated substituents at C-15 and/or C-16, and a disaccharide chain at C-3 isolated from Gordonia chrysandra were evaluated against a wider panel of human cancer cell lines (HCT-8, Bel-7402, BGC823, A549 and A2780) (Yu et al. 2009). The obtained results indicated that a free hydroxyl at C-16 may be of importance in mediating cytotoxicity. Its acetylation and the presence of a hydroxyl at C-15 had a detrimental effect.

However, in studies on triterpene glycosides isolated from sea cucumbers Cucumaria sp. (Jin et al. 2009) against various leukemia cells, acetyl group at C-16 (as opposed to keto group) was 
selected as the structural feature responsible for increased cytotoxicity of these compounds.

Acetylation at another position, namely C-25, proved to be important for the growth inhibitory activity of cimigenol derivatives on the Her2 overexpressing MDA-MB-453 human breast cancer cells (Einbond et al. 2008). The most potent saponin was 25 -acetyl-7,8-didehydrocimigenol $3-O-\beta$-D-xylopyranoside with an $\mathrm{IC}_{50} 5 \mu \mathrm{mol} \mathrm{l}^{-1}$.

Interesting observations were made in a comparison of cytotoxic activity against glioblastoma U251MG cells of saponins isolated from Ardisia pulsilla (Tian et al. 2009). Five tested compounds were all monodesmosides and belonged to two closely related aglycone types, those with olean-12ene or a 13,28-epoxyoleanane skeleton. The saponins differed in a constituent at C-30 and in the length of the branched sugar chain (tetra- or hexasaccharide). Based on the results from this study, as well as earlier reports on similar compounds, it was concluded that both the aglycone and the sugar moiety play an important role in their cytotoxicity. It seems that the most important structural feature is the presence of the aldehyde or methyl group at C-30, a replacement of which by a carboxyl or a hydroxymethyl results in loss of activity. Moreover, the results from this study were also interesting in terms of the used cell line because glioblastoma multiforme is very resistant to chemotherapy. The most active saponin $(3 \beta-O-\{\beta$-Dglucopyranosyl-(1 $\rightarrow 2)-\{\beta$-D-xylopyranosyl- $(1 \rightarrow 2)$ [ $\beta$-D-glucopyranosyl- $(1 \rightarrow 3)$ - $\beta$-D-glucopyranosyl$(1 \rightarrow 3)]-\beta$-D-glucopyranosyl- $(1 \rightarrow 4)\}-\alpha$-L-arabinopyranosyl $\}$-16 $\alpha$-hydroxy-13 $\beta, 28$-epoxy-oleanan-30-al) had $\mathrm{IC}_{50}$ of $2.57 \mu \mathrm{mol} 1^{-1}$ and at the same time did not affect the growth of normal human astrocytes at concentration as high as $100 \mu \mathrm{mol} 1^{-1}$.

Another species of genus Ardisia, A. japonica, afforded 21 saponins which were evaluated against three human cell lines, HL-60 (myeloid leukemia), KATO-III (stomach adenocarcinoma) and A549 (lung adenocarcinoma) (Chang et al. 2007). All cytotoxic saponins ( $\mathrm{IC}_{50}$ from 1.9-37.2 $\mathrm{mol} \mathrm{l}^{-1}$ ) were derivatives of either cyclamiretin $\mathrm{A}$ or protoprimulagenin A, that is they shared a common 13,28epoxyoleanane skeleton and possessed a branched sugar chain with $\alpha$-L-arabinopyranose as the first sugar attached at C-3 of the aglycon. Comparison of $\mathrm{IC}_{50}$ values indicated that the following structural features seem to improve the activity: (1) hydroxyl moiety at C-16, (2) glucopyranosyl moiety at C-2 of $\alpha$-L-arabinopyranose.

Although many studies reported that while monodesmoside saponins are cytotoxic, bidesmosides are often inactive in the same cell lines it was noteworthy that a mixture of two bidesmosides from Sideroxylon foetidissimum subsp. gaumeri exerted cytotoxic activity $\left(\mathrm{IC}_{50} 11.9 \mu \mathrm{g} \mathrm{ml}^{-1}\right.$ ) against the murine macrophage-like cell line RAW 264.7 (SánchezMedina et al. 2009). Moderate activity against human leukemia HL-60, stomach adenocarcinoma KATO-III and lung adenocarcinoma A549 cells, was also reported for echinocystic acid bidesmoside, impatienoside $\mathrm{G}$ ( $\mathrm{IC}_{50} 21.8-36.7 \mu \mathrm{mol} \mathrm{1^{-1 }}$ ) (Li et al. 2009). However, other compounds tested in this study, including mono- and bidesmosides of soyasapogenol A were inactive at concentrations $50 \mu \mathrm{mol} \mathrm{l}^{-1}$.

It seems therefore, that the cytotoxicity of bidesmosidic saponins varies dependent of the aglycone. The presence of an oligosaccharide ester at C-28 was postulated to be an important structural feature essential for growth inhibitory activity of many cytotoxic acacic acid-type saponins, such as for example avicins from Acacia victoriae or julibrosides from Albizia julibrissin. Other structural features essential for their action include a monoterpene-quinovopyranosyl moiety at C-21 and a hydroxyl group at C-16 (Cao et al. 2007). The crucial role in mediating cytotoxicity is attributed to an ester substituent at C-21 (Noté et al. 2009) and for the most potent activity, two monoterpene-quinovopyranosyl groups acylated at C-21 of the aglycon are required (Liu et al. 2009b).

Structurally related compounds isolated from Albizia gummifera had significant antiproliferative effects $\left(\mathrm{IC}_{50} 0.1-6.6 \mu \mathrm{mol} \mathrm{1^{-1 }}\right)$ on the histiocytic lymphoma U937, human ovarian A2780, colon HT29, nonsmall-cell lung H522-T1, and breast MDAMB-435cancer cell lines (Cao et al. 2007). Also, bidesmosidic julibrozide $\mathrm{J} 21$, with acacic acid aglycone, showed a marked inhibitory action against human liver cancer cell line Bel-7402 (Zou et al. 2006b). From a study of Melek et al. it was concluded that saponins containing acacic acid lactone as the triterpene moiety are inactive (Melek et al. 2007).

Some of fairly early SAR experiments were performed on saponins with previously reported antitumor activity, namely tubeimosides I-III from Bolbostemma paniculatum ( $\mathrm{Yu}$ et al. 2001). These compounds are oleananes belonging to a group of 
rare cyclic bidesmosides with a 3-hydroxy-3-methylglutarate bridge joining two sugar chains. Tubeimosides I-III differ in the aglycone part by the presence or absence of a hydroxyl at C-16 and in the linkage position of the bridge between two sugar chains. Antitumor activities were compared in vivo on transplantable mouse $\mathrm{S}_{180}$ in $\mathrm{BALB} / \mathrm{c}$ mice. The obtained data indicated that $\mathrm{C}-16$ hydroxyl group is important for the activity and at the same time for the decrease in toxicity, whereas sugar chain linkage such as in tubeimoside III, elevates antitumor effect but also the toxicity of the compound. So, tubeimoside II seemed to be the most promising agent for cancer chemotherapy among saponins of B. paniculatum.

Correlation between the structure and cytotoxicity of steroid saponins

\section{Influence of sugar chain}

In 2001, Mimaki et al. reported some structureactivity relationships of steroidal saponins. The compounds were mainly isolated from the Liliaceae plants and tested against HL-60 human promyelocytic leukemia cells. Diosgenin $\beta$-D-glucoside was not active $\left(\mathrm{IC}_{50}>20 \mu \mathrm{g} \mathrm{ml}^{-1}\right.$ ), however an additional $\alpha$-L-rhamnopyranosyl moiety at $\mathrm{C}-2$ of the glucose considerably increased the activity $\left(\mathrm{IC}_{50}\right.$ $1.8 \mu \mathrm{g} \mathrm{ml}^{-1}$ ). Among different diosgenin rhamnopyranosyl-glucosides only $\alpha$-L-rhamnopyranosyl$(1 \rightarrow 2)$ - $\beta$-D-glucopyranoside of diosgenin was active. Compounds with $\alpha$-L-Rhap moiety at C-3 or C-4 of the glucose showed no cytotoxic activity. Further attachment of $\alpha$-L-arabinofuranosyl, $\beta$-D-glucopyranosyl or $\alpha$-L-rhamnopyranosyl groups to $\mathrm{C}-3$ or C-4 of the inner glucosyl group did not influence activity or caused only slight increase $\left(0.5-3.3 \mu \mathrm{g} \mathrm{ml}^{-1}\right)$. The authors concluded that the number and the sequence of sugar moieties seem to be important for cytotoxic activity (Mimaki et al. 2001).

Some diosgenyl $\alpha$-L-rhamnopyranosyl- $(1 \rightarrow 2)$ $\beta$-D-glucopyranoside analogues with different monosaccharides (D-Glc, D-Gal, D-Man, L-Ara, D-Xyl, and $\mathrm{D}-\mathrm{Fuc}$ ) in the place of the rhamnose moiety were synthesized (Hernández et al. 2008). Their effects on the growth of human myeloid (HL-60 and U937) and melanoma (SK-MEL-1) cell lines were evaluated.
Similarly to Mimaki's studies, diosgenyl $\alpha$-L-rhamnopyranosyl-( $1 \rightarrow 2)-\beta$-D-glucopyranoside displayed strong cytotoxic activity with an $\mathrm{IC}_{50}$ of about 5-7 $\mu \mathrm{mol} \mathrm{l}^{-1}$. Glycosides containing other sugar instead of rhamnose were, in general, less cytotoxic in this study. Selective acetylation of a hydroxyl group at C- $6^{\prime}$ of glucose of diosgenyl $\alpha$-L-rhamnopyranosyl$(1 \rightarrow 2)$ - $\beta$-D-glucopyranoside did not change significantly the cytotoxic activity when compared to deacetylated compound. It was concluded that free hydroxyl group at C- $6^{\prime}$ of glucose may be of no importance for this effect. Additional acetylation of the hydroxyl group at C-4" of rhamnose significantly decreased the cytotoxic activity. The reduction of cytotoxic effect was observed when a second rhamnose was attached to C-4" of rhamnose. A significant decrease in growth inhibitory activity was observed on SK-MEL-1 in response to the compounds having other than rhamnose moiety attached to glucose residue $\left(\mathrm{IC}_{50}>100 \mu \mathrm{mol} \mathrm{l}^{-1}\right)$. These results showed the importance of rhamnose for diosgenyl glycosides' cytotoxicity.

Diglycosides with mannose or fucose moieties induced significant $G_{1}$ arrest at the expense of $S$ - and $\mathrm{G}_{2} / \mathrm{M}$-phase cell population. Diosgenyl $\alpha$-L-rhamnpyranosyl-( $1 \rightarrow 2)-\beta$-D-glucopyranoside produced alterations in cell cycle progression, induced $\mathrm{G}_{2}-\mathrm{M}$ arrest at the expense of $G_{1}$ phase cell number. No evidence of changes in the cell cycle phases was observed in response to compound containing a galactosyl group (Hernández et al. 2008).

In Mimaki's studies saponins with glycosyl groups at $\mathrm{C}-1$ of aglycone showed no activity, the only exceptions were compounds possessing some acyl groups at the glycosyl moiety. Also, a (25S)-spirost-5ene-1 $\beta, 3 \beta$-diol with a sugar chain containing D-fucose and L-rhamnose was cytotoxic. The authors suggested that cytotoxic activity of such saponins was connected with a certain degree of lipophilicity (Mimaki et al. 2001).

The importance of the number of sugar moieties in a sugar chain and the structure of aglycone was also confirmed by the studies on saponins isolated from Agave fourcroydes. Chlorogenin, hecogenin and tigogenin hexasaccharides (with the same sequence of sugar chains) showed cytotoxic activity against HeLa cells $\left(\mathrm{IC}_{50} 13.1,5.2\right.$, and $4.8 \mu \mathrm{g} \mathrm{ml}^{-1}$, respectively), while diglucosides were inactive (Ohtsuki et al. 2004). 
The correlation between the cytotoxic activity and the number of sugar residues in the sugar chain was observed in cytotoxicity test of saponins isolated from Paris polyphylla var. yunnanensis. Diosgenin tetrasaccharide showed stronger cytotoxic activity than compounds containing three or two sugar residues. Two diosgenin and pennogenin disaccharides exhibited the lowest inhibtion properties. Diosgenin3-O- $\alpha$-L-arabinofuranosyl-( $1 \rightarrow 4)$-[ $\alpha$-L-rhamnopyranosyl-(1 $\rightarrow 2)]-\beta$-D-glycopyranoside showed higher cytotoxicity rate than diosgenin-3-O- $\alpha$-L-rhamnopyranosyl-( $1 \rightarrow 4)$-[ $\alpha$-L-rhamnopyranosyl- $(1 \rightarrow 2)]-\beta$-Dglyco-pyranoside (1.85 and $3.06 \mu \mathrm{mol} \mathrm{l}^{-1}$, respectively). Although the number of monosaccharides in the sugar moiety were the same they varied in composition (Yan et al. 2009).

\section{Influence of aglycone}

A series of steroidal sapogenins (diosgenin, tigogenin, sarsasapogenin, smilagenin and others) has been tested for the influence on cell proliferation, cell cycle distribution and apoptosis in 1,547 human osteosarcoma cells. To study the role of a 5,6-double bond in the cytotoxic effect, the activities of diosgenin (possessing a double bond), smilagenin and tigogenin ( $5 \beta$ and $5 \alpha$ stereoisomers respectively; no 5,6-double bonds) were compared.

Diosgenin induced apoptosis in 1,547 cells (5.6fold compared to control) whereas smilagenin and tigogenin showed weak apoptotic activity. Diosgenin and smilagenin induced strong inhibition of cell proliferation while tigogenin inhibited it only moderately. After $24 \mathrm{~h}$ treatment diosgenin and smilagenin blocked cell cycle in $\mathrm{G}_{0} / \mathrm{G}_{1}$ phase in 54.1 and $54.9 \%$ respectively compared to $39.6 \%$ for control while tigogenin had no effect. The results from this study indicate that the difference in the spatial conformation of the A- and B-rings and the presence or lack of 5,6-double bond do not affect the mode of action on the cell cycle (diosgenin and smilagenin arrested the cell cycle in the same phase) (Trouillas et al. 2005).

The importance of stereoisomery at C-25 on cell proliferation with regard to apoptosis and cell cycle data were studied using sarsasapogenin and smilagenin (the 25-isomer of smilagenin). Sarsasapogenin showed strong apoptotic effect whereas smilagenin induced weak apoptosis. Sarsasapogenin arrested cell cycle in $\mathrm{G}_{2} / \mathrm{M}$ (52.6\% compared to $20.3 \%$ for control), while smilagenin blocked cell cycle in $\mathrm{G}_{0} / \mathrm{G}_{1}$ phase. Sarsasapogenin significantly enhanced DNA fragmentation (6.9-fold compared to control). Results from this study provide evidence for the importance of the conformation at C-25 (Trouillas et al. 2005).

The R/S configuration at C-25 was essential for selectivity in leukemia cells observed between methyl protoneogracillin (C-25 $S$ configuration) and methyl protogracillin (C-25 $R$ configuration) isolated from the rhizomes of Dioscorea collettii var. hypoglauca. A 6-11 fold difference was observed on three leukemia cell lines (CCRF-CEM, MOLT-4 and PRMT-8226), $\mathrm{GI}_{50}$ for methyl protoneogracillin was $1.79,4.59$, and $1.57 \mu \mathrm{mol} \mathrm{l}^{-1}$, respectively whereas for methyl protogracillin 20.2, 25.6, and $12.0 \mu \mathrm{mol} \mathrm{l}^{-1}$, respectively. However, no difference in selectivity against solid tumors was observed for these two compounds, indicating that $R$ or $S$ configuration at C-25 was not critical for the activity against solid tumors ( $\mathrm{Hu}$ and Yao 2003b).

In vitro studies on steroidal saponins of Paris polyphylla var. yunnanensis displayed that glycosides of diosgenin were more active against LA 795 cells than those of pennogenin-type (which belongs to the 17-hydroxy-steroidal sapogenins) (Yan et al. 2009).

In the studies on cytotoxic activity of steroidal saponins isolated from Liliaceae plants the introduction of C-17 hydroxyl group to diosgenyl glycoside reduced the cytotoxicity slightly whereas additional C-27 hydroxyl group considerably decreased the cytotoxic activity (Mimaki et al. 2001).

The cytotoxic activity of steroidal saponins isolated from the fresh whole plants of Agave utahensis against HL-60 human promyelotic leukemia cells was studied. Two smilagenin diglycosides and one trisaccharide showed high cytotoxicity with $\mathrm{IC}_{50} 4.9-7 \mu \mathrm{g} \mathrm{ml}^{-1}$. The additional C-2 hydroxyl group or C-12 carbonyl group in the $5 \beta$-spirostanol structure significantly reduced cytotoxic activity (Yokosuka et al. 2009).

Methyl protodioscin (a furostanol compound) and dioscin (a spirostanol glycoside) isolated from the root of Polygonatum zanlanscianense were tested against human leukemia HL-60 cells in vitro. The spirostanol glycoside induced differentiation, apoptosis and cytotoxicity in the HL-60 cells, while the other had no effect. It was concluded that the 
spirostanol structure must be critical in the effects on the HL-60 cells (Wang et al. 2001).

Some spirostanol diosgenin derivatives were investigated for cytotoxic effect against human colorectal HCT 116 carcinoma cells. Compounds which bear S and Se atoms on the diosgenin F ring were synthesized. Oppenauer oxidation of diosgenin, solasodin (a nitrogen analogue of diosgenin) and the synthesized heterospirostanols gave corresponding $\alpha, \beta$-unsaturated ketones. Amongst compounds studied solasodine and its $\alpha, \beta$-unsaturated ketone derivative exhibited high activity $\left(\mathrm{IC}_{50}=6\right.$ and $14 \mu \mathrm{mol} 1^{-1}$, respectively). The activities of other compounds were lower. The results of this study suggested that $\mathrm{N}$-atom on the $\mathrm{F}$ ring was important for cytotoxic activity against HCT 116 cells. The activity of $N$-spirostanol compound was higher when there was no conjugated system in the A ring (Quan et al. 2002).

\section{Cytotoxic mechanisms of saponins}

Saponins are potential anticancer agents, with different mechanisms of action. Their cytotoxic effects may be due to either apoptosis inducement or nonapoptotic cell death stimulation. There is a number of well-known processes which lead to the same effect—cell death—but involve different mechanisms of action, like stimulation of autophagic cell death, decrease in NO production in cells, or cytoskeleton integrity disassembly.

The cytotoxic effects of saponins, discussed in this paper, were studied mainly in vitro, but also some in vivo experiments were conducted. The most important mechanisms are summarized in Table 4.

In vitro experiments

Apoptosis-programmed cell death-is one of the most important processes involved in the regulation of tissue development and homeostasis. It is also well known that research of novel anticancer agents in recent years focuses on their potential pro-apoptotic properties. The process may be initiated either at plasma membrane (extrinsic pathway) or within the cell (intrinsic pathway) (Bachran et al. 2008).

The extrinsic pathway is triggered by the activation of specific pro-apoptotic receptors on the cell surface, which are stimulated by specific molecules known as pro-apoptotic ligands (Apo2L/TRAIL and CD95L/FasL). Among the reviewed saponins, only saponin fraction isolated from Bupleurum kaoi induced the extrinsic pathway of apoptosis (Hsu et al. 2004).

The influence of triterpene saponin-enriched fraction (SEF) from Bupleurum kaoi on human non-small cell lung cancer A549 was investigated by Hsu et al. The antiproliferative effect of SEF was observed, in a dose-dependent manner, with $\mathrm{IC}_{50}$ values $196 \mu \mathrm{g} \mathrm{ml}^{-1}$. Inhibition of proliferation of the cells was through the apoptotic pathway, with the observed enhancement in Fas and its two ligand forms, membrane-bound Fas ligand and soluble Fas ligand. In cells treated with caspase- 8 inhibitor, growth inhibition and apoptosis were significantly decreased, which also proves an important role of Fas/FasL system in SEF-mediated apoptosis of A549 cells (Hsu et al. 2004).

The intrinsic pathway of apoptosis begins usually in response to different types of cell stress: cellular signals resulting from DNA damage, a defective cell cycle, detachment from the extracellular matrix, hypoxia, loss of cell survival factors. This pathway involves the release of pro-apoptotic proteins that activate caspase enzymes from the mitochondria, but also depends on the balance between the pro- and anti-apoptotic proteins from $\mathrm{Bcl}-2$ superfamily (Xu et al. 2009).

The immunosuppressive activity of a triterpene saikosaponin a from Bupleurum falcatum on the concanavalin A (Con A) stimulated mouse $\mathrm{CD}^{+} \mathrm{T}$ cells, isolated from the lymph node of BALB/c mice, was examined, as well as the underlying mechanism of the action. The compound had potent antiproliferative effect, and also significantly inhibited the activation of the cells, in a concentration-dependent manner. Moreover, saikosaponin a potently suppressed the production of IL-2, IFN- $\gamma$ and TNF- $\alpha$ in T cells stimulated by Con $A$. The $G_{0} / G_{1}$ arrest of the activated $\mathrm{T}$ cells by saikosaponin a was also observed, and the effect was due to down-regulating of CDK6 and cyclin D3 protein level and upregulating of $\mathrm{p} 27^{\mathrm{kip}}$ protein level. The apoptosis of the activated $\mathrm{T}$ cells, in comparison to the nonactivated cells, was induced by the compound in dose-dependent manner, probably via mitochondrial pathway-a significant collapse of the mitochondrial 
Table 4 Mechanisms of cytotoxic activity of saponins

\begin{tabular}{|c|c|c|}
\hline Process & Mode of action & References \\
\hline \multirow[t]{14}{*}{$\begin{array}{l}\text { Apoptosis } \\
\text { intrinsic } \\
\text { pathway }\end{array}$} & Cytochrome c release & $\begin{array}{l}\text { Sun et al. (2009a), Li et al. (2008), Xu et al. (2009), Wang et al. (2008), Jin } \\
\text { et al. (2009), Zhang et al. (2008), Haridas et al. (2009), Hernández et al. } \\
\text { (2004), Siu et al. (2008), Liu et al. (2005) }\end{array}$ \\
\hline & $\begin{array}{l}\text { Mitochondria membrane } \\
\text { depolimerization }\end{array}$ & \\
\hline & $\begin{array}{l}\text { GADD153/CHOP transcription } \\
\text { factor expression increase }\end{array}$ & \\
\hline & Caspase 3 and 9 activation & \\
\hline & PARP-1 cleavage & \\
\hline & MAPK cascade activation & \\
\hline & p-STAT-3 decrease & \\
\hline & $\begin{array}{l}\text { Bcl-2, c-myc, survivin } \\
\text { downregulation }\end{array}$ & \\
\hline & VEGF downregulation & \\
\hline & p53 stimulation & \\
\hline & $\mathrm{NF}-\kappa \mathrm{B}$ inhibition & \\
\hline & JAKs dephosphorylation & \\
\hline & Protein phosphatase- 1 activation & \\
\hline & $\begin{array}{l}\text { Intracellular } \mathrm{Ca}^{2+} \text { homeostasis } \\
\text { disruption }\end{array}$ & \\
\hline \multirow{2}{*}{$\begin{array}{l}\text { Apoptosis } \\
\text { extrinsic } \\
\text { pathway }\end{array}$} & Fas enhancement & Hsu et al. (2004) \\
\hline & Fas ligand enhancement & \\
\hline $\begin{array}{l}\text { Apoptosis non- } \\
\text { specified }\end{array}$ & Telomerase activity inhibition & Kim et al. (2008a) \\
\hline \multirow[t]{5}{*}{ Cell cycle arrest } & CDK6 downregulation & $\begin{array}{l}\text { Sun et al. (2009a, b), Ellington et al. (2005), Raju and Mehta (2009), } \\
\text { Srinivasan et al. (2009), Liu et al. (2005) }\end{array}$ \\
\hline & Cyclin D3 downregulation & \\
\hline & Cyclin D1 downregulation & \\
\hline & $\mathrm{p} 27^{\mathrm{kip}}$ upregulation & \\
\hline & CDK2 inhibition & \\
\hline \multirow[t]{5}{*}{ Autophagy } & $\begin{array}{l}\text { Microtubule-associated protein } \\
\text { light chain-3 increase }\end{array}$ & Ellington et al. (2005), Xu et al. (2007a) \\
\hline & $\begin{array}{l}\text { Autophagic vacuoles number } \\
\text { increase }\end{array}$ & \\
\hline & AMPK-TSC2 regulation & \\
\hline & Cellular ATP decrease & \\
\hline & AMPK activation & \\
\hline \multirow[t]{6}{*}{$\begin{array}{l}\text { Angiogenesis } \\
\text { inhibition }\end{array}$} & $\begin{array}{l}\text { Thrombospondin-1 expression } \\
\text { increase }\end{array}$ & Wang et al. (2008), Tian et al. (2005) \\
\hline & PKC expression decrease & \\
\hline & ERK activation & \\
\hline & P38MAPK activation & \\
\hline & $\begin{array}{l}\text { Endothelial cell proliferation } \\
\text { inhibition }\end{array}$ & \\
\hline & Tube-formation inhibition & \\
\hline
\end{tabular}


Table 4 continued

\begin{tabular}{lll}
\hline Process & Mode of action & References \\
\hline $\begin{array}{c}\text { Cytoskeleton } \\
\text { disintegration }\end{array}$ & Microtubule dissasembly & $\begin{array}{c}\text { Li et al. (2008), Ma et al. (2008), Einbond et al. (2008), Galanty et al. (2008), } \\
\text { Gnoula et al. (2008) }\end{array}$ \\
& $\begin{array}{l}\text { Tubulin polymerization inhibition } \\
\text { Actin filaments disruption }\end{array}$ & \\
& $\begin{array}{l}\text { Intracellular ATP decrease } \\
\text { Nucleus morphology changes }\end{array}$ & \\
Metastasis & Cell motility and migration & Tian et al. (2005), Galanty et al. (2008), Man et al. (2009) \\
inhibition & Cell adhesion inhibition & \\
& MMP-2, MMP-9 downregulation & \\
& TIMP-2 upregulation & \\
\hline
\end{tabular}

membrane potential and release of cytochrome $\mathrm{c}$ from mitochondria to cytosol was observed (Sun et al. 2009a).

The anticancer properties of $\operatorname{ardisiacrispin}(\mathrm{A}+\mathrm{B})$, a mixture (fixed proportion 2:1) of triterpene saponins ardisiacrispin A and B from Ardisia crenata, against a number of human cancer cell lines were evaluated. The highest antiproliferative effect of the tested substance was observed on human hepatoma Bel-7402 cells. Moreover, the substance induced apoptosis in Bel-7402 cells, which was observed by the changes of the mitochondrial membrane depolarization, membrane permeability enhancement and nuclear condensation, and the effects were dose-dependent ( $\mathrm{Li}$ et al. 2008).

Cytotoxic effect of a triterpene saponin tubeimoside 1 (TBMS1) from Bolbostemma paniculatum was tested on HeLa cells. In the cells treated with the compound, profound protein alterations were observed, suggesting apoptotic process, with the involvement of mitochondria and endoplasmic reticulum. TBMS1 induced the depletion of mitochondrial transmembrane potential, causing the activation of caspase-dependent apoptotic cell death. Moreover, the increased expression of GADD153/CHOP transcription factor, associated with growth arrest and apoptosis in the event of prolonged ER stress, was detected. The results of the study suggest the cytotoxic effect of TBMS1 through the mitochondrial, but also ER stress cell death pathways (Xu et al. 2009).

The effect of $\beta$-escin sodium on proliferation, migration and apoptosis of human umbilical vein endothelial cells HUVEC and ECV304 was studied. The compound inhibited both endothelial cell lines proliferation in dose-dependent manner, also causing apoptosis of the cells. Moreover, $\beta$-escin sodium suppressed endothelial cells migration and motility. The possible mechanism of action of the compound may be through increasing expression of thrombospondin-1 and decreasing expression of protein kinase $\mathrm{C}$, an intracellular messenger necessary for endothelial cells proliferation and migration. Additionally, the compound activates $\mathrm{p} 44 / 42$ mitogen-activated protein kinase (ERK) and p38 mitogen-activated protein kinase (p38MAPK), which are involved in MAPK signaling cascade, whose activation is linked to cell proliferation, motility and apoptosis. The obtained data indicate the potential anti-angiogenic activity of $\beta$-escin sodium due to its direct effects on endothelial cells (Wang et al. 2008).

The effects of two triterpene glycosides: frondoside $\mathrm{A}$ and cucumaroside $\mathrm{A}_{2}-2$, isolated from sea cucumber Cucumaria frondosa, on human leukemia cells death-inducing capability were determined and compared in this study. Both compounds strongly induced apoptosis of leukemic cells, but the process was more rapid and potent in cells treated with frondoside $\mathrm{A}$, in comparison to cucumaroside $\mathrm{A}_{2}-2$. The obtained data indicate that only apoptosis induced by cucumaroside $\mathrm{A}_{2}-2$ was caspase-dependent (Jin et al. 2009).

The influence of avicin D and G, triterpene saponins obtained from seedpods of Acacia victoriae, on metabolic state of isolated rat mitochondria was studied by Lemeshko et al. Following avicin 
treatment, a significant decrease in oxygen consumption rate was observed. This process was reversible by the addition of exogenous cytochrome $\mathrm{c}$, which suggests that avicin-induced inhibition of respiration may be due to the release of cytochrome $\mathrm{c}$ from mitochondria. Moreover, avicins increased the rotenone-intensive oxidation of external NADH in the presence of exogenous cytochrome $\mathrm{c}$, which may indicate that the compounds increase permeabilization of mitochondrial membrane to cytochrome c. The results explain selective induction of apoptosis in tumor cells by avicins, especially avicin G (Lemeshko et al. 2006).

The influence of avicin D, also isolated from A. victoriae, on different cutaneous T-cell lymphomas cell lines (CTCL): MJ, Hut78, HH and also on cells obtained from patients with Sézary syndrome and healthy donors, with normal CD4+ and activated CD4+ T-cells was investigated by Zhang et al. Avicin D induced apoptosis in three CTCL cell lines, in time- and dose-dependent manner. Apoptotic cell death was more notable in avicin D-treated cells from the patients with Sézary syndrome than in cells from healthy donors. The compound activated caspase- 3 in CTCL cell lines and cells from Sézary syndrome patients, but not in cells from healthy donors. Avicin D did not influence the expression of signal transducer and activator of transcription-3 (STAT-3) but it decreased phosphor-signal transducer and activator of transcription-3 (p-STAT-3) protein level in CTCL cell lines and cells from the Sézary syndrome patients. The compound also selectively inhibited the expression of antiapoptotic protein bcl-2, while did not influence the expression of proapoptotic protein bax in CTCL cells and cells from the patients with Sézary syndrome. In conclusion, avicin D selectively induced apoptosis, which was probably dependent on caspase-3 and downregulation of p-STAT-3 and bcl-2 proteins (Zhang et al. 2008).

Haridas et al. investigated the effect of avicin D on phosphorylation/dephosphorylation of Stat-3 process in a number of human tumor cell lines: U266, RPMI8226, SKO-007, MM1, A431, OVCAR3, HepG2. Avicin D stimulated dephosphorylation of Stat-3 in all cell lines, what lead to a decrease in transcription rate of Stat-3. This process may be due to avicin D influence on dephosphorylation of JAKs (Janus kinases) and activation of protein phosphatase-1. Moreover, in avicin D-treated cells the reduction of expression of Stat-3-regulated proteins-c-myc, cyclin D1, Bcl2, survivin, VEGF-was observed. Downregulation of Stat-3 activity and inhibitory effect on expression of pro-survival proteins contributed to the induction of apoptotic process in tumor cells treated with avicin D. The results of the study suggest that avicin D, by the inhibition of Stat-3 activity, suppressed also proinflammatory and prooxidant stromal environment of tumors. Moreover, avicin D activated PP-1, a cellular economizer, which can lead to redirecting metabolism of tumor cells from growth promoting to energy sparing pathways (Haridas et al. 2009).

Steroid sapogenin icogenin, isolated from Dracaena draco, was active against the myeloid leukemia cell line HL-60 ( $\mathrm{IC}_{50} 2.6 \mu \mathrm{mol} \mathrm{1^{-1 }}$ at $72 \mathrm{~h}$ ) and inhibited cell growth by induction of apoptosis. Nuclear changes and the fragmentation of poly (ADP-ribose) polymerase-1, an enzyme involved in DNA repairing and in apoptosis process, were observed (Hernández et al. 2004).

Polyphyllin D (PD), a steroid saponin (Fig. 1) isolated from Paris polyphylla, was identified as a potential ER stress inducer on human non-small cell lung cancer NCI-H460 cell line. PD treatment led to upregulation of typical ER stress-related proteins/ genes including glucose-regulated protein 78 (BiP/ GRP78) and protein disulfide isomerase (PDI). In particular, elevated expression of C/EBP homologous transcription factor (chop) and activation of caspase- 4 occurred at early time point $(8 \mathrm{~h})$ of PD treatment, suggesting an initial ER stress-mediated apoptosis. Induction of tumor suppressor p53, disruption of mitochondrial membrane, activation of caspase- 9 and caspase-3 were also detected upon prolonged PD treatment. Collectively, these data revealed that PD induced the cytotoxic effect through a mechanism initiated by ER stress followed by mitochondrial apoptotic pathway (Siu et al. 2008).

Diosgenin, a naturally occurring steroidal sapogenin, has been suggested to play an important role in anticancer protection. Cytotoxic activity of the compound is mainly due to its inhibition of cell cycle signaling and induction of apoptosis. It induced $G_{1}$ phase cell cycle arrest in 1,547 osteosarcoma cells and induced apoptotic demise. The activation of p53 and binding of NF $\kappa \mathrm{B}$ to DNA independent of PPAR$\gamma$ was demonstrated (Raju and Mehta 2009). In other experiment, diosgenin induced cell cycle $\mathrm{G}_{2} / \mathrm{M}$ arrest 
and apoptosis. The disruption of intracellular $\mathrm{Ca}^{2+}$ homeostasis, generation of reactive oxygen species and caspase activation were observed (Liu et al. 2005).

Srinivasan et al. examined the effect of diosgenin on Akt signaling in estrogen receptor positive and negative breast cancer cells. Diosgenin inhibited pAkt expression and Akt kinase activity, but it did not affect the levels of PI3K, which lead to the inhibition of Akt downstream targets, NF- $\kappa \mathrm{B}, \mathrm{Bcl}-2$, survivin and XIAP and the Raf/MEK/ERK pathway in $\mathrm{ER}^{+}$, but not in $\mathrm{ER}^{-} \mathrm{BCa}$ cells. In both $\mathrm{ER}^{+}$and $\mathrm{ER}^{-} \mathrm{BCa}$ cells diosgenin caused $\mathrm{G}_{1}$ cell cycle arrest by downregulating cyclin D1, cdk-2 and cdk-4 expression what resulted in cell proliferation inhibition and induced apoptosis. Diosgenin was not significantly toxic towards the normal breast epithelial cells MCF-10A (Srinivasan et al. 2009).

Platycodin D, a triterpenoid bidesmoside isolated from the root of Platycodon grandiflorum, was examined as a potential antitumor compound on different human leukemia cell lines: U937, THP-1 and K562. The compound exerted a dose-dependent cytotoxic effect, and also inhibited the activity of telomerase via down-regulation of hTERT (telomerase reverse transcriptase) expression, which can be associated with non-specified apoptotic process. In platycodin D treated cells the decrease of c-Myc and Sp1 (regulators of hTERT transcription) protein levels and reducement in their DNA binding activity were observed. The compound also down-regulated the activation of Akt, and thus reduced phosphorylation and nuclear translocation of hTERT. The results indicate that cytotoxic effect of platycodin D on human leukemia cells may be due to telomerase activity suppression through transcriptional and posttranslational suppression of hTERT (Kim et al. 2008b).

Anti-angiogenic and antitumor properties of PE (Fig. 1), a sulfated triterpene saponin isolated from the sea cucumber Pentacta quadrangularis, were examined. The compound inhibited proliferation, migration, adhesion and tube-formation in two types of human endothelial cells: HMECs and HUVECs. Moreover, non-specified apoptosis in the cells treated with PE was also observed (Tian et al. 2005).

Autophagy is a process used by stressed cells to catabolize their own contents (proteins, organelles) to provide cellular energy. The process may also inhibit tumor growth and malignant transformation of cells, which is an interesting alternative, especially in apoptosis-resistant cancer cells (Xu et al. 2007a).

Ellington et al. evaluated the effect of a purified soybean B-group saponin extract on human HCT-15 colon adenocarcinoma cells. The extract significantly decreased the viability of the cells, in dose- and timedependent manner and the cells were accumulated in phase $S$ of the cell cycle, due to the reduction of cyclin-dependent kinase (CDK2) activity. The examination of the cells treated with the extract under the transmission electronic microscope indicated the nonapoptotic programmed cell death morphology changes - a number of autophagic vacuoles, suggesting autophagic cell death. Moreover, the increased level of microtubule-associated protein light-chain 3, a specific marker of macroautophagy, following soyasaponin treatment was observed (Ellington et al. 2005).

The effect of avicin D and avicin $\mathrm{G}$, isolated from the root of Acacia victoriae, on the autophagy induction in a number of human tumor cells: A549, SKOV3, PC3, U2OS, MDA-MB-231 and T47D was examined. Cells treated with an apoptosis inhibitor (benzyloxycarbonylvalyl-alanyl-aspartic acid $(O$ methyl)-fluoro-methylketone) still could undergo cell death under the influence of avicin $\mathrm{D}$, what indicated non-apoptotic cell death. Moreover, this process was not due to the deregulation of amino acids but based on the obtained data it seems that avicin D induced disruption of cellular bioenergetics, what in turn suggested autophagy. Avicin D decreased cellular ATP levels and stimulated the activation of AMPactivated protein kinase (AMPK), which suggests the possible mechanism of avicin D-induced autophagic, caspase-independent cell death, via regulation of AMPK-TSC2 (tuberous sclerosis complex 2)-mTOR (mammalian target of rapamycin) pathway (Xu et al. 2007).

The excessive production of nitric oxide (NO) in the cell may be due to viral or bacterial infections and can promote pathogenesis by promoting oxidative stress, tissue injury and even cancer. There is some evidence that NO production inhibitory activity of saponins is correlated with their cytotoxic effect (Tundis et al. 2009).

The cytotoxic activity of four triterpene saponins-saikosaponin a, buddlejasaponin IV, songarosaponin D and saikosapogenin a (obtained by 
hydrolysis of sugar unit from saikosaponin a)—from the roots of Physospermum verticillatum, against seven cancer cell lines-ACHN, C32, Caco-2, COR-L23, A375, A549 and Huh-7D12-and skin fibroblasts 142BR was examined. All the saponins exhibited strong cytotoxic activity against COR-L23 line, whereas none of the tested compounds was active against the fibroblasts. Buddlejasaponin IV and songarosaponin D inhibited NO production in lipopolysaccharide-stimulated murine monocytic RAW 264.7 macrophages (Tundis et al. 2009).

Normal cell division, cellular motility, intracellular transport and proper cell shape are all dependent on cytoskeleton integrity and stability. Saponins may stimulate disintegration of microtubular network or actin filaments of cancer cells, which can lead to further processes of apoptotic or non-apoptotic cell death (Ma et al. 2008; Einbond et al. 2008).

Anti-microtubule role of tubeimoside I (TBMS1), isolated from Bolbostemma paniculatum, on human nasopharyngeal carcinoma $\mathrm{CNE}-2 \mathrm{Z}$ cell line was investigated by $\mathrm{Ma}$ et al. The dose- and timedependent inhibition of cell growth treated with TBMS1 was significant. In the cells treated with $25 \mu \mathrm{mol} 1^{-1}$ of TBMS1 for $3 \mathrm{~h}$ the disruption of microtubular network was observed, and the analysis showed the increase of the cytosolic tubulin level in the treated cells, which suggest the inhibition of tubulin polymerization. The effect was weak in comparison to colchicine. Moreover, the tested compound inhibited colchicine binding to tubuline, in contrast to vinblastine binding, which indicates the competitive binding of TBMS1 to tubulin at colchicine binding site (Ma et al. 2008).

The growth inhibitory effect of extracts and isolated compounds from Cimicifuga species were investigated on two human breast cancer cells: MDA-MB-453 (ER negative, Her2 overexpressing) and MCF7 (ER positive, Her2 low). The results indicated that the growth inhibitory activity of these extracts was related to triterpene glycoside composition. Actein, a purified isolated compound, influenced the composition of actin cytoskeleton by alteration of distribution of actin filaments in both type of cells-actin was dispersed in the cytoplasm and aggregated around the nucleus. Moreover, the nuclei changed their shape in a manner typical of apoptosis (Einbond et al. 2008).

Ardisiacrispin A and B from Ardisia crenata, mentioned above due to their apoptotic activity, also influenced the cytoskeleton of Bel-7402 cells, causing microtubules dissasembly ( $\mathrm{Li}$ et al. 2008).

In our own investigations, the effect of LTS-4, a triterpene saponoside from Lysimachia thyrsiflora, upon the viability, proliferation, morphology and cell motility of human melanoma HTB-140 cells and human skin fibroblasts (HSFs) was tested. The compound decreased the viability and cell growth of both cell types in time- and dose-dependent manner, and was cytotoxic against cancer cells at significantly lower concentrations in comparison to fibroblasts. LTS-4 affected also the morphology of examined cells, causing vacuolization and cell shape changes. The compound caused actin cytoskeleton disintegration-disappearance of stress fibres and random distribution of actin in the cytoplasm. Moreover, LTS-4 exerted an inhibitory effect on tumour cells motility (Galanty et al. 2008).

The mixture of steroid glycosides balanitin- 6 and balanitin-7 (referred to as bal6/7), isolated from the kernels of African plant Balanites aegyptiaca, displayed high cytotoxic activity against human cancer lines: A549 non-small cell lung cancer and U373 glioblastoma. Its activity was higher than etoposide and oxaliplatine, but markedly lower than paclitaxel. It was suggested that its antitumor activity resulted from the decrease of intracellular ATP, mediated by bal6/7, which induced in turn major disorganization of actin cytoskeleton. The experiment indicated that the cytotoxic effect was not mediated by apoptotic mechanism (Gnoula et al. 2008).

In vivo experiments

Steroidal saponins of Paris polyphylla var. yunnanensis (e.g. polyphyllin D, dioscin, formosanin C, methylprotogracillin, and trillin) have been found to possess strong antitumor activity. The experiment was performed on T739 bearing LA795 mice which received the saponin extract by intragastric administration. The observed antitumor and antimetastatic effects were due to inducing apoptosis and upregulating the expression of TIMP-2 and down-regulating the level of MMP-2 and MMP-9 (Man et al. 2009).

Oral administration of diosgenin-3-O- $\alpha$-L-arabinofuranosyl-(1 $\rightarrow 4)$-[ $\alpha$-L-rhamnopyranosyl-(1 $\rightarrow 2)]$ $\beta$-D-glucopyranoside, isolated from the rhizome of Paris polyphylla var. yunnanensis, to T739 mice bearing LA795 lung adenocarcinoma significantly 
inhibited tumor growth (by 29.44\%). The increase of apoptosis rate in tumor cells in comparison to cells in control mice was observed (Yan et al. 2009).

Diosgenin significantly inhibited tumor growth in vivo in MCF-7 and MDA-231 (breast cancer) xenografts in nude mice. Both in vivo and in vitro results (diosgenin inhibited pAkt expression and Akt kinase activity in vitro) led authors to conclude that diosgenin may be a potential chemotherapeutic agent for the treatment of breast cancer, however no data on the route of administration were given (Srinivasan et al. 2009).

Diosgenin when administrated with diet to azoxymethane-induced colon carcinogenesis rats suppressed both invasive and non-invasive colon tumor incidence (up to 60\%). Experimental diet containing $0.1 \%$ of diosgenin significantly reduced colon tumor multiplicity (adenocarcinomas/rat) in rats. A significant increase in BrdU labeling and decrease in PCNA labeling in colonic crypts and tumors was detected (Malisetty et al. 2005).

The mixture of steroidal saponins balanitin- 6 and balanitin-7 (bal6/7) isolated from Balanites aegyptiaca led to increase of the survival time of mice bearing murine L1210 leukemia grafts to the same extent as vincristine, when administered i.p. (Gnoula et al. 2008).

Fifteen triterpene saponins from Pulsatilla koreana were administered intraperitoneally to BDF1 mice bearing Lewis lung carcinoma. Saponins containing an ester group at C-28 of the aglycone were inactive while those with $\alpha$-L-rhamnopyranosyl$(1 \rightarrow 2)-\alpha$-L-arabinopyranosyl moiety at C-3 and a free carboxylic acid at C-28 of the oleanane skeleton had the highest antitumor potency. The authors claimed that the oleanane-type saponins were more active in vivo than the lupane-type saponins. The most potent antitumor compound was hederagenin 3- $O$ - $\alpha$-L-rhamnopyranosyl-( $1 \rightarrow 2)$-[ $\beta$-D-glucopyranosyl-(1 $\rightarrow 4)]-\alpha$-L-arabinopyranoside, the activity of which was higher than standard chemotherapeutic agent-paclitaxel (Bang et al. 2005).

In the study by Wang et al, hederagenin saponin macranthoside $\mathrm{B}$, isolated from the flower buds of Lonicera macranthoides, was injected intravenously to BALB/cA nude mice. The compound significantly supressed the tumor growth and the effect was similar to cyclophosphamide treated control group (Wang et al. 2009).
PE, a triterpene saponin isolated from the sea cucumber Pentacta quadrangularis, suppressed spontaneous angiogenesis in chorioallantoic membrane of the chicken embryo at very low concentrations ( $5 \mathrm{nmol} \mathrm{l}^{-1}$ per egg). Moreover, in two animal tumor models: sarcoma 180 and hepatoma 22, PE on intravenous administration significantly inhibited tumor growth by triggering apoptosis. It was also shown that PE suppressed the active forms of VEGFR2 (vascular endothelial growth factor), Akt, ERK (extracellular signal-regulated kinase), FAK (focal adhesion kinase) and paxillin, which mediate the angiogenesis of endothelial cells and apoptosis (Tian et al. 2005).

Avicin D from Acacia victoriae inhibited the level of VEGF (vascular endothelial growth factor) and CD31, an endothelial cell marker indicating the microvascular networks within the cells, in mouse skin carcinogenesis model. The compound was applied to the shaved skin of animals. The results suggest its antiangiogenic potential (Haridas et al. 2009).

\section{Saponins-toxin cytotoxicity enhancement}

The combined application of saponins with other antitumor compounds may increase cytotoxic activity of the latter, which is an interesting new possibility in cancer treatment research. One of the first experiments was done by Hebestreit (Hebestreit and Melzig 2003) on the saponins from Agrostemma githago seeds. The agrostemmasaponins significantly increased cytotoxicity of agrostin, a toxic protein of the seeds. The effect was probably due to the enhanced penetration of agrostin, when applicated with the saponins, through the cell membrane. Although no summarizing review has been published so far, a number of experiments were conducted in recent years to examine this promising option in tumor therapy.

In vitro experiments

Bachran et al. analyzed the influence of seven saponins: saponinum album (from Gypsophila paniculata L.), $\beta$-aescin (from Aesculus hippocastanum L.), quillajasaponin (from Quillaja saponaria Mol.), hederasaponin C (from Hedera helix L.), ginsenoside 
Rd (from Panax ginseng C.A. Mey.), glycyrrhizic acid (from Glycyrrhiza glabra L.) and helianthoside 2 (from Helianthus annuus L.), on the cytotoxicity enhancement of a targeted chimeric toxin, composed of saporin and human epidermal growth factor, against untransfected Swiss mouse embryo NIH-3T3 cells and HER14 cells (NIH-3T3 cells transfected with human epidermal growth factor receptor). The compounds differed in their structures mainly by a formyl group at C-4 or a branched sugar chain at C-3. Cytotoxicity of the saponins alone was also determined against HER14 and NIH-3T3 cells, resulting in 90\% cell survival at the concentration of $1.5 \mu \mathrm{g} \mathrm{ml}^{-1}$. This concentration was chosen for further experiments with saponin-toxin combination. Two of the tested saponins-quillajasaponin and saponinum albumenhanced the cytotoxicity of the chimeric toxin by more than 1,000-fold, the enhancement factors of the other saponins were about tenfold only. For saponinum album, the effect was receptor specific, in contrast to quillajasaponin and the saponins with low enhancement factor. The compound decreased $\mathrm{IC}_{50}$ value from $2.4 \mathrm{nmol} \mathrm{l}^{-1}$ to $0.18 \mathrm{pmol} \mathrm{l}^{-1}$. The authors conclude that the overall structure of the triterpenoid aglycone cannot be solely responsible for the enhancement, also the branched sugar chain at C-3 may play a role (Bachran et al. 2006). This statement conforms to observations of Melzig et al. (2005), who studied agrostin cytotoxicity enhancement by a number of different saponins. As far as aglycone structure is concerned, the authors emphasize the importance of formyl group at C-4 (Bachran et al. 2006). This feature was also pointed our by Sołtysik et al. (1995), who suggested that it may be of importance in the adjuvant function of saponins. However, these conclusions need further verification and more SAR studies are certainly needed.

In 2009, the same authors described the effect of the combined application of saponinum album and epidermal growth factor receptor (EGFR)-targeted chimeric toxins (SA2E) against murine mammary adenocarcinoma cells (TSA), transfected with EGFR. The 20,000-fold enhancement of cytotoxicity of SA2E was observed with low concentrations of saponinum album, in a synergistic manner (Bachran et al. 2009).

Cytotoxicity of ${ }^{3} \mathrm{H}$-labeled saponinum album alone and in combination with chimeric toxin was analysed on HER 14 cells. ${ }^{3} \mathrm{H}$-labeled saponin was much less active in comparison to their previous experiments with unlabeled compound, which was also observed in the case of combined ${ }^{3} \mathrm{H}$-labeled saponinum album and chimeric toxin (Bachran et al. 2010).

Enhancement of cytotoxicity of lectins and peptidic toxins-agrostin, microcystin-LR, nigrin $b$, saporin, his-saporin, diphtheria toxin, diphtheria toxin A-chain and ricin A-chain-against ECV-304 cells was tested in the presence of saponinum album by Hebestreit et al. The significant effect was observed for lectins, but not for other peptidic toxins, with the highest enhancement for agrostin and saporin, which suggest the specific interaction between the lectins and saponins. The increase in cytotoxicity of lectins was due to the enhancement of their penetration through the cell membrane. The effect was attenuated by latruculin (inhibitor of endocytosis) and bafilomycin (inhibitor of transport from early to late endosomes and lysosomes) but was neither influenced by brefeldin A, which causes dissolution of the Golgi stacks nor by the addition of monosaccharides, which support the probable mechanism of the enhancement as receptor-mediated endocytosis. The effect might be associated with an enhanced capacity to form vesicles, induced by saponins, which transport the proteins via endocytosis into the cell (Hebestreit et al. 2006).

Heisler et al. investigated the effect of the combined application of saponinum album and chimeric toxin (consisting of saporin-3, epidermal growth factor and a molecular adapter) on the untransfected Swiss mouse embryo NIH-3T3 cells, as control, HER 14 cells (NIH-3T3 cells transfected with human epidermal growth factor receptor) and human breast adenocarcinoma cell line MCF-7 as targeted cell lines. Pre-applied saponin enhanced the cytotoxic effect of the chimeric toxin against the targeted cell lines, whereas no effect was observed on the control cells at the same concentration. The application of the chimeric toxin or the saponin alone at the optimal concentration did not exhibit cytotoxic effect, which indicates the synergistic effect of the combined application of both compounds (Heisler et al. 2005).

In vivo experiments

In the study by Heisler et al. saponinum album and chimeric toxin were applied subcutaneously to 
$\mathrm{BALB} / \mathrm{c}$ mice in combination or alone. Only the combined treatment gave good therapeutic effects, with only slight side effects. The probable mechanism suggests the saponin-mediated elongation of the retention period of endocytosed proteins inside the endosome and thus, a greater chance of crossing the endosomal membrane by the toxins (Heisler et al. 2005).

Bachran et al. investigated the effects of application of saponinum album to mice bearing tumor cells. In their first study, saponinum album and SA2E were applicated subcutaneously to BALB/c mice with solid tumor (TSA cells transfected with EGFR). The application resulted in $94 \%$ tumor volume reduction, and the effect was obtained with 50-fold lower chimeric toxin concentration in comparison to pure SA2E treatment. Only moderate and reversible side effects were observed during the application (Bachran et al. 2009).

In another experiment of this group, the distribution of labeled saponinum album in BALB/c mice with tumor was measured by radioactivity analysis in samples of organs, blood, urine and tumor tissues. No preferential accumulation in tumor tissues or other organs was observed and the highest radioactivity level in the urine was after $30 \mathrm{~min}$. Different pretreatment times were measured in tumor-bearing mice, using sequential combination of saponin (given first) and chimeric toxin. Promising antitumor efficacy was observed after $60 \mathrm{~min}$ pretreatment with saponin, but no significant changes after $10 \mathrm{~min}$ pretreatment with the compound. No information was provided on the metabolism of this labeled saponin mixture and no control group which would receive non-labeled, acetylated saponinum album was used for comparison of the results (Bachran et al. 2010). In another experiment of the same group, the authors claimed that the ${ }^{3} \mathrm{H}$-acetyl labeling of the sugar chain did not influence the activity of the saponinum album in vitro (Weng et al. 2009). However, data on saponin labeling and its effect on the activity are still very scarce.

\section{Summary and conclusions}

In recent years more and more researchers who isolated new saponins from natural sources, along with structure elucidation process, reported also on their cytotoxic activity. This review has summarized saponins with such an activity, which were reported in the last 5 years and their most common mechanisms of action. Correlations between structure and the cytotoxicity of both triterpenoid and steroid saponins were also described.

In the majority of cases these were in vitro studies, only a limited number was performed in animal models. The most preferred assays used were formazan based (MTT) and sulphorhodamine B (SRB). The choice of cell lines (usually from one to five) in most reports cited in this review seemed to be random and very few compared cells from the same tumor but differing, e.g. in malignancy, or activity against normal cells. Reference compounds were used in most of studies cited here and in general saponins, both triterpenoid and steroid, were less active. Comparison of cytotoxicity level is however only an approximation as there were notable differences in $\mathrm{IC}_{50}$ values between control compounds themselves.

As far as structure-activity relationship is concerned, some information was usually given by authors who isolated, from a plant source, a greater variety of structures. In recent years some wider comparative studies have appeared, which directly concentrated on establishment of SARs relevant to cytotoxicity. From these data some general conclusions can be drawn, however with such an enormous structural diversity of saponins and still fairly limited sets of compounds that were evaluated in this regard, this is very difficult and may be subject to bias. Nevertheless, it seems that for all saponins both aglycone and sugar part play an important role for cytotoxic activity. The main structural features responsible for enhancement of cytotoxicity of oleananes are: free carboxyl at C-28, free hydroxyl at C-16 and acylation at C-21 and C-22. As far as sugar moiety is concerned the presence of $\alpha$-L-Ara $p$ as the first sugar attached at C-3 in oleananes (and especially an $\alpha$-L-Rhap-( $\rightarrow 2)$ - $\alpha$-L-Arap sequence) and $\alpha$-L-Rhap in lupanes was pointed out.

With respect to steroidal saponins, similarly to triterpenes, the number and the sequence of sugar residues in a carbohydrate chain, and the position of sugar attachment to the aglycone were important for cytotoxicity. For diosgenyl saponins the presence of an $\alpha$-L-Rhap-( $1 \rightarrow 2)-\beta$-D-Glc $p$ sequence at C-3 was considered beneficial for this activity. Also, elongation of the sugar chain resulted in an increase in 
cytotoxicity. However, in order to obtain a better insight into SAR relevant to cytotoxicity there is still a need for a greater number of studies which would compare a wider array of compounds, ideally derivatives of a single sapogenin with systematic variations of the sugar chains(s) or a group of different sapogenins bearing identical sugar chain(s). Another aspect worth studying in more detail are the differences between in vitro and in vivo effects, which were highlighted by some of the reports cited in this review. So, more studies on the bioavailability and pharmacokinetics of saponins would certainly be welcome.

With respect to cytotoxic mechanisms of both triterpene and steroid saponins a wide variety of these was reported. Cytotoxic effect of most of the reviewed saponins was due to their ability to stimulate apoptotic process in tumor cells, usually through its intrinsic pathway. Moreover, non apoptotic processes were also involved in saponin cytotoxic activity, such as cell cycle arrestment, autophagic cell death stimulation, inhibiting of metastasis and cytoskeleton disintegration. Another interesting mode of action that could be more exploited in the future is the ability of some saponins, e.g. $\beta$-escin sodium and PE, to inhibit tumor cells angiogenesis.

Yet another promising potential of saponins is their combined application with recombinant protein toxins that may be of use in more efficient cancer targeting. All the cited papers described a significant enhancement of cytotoxicity of chimeric toxins when applied with saponinum album, both in vitro and in vivo.

Acknowledgments We acknowledge the financial support of the grant N N405 297636 from the Ministry of Science and Higher Education, Poland.

Open Access This article is distributed under the terms of the Creative Commons Attribution Noncommercial License which permits any noncommercial use, distribution, and reproduction in any medium, provided the original author(s) and source are credited.

\section{References}

Abe H, Konishi H, Komiya $H$ et al (1981) Effects of saikosaponins on biological membranes. Planta Med 42: 356-363

Acharya D, Mitaine-Offer A-C, Kaushik N et al (2009) Cytotoxic spirostane-type saponins from the roots of Chlorophytum borivilianum. J Nat Prod 72:177-181
Ahmed WS, Mohamed MA, El-Dib RA et al (2009) New triterpene saponins from Duranta repens Linn. and their cytotoxic activity. Molecules 14:1952-1965

Avilov SA, Silchenko AS, Antonov AS et al (2008) Synaptosides A and A1, triterpene glycosides from the sea cucumber Synapta maculata containing 3-O-methylglucuronic acid and their cytotoxic activity against tumor cells. J Nat Prod 71:525-531

Bachran C, Sutherland M, Heisler I et al (2006) The saponinmediated enhanced uptake of targeted saporin-based drugs is strongly dependent on the saponin structure. Exp Biol Med 231:412-420

Bachran C, Bachran S, Sutherland M et al (2008) Saponins in tumor therapy. Mini Rev Med Chem 8:575-584

Bachran C, Dürkop H, Sutherland M et al (2009) Inhibition of tumor growth by targeted toxins in mice is dramatically improved by saponinum album in a synergistic way. J Immunother 32:713-725

Bachran C, Weng A, Bachran D et al (2010) The distribution of saponins in vivo affects their synergy with chimeric toxins against tumours expressing human epidermal growth factor receptors in mice. Br J Pharmacol 159:345-352

Bang S-C, Lee J-H, Song G-Y et al (2005) Antitumor activity of Pulsatilla koreana saponins and their structureactivity relationship. Chem Pharm Bull 53(11):14511454

Bang S-C, Seo H-H, Yun H-Y et al (2007) Facile synthesis of trisaccharide moiety corresponding to antitumor activity in triterpenoid saponins isolated from Pulsatilla roots. Chem Pharm Bull 55:1734-1739

Bao W, Pan H, Lu M et al (2007) The apoptotic effect of sarsasapogenin from Anemarrhena asphodeloides on HepG2 human hepatoma cells. Cell Biol Int 31:887-892

Blunden G, Culling MC, Jewers K (1975) Steroidal sapogenins: a review of actual and potential plant sources. Trop Sci 17:139-154

Bruneton J (1995) Pharmacognosie, Phytochimie, Plantes Médicinales; Éditions Technique \& Documentation, Paris, p 1120

Calabria LM, Piacente S, Kapusta I et al (2008) Triterpene saponins from Silphium radula. Phytochemistry 69: 961-972

Cao S, Norris A, Miller JS et al (2007) Cytotoxic triterpenoid saponins of Albizia gummifera from the Madagascar rain forest. J Nat Prod 70:361-366

Cham BE, Daunter B (1990) Solasodine glycosides. Selective cytotoxicity for cancer cells and inhibition of cytotoxicity by rhamnose in mice with sarcoma 180 . Cancer Lett 55:221-225

Chan P-K (2007) Acylation with diangeloyl groups at C21-22 positions in triterpenoid saponins is essential for cytotoxicity towards tumor cells. Biochem Pharmacol 73: 341-350

Chan P-K, Zhao M, Che C-T et al (2008) Cytotoxic acylated triterpene saponins from the husks of Xanthoceras sorbifolia. J Nat Prod 71:1247-1250

Chang L-C, Tsai T-R, Wang J-J et al (1998) The rhamnose moiety of solamargine plays a crucial role in triggering cell death by apoptosis. Biochem Biophys Res Commun 242:21-25 
Chang X, Li W, Jia Z et al (2007) Biologically active triterpenoid saponins from Ardisia japonica. J Nat Prod 70:179-187

Chen HF, Wang GH, Luo Q et al (2009) Two new steroidal saponins from Allium macrostemon Bunge and their cytotoxity on different cancer cell lines. Molecules 14(6):2246-2253

Chwalek M, Plé K, Voutquenne-Nazabadioko L (2004) Synthesis and hemolytic activity of some hederagenin diglycosides. Chem Pharm Bull 52:965-971

Chwalek M, Lalun N, Bobichon H et al (2006) Structureactivity relationships of some hederagenin diglycosides: haemolysis, cytotoxicity and apoptosis induction. Biochim Biophys Acta 1760:1418-1427

Cmoch P, Pakulski Z, Swaczynova J et al (2008) Synthesis of lupane-type saponins bearing mannosyl and 3,6-branched trimannosyl residues and their evaluation as anticancer agents. Carbohydrate Res 343:995-1003

Dongre SH, Badami S, Ashok G et al (2007) In vitro cytotoxic properties of $O$-methylsolanocapsine isolated from Solanum pseudocapsicum leaves. Indian J Pharmacol 39(4): 208-209

Einbond LS, Wen-Cai Y, He K et al (2008) Growth inhibitory activity of extracts and compounds from Cimicifuga species on human breast cancer cells. Phytomedicine 15:504-511

Ellington A, Berhow M, Singletary KW (2005) Induction of macroautophagy in human colon cancer cells by soybean B-group triterpenoid saponins. Carcinogenesis 26: 159-167

Fiore C, Eisenhut M, Ragazzi E et al (2005) A history of the therapeutic use of liquorice in Europe. J Ethnopharmacol 99:317-324

Francis G, Kerem Z, Makkar HPS et al (2002) The biological action of saponins in animal systems: a review. Br J Nutr 88:587-605

Fuchs H, Bachran D, Panijdeh H et al (2009) Saponins as tool for improved targeted tumor therapies. Curr Drug Targets 10:140-151

Galanty A, Michalik M, Sędek $€$ et al (2008) The influence of LTS-4, a saponoside from Lysimachia thyrsiflora L., on human skin fibroblasts and human melanoma cells. Cell Mol Biol Lett 13:585-598

Gauthier C, Legault J, Lebrun M et al (2006) Glycosidation of lupane-type triterpenoids as potent in vitro cytotoxic agents. Bioorg Med Chem 14:6713-6725

Gauthier C, Legault J, Girard-Lalancette K et al (2009a) Haemolytic activity, cytotoxicity and membrane cell permeabilization of semi-synthetic and natural lupane- and oleanane-type saponins. Bioorg Med Chem 17:20022008

Gauthier C, Legault J, Pichette A (2009b) Recent progress in the synthesis of naturally ocurring triterpenoid saponins. Mini-Rev Org Chem 6:321-344

Gnoula C, Megalizzi V, De Neve N et al (2008) Balanitin-6 and -7: diosgenyl saponins isolated from Balanites aegyptiaca Del. display significant anti-tumor activity in vitro and in vivo. Int $\mathrm{J}$ Oncol 32:5-15

Gu Y, Wang G, Sun J et al (2006) Development of a sensitive LC-ESI-MS assay for 20(R)-ginsenoside $\mathrm{Rh}_{2}$ and its pharmacokinetic application in dogs: a case for the influence of micronization on traditional Chinese medicine. Int J Mass Spectrom 252:11-19

Güçlü-Üstündağ Ö, Mazza G (2007) Saponins: properties, applications and processing. Crit Rev Food Sci Nutr 47:231-258

Hamed AI, Piacente S, Autore G et al (2005) Antiproliferative hopane and oleanane glycosides from the roots of Glinus lotoides. Planta Med 71:554-560

Haralampidis K, Trojanowska M, Osbourn AE (2002) Biosynthesis of triterpenoid saponins in plants. Adv Biochem Eng/Biotechnol 75:31-48

Haridas V, Nishimura G, Xu Z-X et al (2009) Avicin D: a protein reactive plant isoprenoid dephosphorylates Stat 3 by regulating both kinase and phosphatase activities. PloS ONE 5:1-13

He X, Qiao A, Wang X et al (2006) Structural identification of methyl protodioscin metabolites in rats' urine and their antiproliferative activities against human tumor cell lines. Steroids 71:828-833

Hebestreit P, Melzig MF (2003) Cytotoxic activity of the seeds from Agrostemma githago var. githago. Planta Med 69:921-925

Hebestreit P, Weng A, Bachran C et al (2006) Enhancement of cytotoxicity of lectins by saponinum album. Toxicon 47:330-335

Heisler I, Sutherland M, Bachran C et al (2005) Combined application of saponin and chimeric toxins drastically enhances the targeted cytotoxicity on tumor cells. J Cont Release 106:123-137

Henry M (2005) Saponins and phylogeny: example of the "gypsogenin group" saponins. Phytochem Rev 4:89-94

Hernández JC, Leon F, Quintana J et al (2004) Icogenin, a new cytotoxic steroidal saponin isolated from Dracaena draco. Bioorg Med Chem Lett 12(16):4423-4429

Hernández JC, Leon F, Brouard I et al (2008) Synthesis of novel spirostanic saponins and their cytotoxic activity. Bioorg Med Chem 16(4):2063-2076

Houghton P, Fang R, Techatanawat I et al (2007) The sulphorhodamine (SRB) assay and other approaches to testing plant extracts and derived compounds for activities related to reputed anticancer activity. Methods 42: 377-387

Hsu Y-L, Kuo P-L, Weng T-C et al (2004) The antiproliferative activity of saponin-enriched fraction from Bupleurum Kaoi is through Fas-dependent apoptotic pathway in human non-small cell lung cancer A549 Cells. Biol Pharm Bull 27:1112-1115

Hu K, Yao X (2002) The cytotoxicity of protoneodioscin (NSC-698789), a furostanol saponin from the rhizomes of Dioscorea colletti var. hypoglauca, against human cancer cells in vitro. Phytomedicine 9:560-562

Hu K, Yao X (2003a) The cytotoxicity of methyl protodioscin against human cancer cell lines in vitro. Cancer Invest 21(3):389-393

Hu K, Yao X (2003b) The cytotoxicity of methyl protoneogracillin (NSC-698793) and gracillin (NSC-698787), two steroidal saponins from the rhizomes of Dioscorea colletti var.hypoglauca, against human cancer cells in vitro. Phytother Res 17:620-626

Hu C-C, Lin J-T, Liu S-C et al (2007) A spirostanol glycoside from wild yam (Dioscorea villosa) extract and its 
cytostatic activity on three cancer cells. J Food Drug Anal 15(3):310-315

Huang H-C, Wu M-D, Tsai W-J et al (2008a) Triterpenoid saponins from the fruits and galls of Sapindus mukorossi. Phytochemistry 69:1609-1616

Huang H-C, Liaw C-C, Zhang L-J et al (2008b) Triterpenoidal saponins from Hydrocotyle sibthorpioides. Phytochemistry 69:1597-1603

Huang X-F, Lin Y-Y, Kong L-Y (2008c) Steroids from the roots of Asparagus officinalis and their cytotoxic activity. J Integr Plant Biol 50(6):717-722

Inoue M, Ohtani K, Kasai R et al (2009) Cytotoxic 16- $\beta$-[(Dxylopyranosyl)oxy] oxohexadecanyl triterpene glycosides from a Malagasy plant, Physena sessiliflora. Phytochemistry 70:1195-1202

Jin J-O, Shastina V-V, Shin S-W et al (2009) Differential effects of triterpene glycosides, frondoside $\mathrm{A}$ and cucumarioside A2-2 isolated from sea cucumbers on caspase activation and apoptosis of human leukemia cells. FEBS Letters 583:697-702

Jung H-J, Lee C-O, Lee K-T et al (2004) Structure-activity relationship of oleanane disaccharides isolated from Akebia quinata versus cytotoxicity against cancer cells and NO inhibition. Biol Pharm Bull 27:744-747

Kalinowska M, Zimowski J, Paczkowski C et al (2005) The formation of sugar chains in triterpenoid saponins and glycoalkaloids. Phytochem Rev 4:237-257

Kerwin SM (2004) Soy saponins and the anticancer effects of soybeans and soy-based foods. Curr Med Chem Anticancer Agents 4:263-272

Khanna VG, Kannabiran K (2009) Anticancer-cytotoxic activity of saponins isolated from the leaves of Gymnema sylvestre and Eclipta prostrata on HeLa cells. Int J Green Pharmacy 3:227-229

Kiem PV, Thu VK, Yen PH et al (2009) New triterpenoid saponins from Glochidion eriocarpum and their cytotoxic activity. Chem Pharm Bull 57:102-105

Kim J (2008) Protective effects of Asian dietary items on cancers-soy and ginseng. Asian Pac J Cancer Prev 9:543-548

Kim Y, Bang S-C, Lee J-H et al (2004) Pulsatilla Saponin D: the antitumor principle from Pulsatilla koreana. Arch Pharm Res 27:915-918

Kim G-S, Kim H-T, Seong J-D et al (2005) Cytotoxic steroidal saponins from the rhizomes of Asparagus oligoclonos. J Nat Prod 68(5):766-768

Kim Y-J, Kwon H-C, Ko H et al (2008a) Anti-tumor activity of the ginsenoside $\mathrm{Rk}_{1}$ in human hepatocellular carcinoma cells through inhibition of telomerase activity and induction of apoptosis. Biol Pharm Bull 31:826-830

Kim M-O, Moon D-O, Choi YH et al (2008b) Platycodin D induces apoptosis and decreases activity in human leukemia cells. Cancer Lett 261:98-107

Konoshima T (1996) Anti-tumor-promoting activities of triterpenoid glycosides; cancer chemoprevention by saponins. Adv Exp Med Biol 404:87-100

Lemeshko VV, Haridas V, Quijano Perez JC et al (2006) Avicins, natural anticancer saponins, permeabilize mitochondrial membranes. Arch Biochem Biophys 454:114-122

Li K, Tang Y, Fawcett JP et al (2005) Characterization of the pharmacokinetics of dioscin in rat. Steroids 70:525-530
Li M, Wei S-Y, Xu B et al (2008) Pro-apoptotic and microtubule-dissasembly effects of ardisiacrispin $(\mathrm{A}+\mathrm{B})$, triterpenoid saponins from Ardisia crenata on human hepatoma Bel-7402 cells. J Asian Nat Prod Res 10: 729-736

Li W, Bi X, Wang K et al (2009) Triterpenoid saponins from Impatiens siculifer. Phytochemistry 70:816-821

Liang M-J, Zhang W-D, Zhang C et al (2007) Quantitative determination of the anticancer agent tubeimoside $\mathrm{I}$ in rat plasma by liquid chromatography coupled with mass spectrometry. J Chromatogr B 845:84-89

Liu M-J, Wang Z, Ju Y et al (2005) Diosgenin induces cell cycle arrest and apoptosis in human leukemia K562 cells with the disruption of $\mathrm{Ca}^{2+}$ homeostasis. Cancer Chemother Pharmacol 55:79-90

Liu H, Chou G-X, Wu T et al (2009a) Steroidal sapogenins and glycosides from the rhizomes of Dioscorea bulbifera. J Nat Prod 72(11):1964-1968

Liu R, Ma S, Yu S et al (2009b) Cytotoxic oleanane triterpene saponins from Albizia chinensis. J Nat Prod 72: 632-639

Lu Y, Luo J, Huang X et al (2009) Four new steroidal glycosides from Solanum torvum and their cytotoxic activities. Steroids 74(1):95-101

Ma R, Song G, You W et al (2008) Anti-microtubule activity of tubeimoside I and its colchicines binding site of tubulin. Cancer Chemother Pharmacol 62:559-568

Ma L, Gu YC, Luo JG et al (2009) Triterpenoid saponins from Dianthus versicolor. J Nat Prod 72:640-644

Magid AA, Voutquenne-Nazabadioko L, Renimel I et al (2006) Triterpenoid saponins from the stem bark of Caryocar villosum. Phytochemistry 67:2096-2102

Malisetty VS, Patlolla JMR, Raju J et al (2005) Chemoprevention of colon cancer by diosgenin, a steroidal saponin constituent of fenugreek. Proc Amer Assoc Cancer Res 46:2473

Man S, Gao W, Zhang Y et al (2009) Antitumor and antimetastatic activities of Rhizoma Paridis saponins. Steroids $74: 1051-1056$

Melek FR, Miyase T, Ghaly NS et al (2007) Triterpenoid saponins with $\mathrm{N}$-acetyl sugar from the bark of Albizia procera. Phytochemistry 68:1261-1266

Melzig MF, Bader G, Loose R (2001) Investigations of the mechanism of membrane activity of selected triterpenoid saponins. Planta Med 67:43-48

Melzig MF, Hebestreit P, Gaidi G et al (2005) Structureactivity relationship of saponins to enhance toxic effects of agrostin. Planta Med 71:1088-1090

Mimaki Y, Yokosuka A, Kuroda M et al (2001) Cytotoxic activities and structure-cytotoxic relationships of steroidal saponins. Biol Pharm Bull 24(11):1286-1289

Mskhiladze L, Legault J, Lavoie S et al (2008) Cytotoxic steroidal saponins from the flowers of Allium leucanthum. Molecules 13:2925-2934

Noté OP, Mitaine-Offer AC, Miyamoto T et al (2009) Cytotoxic acacic acid glycosides from the roots of Albizia coriaria. J Nat Prod 72:1725-1730

Ohtsuki T, Koyano T, Kowithayakorn T et al (2004) New chlorogenin hexasaccharide isolated from Agave fourcroydes with cytotoxic and cell cycle inhibitory activities. Bioorg Med Chem 12:3841-3845 
Oleszek W, Bialy Z (2006) Chromatographic determination of plant saponins-an update (2002-2005). J Chromatogr A 1112:78-91

Osbourn AE (2003) Saponins in cereals. Phytochemistry 62:1-4

Perrone A, Plaza A, Bloise E et al (2005) Cytotoxic furostanol saponins and a megastigmane glucoside from Tribulus parvispinus. J Nat Prod 68:1549-1553

Pettit GR, Zhang Q, Pinilla V et al (2005) Antineoplastic agents. 534. Isolation and structure of Sansevistatins 1 and 2 from the African Sansevieria ehrenbergii. J Nat Prod 68:729-733

Qiu YK, Dou DQ, Cai LP et al (2009) Dammarane-type saponins from Panax quinquefolium and their inhibition activity on human breast cancer MCF-7 cells. Fitoterapia 80:219-222

Quan H-J, Koyanagi J, Ohomori K et al (2002) Preparations of spirostanols and their pharmacological activities. Eur J Med Chem 37:659-669

Raju J, Mehta R (2009) Chemopreventive and therapeutic effects of diosgenin, a food saponin. Nutr Cancer 61(1):27-35

Rao AV, Gurfinkel DM (2000) The bioactivity of saponins: triterpenoid and steroid glycosides. Drug Metab Drug Interact 17:211-235

Rao AV, Sung MK (1995) Saponins as anticarcinogens. J Nutr 125:717S-724S

Ren H, Chen JP, Tan BY et al (2008) The disposition and pharmacokinetics of Dioscorea nipponica Makino extract in rats. Afr J Biotechnol 7(22):4015-4018

Sahu NP, Banerjee S, Mondal NB, Mandal D (2008) Steroidal saponins. In: Fortschritte der Chemie Organischer Naturstoffe/progress in the chemistry of organic natural products, fortschritte der chemie organischer naturstoffe/ progress in the chemistry of organic natural products, vol 89. Springer, Vienna, pp 45-141

Sánchez-Medina A, Stevenson PC, Habtemariam S et al (2009) Triterpenoid saponins from a cytotoxic root extract of Sideroxylon foetidissimum subsp. gaumeri. Phytochemistry 70:765-772

Sautour M, Mitaine-Offer A-C (2007) The Dioscorea genus: a review of bioactive steroid saponins. J Nat Med 61: 91-101

Shibata S (2001) Chemistry and cancer preventing activities of ginseng saponins and some related triterpenoid compounds. J Korean Med Sci 16(Suppl):S28-S37

Siu F-M, Ma D-L, Cheung Y-W et al (2008) Proteomic and transcriptomic study on the action of a cytotoxic saponin (Polyphyllin D): induction of endoplasmic reticulum stress and mitochondria-mediated apoptotic pathways. Proteomics 8:3105-3117

Sivaramakrishna C, Rao CV, Trimurtulu G et al (2005) Triterpenoid glycosides from Bacopa monnieri. Phytochemistry 66:2719-2728

Sobolewska D, Janeczko Z, Kisiel W et al (2006) Steroidal glycosides from the underground parts of Allium ursinum L. and their cytostatic and antimicrobial activity. Acta Pol Pharm Drug Res 63(2):219-223

Soltysik S, Wu JY, Recchia J et al (1995) Structure/function studies of QS-21 adjuvant: assessment of triterpene aldehyde and glucuronic acid roles in adjuvant function. Vaccine 13:1403-1410
Sparg SG, Light ME, van Staden J (2004) Biological activities and distribution of plant saponins. J Ethnopharmacol 94:219-243

Srinivasan S, Koduru S, Kumar R et al (2009) Diosgenin targets Akt-mediated prosurvival signaling in human breast cancer cells. Int J Cancer 125:961-967

Sun Y, Cai T-T, Zhou X-B et al (2009a) Saikosaponin a inhibits the proliferation and activation of $\mathrm{T}$ cells through cell cycle arrest and induction of apoptosis. Int Immunopharmacol 9:978-983

Sun HX, Xie Y, Ye YP (2009b) Advances in saponin-based adjuvants. Vaccine 27:1787-1796

Tabatadze N, Elias R, Faure R et al (2007) Cytotoxic triterpenoid saponins from the roots of Cephalaria gigantea. Chem Pharm Bull 55:102-105

Tapondjou LA, Mitaine-Offer AC, Miyamoto T et al (2006) Triterpene saponins from Schefflera abyssinica. Bioch System Ecol 34:887-889

Thibeault D, Gauthier C, Legault J et al (2007) Synthesis and structure-activity relationship study of cytotoxic germanicane- and lupane-type 3 $\beta$-O-monodesmosidic saponins starting from betulin. Bioorg Med Chem 15:6144-6157

Tian F, Zhang X, Tong Y et al (2005) PE, a new sulfated saponin from sea cucumber, exhibits anti-angiogenic and anti-tumor activities in vitro and in vivo. Cancer Biol Therapy 4:874-882

Tian J, Xu L, Zou Z et al (2006) New antitumor triterpene saponin from Lysimachia capillipes. Chem Nat Compd 42:328-331

Tian Y, Tang HF, Qiu F et al (2009) Triterpenoid saponins from Ardisia pusilla and their cytotoxic activity. Planta Med 75:70-75

Trouillas P, Corbiere C, Liagre B et al (2005) Structure-function relationship for saponin effects on cell cycle arrest and apoptosis in the human 1547 osteosarcoma cells: a molecular modeling approach of natural molecules structurally close to diosgenin. Bioorg Med Chem 13:1141-1149

Tundis R, Bonesi M, Deguin B et al (2009) Cytotoxic activity and inhibitory effect on nitric oxide production of triterpene saponins from the roots of Physospermum verticillatum (Waldst \& Kit) (Apiaceae). Bioorg Med Chem 17:4542-4547

Vincken JP, Heng L, de Groot A et al (2007) Saponins, classification and occurence in the plant kingdom. Phytochemistry 68:275-297

Wang Z, Zhou J, Ju Y et al (2001) Effects of two saponins from the Polygonatum zanlanscianense Pamp on the human leukemia (HL-60) cells. Biol Pharm Bull 24(2):159-162

Wang G, Chen H, Huang M et al (2006) Methyl protodioscin induces G2/M cell cycle arrest and apoptosis in HepG2 live cancer cells. Cancer Lett 241(1):102-109

Wang Y, Zhang Y, Zhu Z et al (2007) Exploration of the correlation between the structure, hemolytic activity, and cytotoxicity of steroid saponins. Bioorg Med Chem 15:2528-2532

Wang X-H, Xu B, Liu J-T et al (2008) Effect of $\beta$-escin sodium on endothelial cells proliferation, migration and apoptosis. Vasc Pharmacol 49:158-165

Wang J, Zhao X-Z, Qi Q et al (2009) Macranthoside B, a hederagenin saponin extracted from Lonicera 
macranthoides and its anti-tumor activities in vitro and in vivo. Food Chem Toxicol 47:1716-1721

Weng A, Görick C, Melzig MF (2009) Enhancement of toxicity of saporin-based toxins by Gypsophilla saponinskinetic of the saponin. Exp Biol Med 234:961-966

Xie B-B, Liu H-Y, Ni W et al (2009) Ypsilandrosides C-G, five new spirostanol saponins from Ypsilandra thibetica. Steroids 74:950-955

Xiong J, Guo J, Huang L et al (2008) Self-micelle formation and the incorporation of lipid in the formulation affect the intestinal absorption of Panax notoginseng. Int $\mathrm{J}$ Pharm 360:191-196

Xu Z-X, Liang J, Haridas V et al (2007a) A plant triterpenoid, avicin D, induces autophagy by activation of AMP-activated protein kinase. Cell Death Differ 14:1948-1957

Xu FQ, Zhong HM, Liu HY et al (2007b) Steroidal saponins from Lysimachia Paridiformis. J Asian Nat Prod Res 9:493-497

Xu Y, Chiu JF, He Q-Y et al (2009) Tubeimoside-1 exerts cytotoxicity in HeLa cells through mitochondrial dysfunction and endoplasmic reticulum stress pathways. J Proteome Res 8:1585-1593

Yan LL, Zhang YJ, Gao WY et al (2009) In vitro and in vivo anticancer activity of steroid saponins of Paris polyphylla var. yunanensis. Exp Oncol 31(1):27-32

Yang Q-X, Yang C-R (2006) Cytotoxic steroidal saponins from Polygonatum punctatum. Chem Biodiver 3:1349-1355

Yang C-R, Zhang Y, Jacob MR et al (2006) Antifungal activity of C-27 steroidal saponins. Antimicrob Agents Chemother 50(5):1710-1714

Yokosuka A, Mimaki Y (2009) Steroidal saponins from the whole plants of Agave utahensis and their cytotoxic activity. Phytochemistry 70:807-815

Yokosuka A, Jitsuno M, Yui S et al (2009) Steroidal glycosides from Agave utahensis and their cytotoxic activity. J Nat Prod 72:1399-1404

Yu B, Sun J (2009) Current synthesis of triterpene saponins. Chem Asian J 4:642-654
Yu T-X, Ma R-D, Yu L-J (2001) Structure-activity relationship of tubeimosides In anti-inflammatory, antitumor, and antitumor-promoting effects. Acta Pharmacol Sin 22: 463-468

Yu B, Zhang Y, Tang P (2007) Carbohydrate chemistry in the total synthesis of saponins. Eur J Org Chem 31:5145-5161

Yu L, Yang JZ, Chen XG et al (2009) Cytotoxic triterpenoid glycosides from the roots of Gordonia chrysandra. J Nat Prod 72:866-870

Yun H, Lijan C, Wenhong Z et al (2007) Separation and identification of steroidal compounds with cytotoxic activity against human gastric cancer cell lines in vitro from the rhizomes of Paris polyphylla var. chinensis. Chem Nat Compd 43(6):672-677

Zhang Z, Li S (2007) Cytotoxic triterpenoid saponins from the fruits of Aesculus pavia L. Phytochemistry 68:2075-2086

Zhang SY, Tang HF, Yi YH (2007) Cytotoxic triterpene glycosides from the sea cucumber Pseudocolochirus violaceus. Fitoterapia 78:283-287

Zhang C, Li B, Gaikwad AS et al (2008) Avicin D selectively induces apoptosis and downregulates p-STAT-3, bcl-2, and survivin in cutaneous T-cell lymphoma cells. J Invest Dermatol 128:2728-2735

Zhao Y, Kang L-P, Liu Y-X et al (2009) Steroidal saponins from the rhizome of Paris polyphylla and their cytotoxic activities. Planta Med 75:356-363

Zhou X, He X, Wang G et al (2006) Steroidal saponins from Solanum nigrum. J Nat Prod 69(8):1158-1163

Zhou L-B, Chen T-H, Bastow KF et al (2007) Filiasparosides A-D, cytotoxic steroidal saponins from the roots of Asparagus filicinus. J Nat Prod 70:1263-1267

Zou K, Wang J, Du M et al (2006a) A pair of diastereoisomeric steroidal saponins from cytotoxic extracts of Tupistra chinensis rhizomes. Chem Pharm Bull 54(10):1440-1442

Zou K, Zhao YY, Zhang RY (2006b) A cytotoxic saponin from Albizia julibrissin. Chem Pharm Bull 54:1211-1212 